\title{
Regulation of HDL Genes: Transcriptional, Posttranscriptional, and Posttranslational
}

\author{
Dimitris Kardassis, Anca Gafencu, Vassilis I. Zannis, and Alberto \\ Davalos
}

\section{Contents}

1 Regulation of Genes Involved in HDL Metabolism at the Transcriptional Level . . . . . 117

1.1 General Introduction to Hormone Nuclear Receptors ....................... 118

1.2 Transcriptional Regulation of the apoA-I Gene in the Liver ................ 119

1.2.1 The Role of the Distal Enhancer in apoA-I Gene Transcription ......... 123

1.2.2 Other Factors Regulating apoA-I Gene Transcription ................ 124

1.3 Transcriptional Regulation of the ABCA1 Gene ........................ 125

1.3.1 Upregulatory Mechanisms of ABCA1 Gene Expression ............... 125

1.3.2 Negative Regulation of ABCA1 Gene Transcription ................. 129

1.4 Transcriptional Regulation of the ABCG1 Gene .......................... 130

1.5 Transcriptional Regulation of the Apolipoprotein E Gene .................. 132

1.5.1 Proximal Regulatory Binding Sites Involved in the apoE Gene Expression 134

1.5.2 Distal Regulatory Binding Sites That Modulate apoE Gene Expression in Macrophages .......................................... 135

1.6 Transcriptional Regulation of the Human apoM Gene in the Liver ............ 136

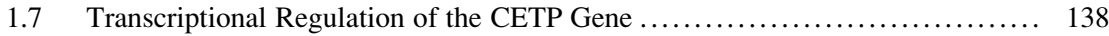

1.8 Transcriptional Regulation of the PLTP Gene ......................... 139

1.9 Transcriptional Regulation of the Bile Acid Transporters ABCG5/ABCG8 . . . . 140

1.10 Transcriptional Regulation of the HDL Receptor SR-BI ................. 141

D. Kardassis $(\bowtie)$

Department of Biochemistry, University of Crete Medical School and Institute of Molecular Biology and Biotechnology, Foundation of Research and Technology of Hellas, Heraklion, Crete 71110, Greece

e-mail: kardasis@imbb.forth.gr

A. Gafencu

Institute of Cellular Biology and Pathology "Nicolae Simionescu”, Bucharest, Romania

V.I. Zannis

Section of Molecular Genetics, Boston University Medical Center, Boston, MA 02118, USA

A. Davalos

Laboratory of Disorders of Lipid Metabolism and Molecular Nutrition, Madrid Institute for Advanced Studies (IMDEA)-Food, Ctra. de Cantoblanco 8, 28049 Madrid, Spain

A. von Eckardstein, D. Kardassis (eds.), High Density Lipoproteins, Handbook of Experimental Pharmacology 224, DOI 10.1007/978-3-319-09665-0_3 
2 Posttranscriptional Regulation of HDL Genes by Noncoding RNAs and microRNAs . . 143

2.1 miRNAs: Biogenesis and Function ................................... 144

2.2 Posttranscriptional Modulation of HDL Metabolism by miRNAs ............... 146

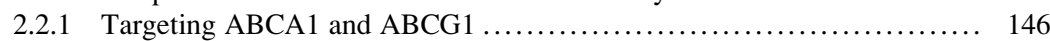

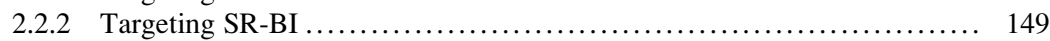

2.2.3 Targeting Other miRNAs Related to HDL Biogenesis and Function ..... 150

3 Posttranslational Mechanisms of HDL Regulation ........................... 150

$3.1 \quad$ ABCA1 ........................................................ 150

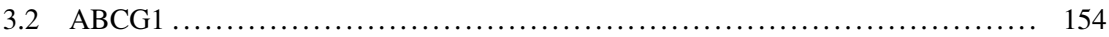

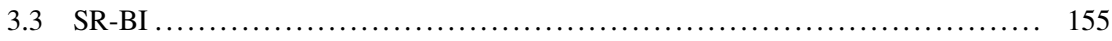

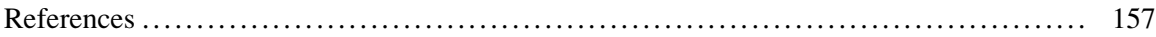

\section{Abstract}

HDL regulation is exerted at multiple levels including regulation at the level of transcription initiation by transcription factors and signal transduction cascades; regulation at the posttranscriptional level by microRNAs and other noncoding RNAs which bind to the coding or noncoding regions of HDL genes regulating mRNA stability and translation; as well as regulation at the posttranslational level by protein modifications, intracellular trafficking, and degradation. The above mechanisms have drastic effects on several HDL-mediated processes including HDL biogenesis, remodeling, cholesterol efflux and uptake, as well as atheroprotective functions on the cells of the arterial wall. The emphasis is on mechanisms that operate in physiologically relevant tissues such as the liver (which accounts for $80 \%$ of the total HDL-C levels in the plasma), the macrophages, the adrenals, and the endothelium. Transcription factors that have a significant impact on HDL regulation such as hormone nuclear receptors and hepatocyte nuclear factors are extensively discussed both in terms of gene promoter recognition and regulation but also in terms of their impact on plasma HDL levels as was revealed by knockout studies. Understanding the different modes of regulation of this complex lipoprotein may provide useful insights for the development of novel HDL-raising therapies that could be used to fight against atherosclerosis which is the underlying cause of coronary heart disease.

\section{Keywords}

High-density lipoprotein • Regulation • Transcriptional • Posttranscriptional • Posttranslational • miRNAs • Protein stability • Hormone nuclear receptors • Hepatocyte nuclear factors • apoA-I • ABCA1 • ABCG1 • ABCG5 • ABCG8 • apoE $\bullet \mathrm{SR}-\mathrm{BI} \cdot \mathrm{CETP}$ 


\section{List of Abbreviations}

\begin{tabular}{|c|c|}
\hline HMG-CoA & 3-Hydroxy-3-methylglutaryl-coenzyme A \\
\hline $12 / 15 \mathrm{LO}$ & 12/15-Lipoxygenase \\
\hline AP1 & Activator protein 1 \\
\hline AF1 & Activation function 1 \\
\hline Ang & Angiotensin \\
\hline apoA-I & Apolipoprotein A-I \\
\hline apoB & Apolipoprotein B \\
\hline apoE & Apolipoprotein E \\
\hline apoM & Apolipoprotein $\mathrm{M}$ \\
\hline ARP-1 & Apolipoprotein A-I-regulated protein 1 \\
\hline DHHC8 & Asp-His-His-Cys 8 \\
\hline ABCA1 & ATP-binding cassette transporter A1 \\
\hline ABCG1 & ATP-binding cassette transporter G1 \\
\hline BIG1 & Brefeldin A-inhibited guanine nucleotide-exchange protein 1 \\
\hline JNK & c-Jun N-terminal kinase \\
\hline $\mathrm{C} / \mathrm{EBP}$ & CCAAT/enhancer-binding protein \\
\hline CAV-1 & Caveolin 1 \\
\hline CXCL & Chemokine (C-X-C motif) ligand \\
\hline COUP-TFI & Chicken ovalbumin upstream promoter transcription factor I \\
\hline $\mathrm{CEH}$ & Cholesterol ester hydrolase \\
\hline CETP & Cholesterol ester transfer protein \\
\hline $3 \mathrm{C}$ & Chromosome conformational capture \\
\hline CLA & Conjugated linoleic acid \\
\hline CAR & Constitutive androstane receptor \\
\hline CREB & Cyclic AMP response element-binding protein \\
\hline DNase & Deoxyribonuclease \\
\hline DR4 & Direct repeat with 4 nucleotides in the spacer region \\
\hline DBD & DNA-binding domain \\
\hline EGR-1 & Early growth response protein 1 \\
\hline LIPG & Endothelial lipase \\
\hline $\mathrm{EE}$ & Early endosome \\
\hline ER & Endoplasmic reticulum \\
\hline ESCRT & Endosomal sorting complex required for transport \\
\hline $\mathrm{ER} \alpha$ and $\beta$ & Estrogen receptors $\alpha$ and $\beta$ \\
\hline ERE & Estrogen response element \\
\hline ESRRG & Estrogen receptor-related gamma \\
\hline FXR & Farnesoid X receptor \\
\hline FXRE & Farnesoid X receptor-responsive element \\
\hline FF & Fenofibrate \\
\hline FOXA2 & Forkhead box A2 \\
\hline FOXO1 & Forkhead box $\mathrm{O} 1$ \\
\hline GF & Gemfibrozil \\
\hline
\end{tabular}




\begin{tabular}{|c|c|}
\hline GR & Glucocorticoid receptor \\
\hline GSK3 $\beta$ & Glycogen synthase kinase $3 \beta$ \\
\hline HNF-4 & Hepatocyte nuclear factor-4 \\
\hline HDL & High-density lipoprotein \\
\hline HDL-C & High-density lipoprotein cholesterol \\
\hline Hcy & Homocysteine \\
\hline HRE & Hormone response element \\
\hline IRAK-1 & IL-1 receptor-associated kinase 1 \\
\hline IDOL & Inducible degrader of the LDLR \\
\hline IFN & Interferon \\
\hline IL & Interleukin \\
\hline $\mathrm{KO}$ & Knockout \\
\hline KLF4 & Kruppel-like factor 4 \\
\hline LCAT & Lecithin-cholesterol acyltransferase \\
\hline LXR & Liver $\mathrm{X}$ receptor \\
\hline LXRE & Liver $\mathrm{X}$ receptor response element \\
\hline LRH-1 & Liver receptor homologue-1 \\
\hline LBD & Ligand-binding domain \\
\hline LPS & Lipopolysaccharide \\
\hline LDLR & Low-density lipoprotein receptor \\
\hline LAL & Lysosomal acid lipase \\
\hline MCSF & Macrophage colony-stimulating factor \\
\hline miRNAs & microRNAs \\
\hline MEKK & Mitogen-activated protein kinase/ERK kinase kinase \\
\hline MCP-1 & Monocyte chemoattractant protein-1 \\
\hline ME & Multienhancer \\
\hline MVB & Multivesicular bodies \\
\hline DMHCA & N,N-Dimethyl-3 $\beta$-hydroxycholenamide \\
\hline NHERF & $\mathrm{Na}^{+} / \mathrm{H}^{+}$exchanger regulator factor \\
\hline $\mathrm{NF}-\kappa \mathrm{B}$ & Nuclear factor kappa-light-chain-enhancer of activated B cells \\
\hline NFY & Nuclear factor $Y$ \\
\hline ORP1S & Oxysterol-binding protein-related protein $1 \mathrm{~S}$ \\
\hline PDZK1 & PDZ domain-containing adaptor protein \\
\hline PPAR & Peroxisome proliferator-activated receptors \\
\hline PPRE & Peroxisome proliferator-activated receptor-responsive element \\
\hline PMA & Phorbol 12-myristate 13-acetate \\
\hline PI3K & phosphatidylinositol 3- kinase \\
\hline PLD & Phospholipase D \\
\hline PGC-1 & PPARgamma coactivator 1 \\
\hline PLTP & Phospholipid transfer protein \\
\hline pri-miRNA & Primary long miRNA \\
\hline PREB & Prolactin regulatory element-binding \\
\hline PEST & Proline, glutamic acid, serine, threonine \\
\hline PKC & Protein kinase $\mathrm{C}$ \\
\hline PCA & Protocatechuic acid \\
\hline
\end{tabular}




$\begin{array}{ll}\text { PCSK9 } & \text { Proprotein convertase subtilisin/kexin type } 9 \\ \text { RAR } & \text { Retinoic acid receptor } \\ \text { ROR } \alpha & \text { Retinoic acid receptor-related orphan receptor } \alpha \\ \text { RXR } \alpha & \text { Retinoid X receptor } \alpha \\ \text { RISC } & \text { RNA-induced silencing complex } \\ \text { SR-BI } & \text { Scavenger receptor class B type I } \\ \text { SPTLC1 } & \text { Serine palmitoyltransferase 1 } \\ \text { STAT } & \text { Signal transducer and activator of transcription } \\ \text { SHP } & \text { Small heterodimer partner } \\ \text { siRNAs } & \text { Small interfering RNAs } \\ \text { SP1 } & \text { Specificity protein 1 } \\ \text { S1P } & \text { Sphingosine 1 phosphate } \\ \text { SRC-1 } & \text { Steroid receptor coactivator-1 } \\ \text { SF-1 } & \text { Steroidogenic factor-1 } \\ \text { SREBP } & \text { Sterol regulatory element-binding protein } \\ \text { SREs } & \text { Sterol-responsive elements } \\ \text { TR } \beta & \text { Thyroid hormone receptor } \beta \\ \text { TAD } & \text { Transactivation domain } \\ \text { TGF } \beta 1 & \text { Transforming growth factor } \beta 1 \\ \text { TNF } \alpha & \text { Tumor necrosis factor } \alpha \\ \text { Tpl2 } & \text { Tumor progression locus } 2 \\ \text { UTR } & \text { Untranslated region } \\ \text { URE } & \text { Upstream regulatory element } \\ \text { USF } & \text { Upstream stimulatory factors } \\ \text { VDR } & \text { Vitamin D receptor } \\ \text { WT } & \text { Wild type } \\ \text { YY1 } & \text { Yin Yang 1 } \\ \text { ZIC } & \text { Zinc finger of the cerebellum } \\ \text { ZNF202 } & \text { Zinc finger protein 202 } \\ & \end{array}$

\section{Regulation of Genes Involved in HDL Metabolism at the Transcriptional Level}

A large body of work generated over the past four decades has revealed that eukaryotic gene transcription is a remarkably intricate biochemical process that is tightly regulated at many levels by the ordered assembly of multiprotein transcription initiation complexes to specific regulatory regions in the promoters of genes (Roeder 1998, 2005; Lemon and Tjian 2000). Despite the progress made, still limited knowledge regarding the details exists. It is believed that specificity in gene regulation is determined by the unique order of cis-acting regulatory regions which are recognized by sequence-specific DNA-binding transcription factors. Recent advances in gene regulation technologies including the powerful chromatin 
immunoprecipitation assay have enabled the monitoring in real time of the ordered assembly and the disassembly of transcription factor complexes on the promoters and the enhancers of genes in response to extracellular or intracellular cues (Christova 2013; Rodriguez-Ubreva and Ballestar 2014). High-throughput sequencing technologies have revolutionized the fields of genomics, epigenomics, and transcriptomics and have provided novel insights into the transcription signatures of human diseases (Churko et al. 2013). Furthermore, using new powerful methodologies such as chromosome conformation capture (3C) and its derivatives, we are at a position to monitor dynamic intra- and interchromosomal interactions that allow the optimal expression of genes at a given time and space (Gavrilov et al. 2009; Wei et al. 2013).

Transcription factors may be constitutively active in a cell or work in an inducible mode in response to various ligands and signal transduction pathways. The cross talk between different signaling pathways which orchestrate the cellular responses can be facilitated by the physical and functional interactions between transcription factors, and these interactions can be monitored by various methods both in vivo and in vitro. All known transcription factors are modular in nature and contain a DNA-binding domain and a transcriptional activation domain (Mitchell and Tjian 1989; Lemon and Tjian 2000). In addition, several factors contain a dimerization domain that permits them to form homodimers and/or heterodimers. A variety of nuclear receptors for steroids, thyroids, retinoids, etc. contain a ligand binding site. Via their transcription activation domains, transcription factors appear to facilitate the recruitment of the proteins of the coactivator complex and the basal transcription complex to the transcription initiation site of each gene and thus initiate transcription (Roeder 2005). Importantly, the activity of transcription factors can be modulated by drugs against diseases such as cancer and cardiovascular disease as exemplified by the drugs that activate or repress the hormone nuclear receptors (Gronemeyer et al. 2004).

It is beyond the scope of this chapter to provide a thorough review of the different mechanisms of transcriptional regulation of eukaryotic genes or to describe extensively the different classes of transcription factors, their structures, and their mode of regulation. We will only focus on those classes of transcription factors that have been shown to play key roles in the regulation of the genes involved in lipid and lipoprotein metabolism and more specifically on those involved in the metabolism of high-density lipoproteins (HDL) such as the hormone nuclear receptors.

\subsection{General Introduction to Hormone Nuclear Receptors}

Hormone nuclear receptors belong to a superfamily of transcription factors that are activated by steroid hormones (estrogens, androgens, glucocorticoids, etc.), retinoids, thyroids, and products of intermediate metabolism such as bile acids, fatty acids, and cholesterol derivatives, among others (Gronemeyer et al. 2004). Some members of this family do not need ligand binding to regulate transcription 
and are classified as "orphans" (Blumberg and Evans 1998). Nuclear receptors are structurally highly conserved. In terms of primary structure, the highest degree of homology among family members is in the DNA-binding domain that contains two zinc fingers (Helsen et al. 2012). Nuclear receptors also contain two transactivation domains (TADs), one N-terminal ligand-independent TAD called activation function 1 (AF1) and a ligand-dependent TAD called AF2 located close to the ligandbinding domain (LBD) (Rochel et al. 2011). Nuclear receptors bind to hormone response elements (HREs) on the promoters of target genes either as homodimers or as heterodimers with the retinoid X receptor (RXR). The HREs consist of direct repeats (DRs), inverted repeats (IRs), or palindromic repeats (PRs) of the consensus sequence $5^{\prime} \mathrm{AG}(\mathrm{G} / \mathrm{T}) \mathrm{TCA} 3^{\prime}$. The repeats are separated by $1,2,3,4$, or 5 nucleotides and are designated DR1, DR2, etc. (for the direct repeats); IR1, IR2, etc. (for the inverted repeats); and PR1, PR2, etc. (for the palindromic repeats) as described previously (Kardassis et al. 2007; Helsen et al. 2012). The HRE type and inter-repeat spacing determine to a large degree the specificity in nuclear receptor binding, but this rule is not strict at all. For instance, both $L X R / R X R$ and T3R/RXR heterodimers prefer to bind to DR4 HREs, whereas RAR/RXR heterodimers bind to DR5. The direct repeats with one base spacing (DR1 type) appear to be very promiscuous as they bind RXR, COUP-TFI, ARP-1, and HNF-4 homodimers and PPAR/RXR, RAR/RXR, COUP-TFI/RXR, and ARP-1/RXR heterodimers (Nakshatri and Bhat-Nakshatri 1998). The elucidation of the threedimensional structure of the ligand-binding domain of several nuclear receptors by $\mathrm{X}$-ray crystallography in the absence and in the presence of ligands has allowed a good understanding of the modulation of nuclear receptor action by ligands and the development of very potent agonists and antagonists, some of which have been used therapeutically (Bourguet et al. 2000). Chromatin immunoprecipitation studies usually reveal that nuclear receptors are constitutively nuclear and bound to chromatin but they are transcriptionally silent in the absence of ligand. The binding of the ligand to the LBD causes a major conformational change to this domain which culminates in the recruitment of nuclear receptor coactivators such as PGC-1 and CBP/p300 and the displacement of corepressors (Chen and Li 1998; Liu and Lin 2011). Nuclear receptors can cross talk with other transcription factors in a positive or a negative manner as exemplified by the negative regulation of Jun or NF- $\mathrm{kB}$ transcription factors by the glucocorticoid receptors during inflammation, a mechanism termed trans-repression (Adcock and Caramori 2001).

\subsection{Transcriptional Regulation of the apoA-I Gene in the Liver}

The hypothesis that apolipoprotein (apo) A-I overexpression positively influences plasma concentrations of HDL cholesterol (HDL-C) has been validated experimentally in transgenic mice expressing human apoA-I under homologous or heterologous regulatory sequences. These mice have significantly elevated plasma levels of HDL-C and human apoA-I (Rubin et al. 1991; Kan et al. 2000). These "humanized" apoA-I transgenic mice are valuable tools for the study of apoA-I gene regulation 
in vivo. Furthermore, it was demonstrated that the overexpression of apoA-I in apoE $\mathrm{KO}$ or LDLR KO mice via transgene- or adenovirus-mediated gene transfer reduced atherosclerosis development confirming the anti-atherogenic role of apoA-I upregulation (Paszty et al. 1994; Belalcazar et al. 2003; Valenta et al. 2006).

In humans, the apoA-I gene is expressed abundantly in the liver and intestine and to a lesser extent in other tissues (Zannis et al. 1985). Early studies had established that the human apoA-I promoter containing $250 \mathrm{bp}$ upstream from the transcription start site of the gene is sufficient to drive liver-specific gene expression both in cell cultures and in mice (Walsh et al. 1989; Tzameli and Zannis 1996; Hu et al. 2010a). This promoter region is rich in nuclear factor binding sites and responds to various intracellular as well as extracellular ligands (Zannis et al. 2001a; Haas and Mooradian 2010). As shown in Fig. 1, prominent role in the regulation of the apoA-I promoter play two hormone response elements (HREs) located at positions $-210 /-190$ and $-132 /-120$ that bind members of the hormone nuclear receptor superfamily in a competitive manner (Tzameli and Zannis 1996).

One of the nuclear receptors that plays a prominent role in apoA-I gene regulation in the liver and the intestine is the hepatocyte nuclear factor-4 (HNF-4).

HNF-4 was discovered as a rat liver nuclear protein that binds to the promoters of liver-specific genes such as transthyretin and apolipoprotein C-III (Sladek 1994). In the adult organism, HNF-4 is expressed in the liver, kidney, intestine, and pancreas (Sladek 1994). The total disruption of the HNF-4 gene in mice leads to an embryonic lethal phenotype due to the impairment of endodermal differentiation and gastrulation (Chen et al. 1994). This early developmental arrest was rescued by the complementation of the HNF- $4 \alpha^{-/-}$embryos with a tetraploid embryo-derived

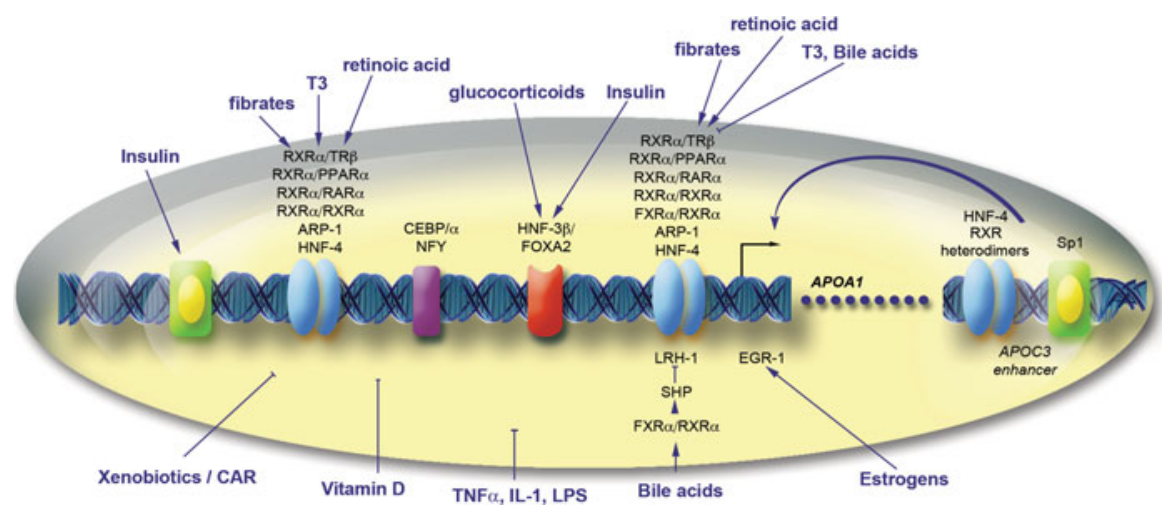

Fig. 1 Regulatory elements and transcription factors that control the expression of the apoA-I gene. Arrows and block lines denote activation and repression, respectively. The mechanisms are described in detail in the text. Abbreviations: retinoic acid receptor (RAR); retinoid X receptor (RXR); thyroid receptor $\beta$ (TR $\beta$ ); farnesoid $X$ receptor (FXR); hepatocyte nuclear factor (HNF); apoA-I regulatory protein 1 (ARP-1); forkhead box 2 (FOXA2); nuclear factor Y (NFY); CCAAT/ enhancer-binding protein (CEBP); liver receptor homologue-1 (LRH-1); small heterodimer partner (SHP); specificity protein 1 (Sp1); tumor necrosis factor $\alpha(\mathrm{TNF} \alpha)$, interleukin-1 (IL-1); lipopolysaccharide (LPS) 
wild-type visceral endoderm ( $\mathrm{Li}$ et al. 2000). The analysis of the rescued mice showed that the expression of the apoA-I gene as well as of other apolipoprotein genes, shown previously to be regulated by HNF-4 including apoA-II, apoB, apoCIII, and apoC-II, was abolished confirming the cell culture data ( $\mathrm{Li}$ et al. 2000). Experiments in mice in which the HNF-4 gene was disrupted in the adult liver using Alb-Cre revealed that HNF-4 is essential not only for the establishment but also for the maintenance of hepatic differentiation status (Hayhurst et al. 2001). Lipid and lipoprotein analysis of plasma of these mice revealed a dramatic reduction in total cholesterol, HDL cholesterol, and triglycerides as well as a dramatic increase in the concentration of bile acids (Hayhurst et al. 2001). Furthermore, FPLC analysis showed that HDL cholesterol from the HNF-4 Liv KO mice eluted later than that from controls indicative of the presence of smaller HDL populations. Interestingly, the expression of the two essential genes for HDL biogenesis, namely apoA-I and ABCA1, was not affected in the livers of the HNF-4 Liv KO, suggesting that the reduction in the plasma HDL levels was the result of altered HDL remodeling rather than reduced biosynthesis. In agreement with this, the expression level of the HDL receptor SR-BI gene was dramatically increased (Hayhurst et al. 2001).

Studies in transgenic mice expressing the human apoA-I gene under its own regulatory sequences and clinical studies in humans have shown that fibrates have a positive effect on apoA-I gene transcription as well as on plasma HDL levels. The increase in human apoA-I gene transcription by fibrates is mediated by peroxisome proliferator-activated receptor $\alpha$ (PPAR $\alpha)$ which binds to a PPRE on the proximal apoA-I promoter as a heterodimer with RXR $\alpha$ (Tzameli and Zannis 1996; Staels and Auwerx 1998). This was confirmed by in vivo experiments performed in mice that express human apoA-I under the control of its own promoter but lack the expression of PPAR $\alpha$. When these mice were given fenofibrate (FF) or gemfibrozil (GF) for 17 days, an increase in plasma HDL-C levels was observed by FF and to a lesser extent by GF only in the mice that express endogenous PPAR $\alpha$ (Duez et al. 2005). The fibrate-treated mice had larger HDL particles possibly due to the upregulation of phospholipid transfer protein and downregulation of SR-BI (Duez et al. 2005). Interestingly, the apoA-I gene cannot be upregulated by fibrates in rodents due to a three base pair difference in the PPRE rendering the rodent apoA-I PPRE nonfunctional (Vu-Dac et al. 1994). In line with the above findings, liverspecific inactivation of the PPAR $\alpha$ heterodimer partner retinoid $\mathrm{X}$ receptor $\alpha$ $(\mathrm{RXR} \alpha)$ gene in mice was associated with increased expression of the apoA-I gene (Wan et al. 2000).

In a clinical study involving 234 patients with combined hyperlipidemia, both FF and GF reduced triglycerides and increased HDL-C to a similar extent, but only FF treatment increased apoA-I plasma levels, and this was in agreement with the previous clinical trials (Schaefer et al. 1996; Durrington et al. 1998; Sakai et al. 2001; Duez et al. 2005).

A humanized apoA-I transgenic mouse model expressing human apoA-I under its own regulatory sequences in a mouse apoA-I null background was recently used to identify by global gene expression profiling candidate genes that affect lipid and lipoprotein metabolism in response to fenofibrate treatment (Sanoudou et al. 2009). 
Bioinformatical analysis and stringent selection criteria (twofold change, $0 \%$ false discovery rate) identified 267 significantly changed genes. In contrast to the study by Duez et al. discussed above (Duez et al. 2005), fenofibrates (FF) did not significantly alter the levels of hepatic human apoA-I mRNA and plasma apoA-I protein. This could be due to differences either in the mouse models used (for instance, the humanized apoA-I mouse of Sanoudou et al. has $2.1 \mathrm{~kb}$ apoA-I promoter fragment, whereas the model of Duez et al. has a $5.5 \mathrm{~kb}$ apoA-I promoter) or the doses of fibrates $(0.2 \% \mathrm{w} / \mathrm{w}$ in the paper of Duez et al. and $0.03 \%$ in the paper by Sanoudou et al.). Despite the lack of apoA-I responsiveness, the FF treatment increased cholesterol levels 1.95 -fold mainly due to the increase in HDL-C. The observed changes in HDL were associated with the upregulation of genes involved in phospholipid biosynthesis and lipid hydrolysis, as well as in the phospholipid transfer protein. The gene encoding the estrogen receptor-related gamma (ESRRG) transcription factor was upregulated 2.36-fold by FF and had a significant positive correlation with genes of lipid and lipoprotein metabolism and mitochondrial functions, indicating an important role of this orphan receptor in mediating the FF-induced activation of a specific subset of its target genes (Sanoudou et al. 2009).

In addition to HNF-4 and PPAR $\alpha$, the two HREs of the proximal human apoA-I promoter bind apoA-I regulatory protein 1 (ARP-1) and liver receptor homologue-1 (LRH-1) which repress and activate the apoA-I promoter, respectively, as illustrated in Fig. 1 (Ladias and Karathanasis 1991; Delerive et al. 2004). LRH-1 is a member of the fushi tarazu subfamily of nuclear receptors that is highly expressed in the liver, intestine, pancreas, and ovary (Fayard et al. 2004). In the liver, LRH-1 plays a key role in cholesterol homeostasis, through the control of the expression of genes that are implicated in bile acid biosynthesis and enterohepatic circulation such as CYP7A1, CYP8B1, and ABCG5/8 (del Castillo-Olivares and Gil 2000; Freeman et al. 2004; Kir et al. 2012; Back et al. 2013), reverse cholesterol transport (SR-BI, apoA-I) (Schoonjans et al. 2002; Delerive et al. 2004), and HDL remodeling (CETP) (Luo et al. 2001). However, mice with targeted inactivation of the LRH-1 gene in the liver are characterized by physiological levels of HDL cholesterol, LDL cholesterol, and triglycerides but have a profound effect on bile acid composition in the liver which leads to reduced intestinal reuptake of bile acids and to the enhanced removal of lipids from the body (Mataki et al. 2007). Recent data suggest that LRH-1 functions in a compensatory safeguard mechanism for adequate induction of bile salt synthesis under conditions of high bile salt loss (Out et al. 2011).

The two HREs of the apoA-I promoter also mediate the response of apoA-I to thyroids, retinoids, and bile acids via heterodimers of $\mathrm{RXR} \alpha$ with thyroid hormone receptor $\beta(\operatorname{TR} \beta)$, retinoic acid receptor $\alpha(\operatorname{RAR} \alpha)$, and farnesoid X receptor $\alpha$ $(\mathrm{FXR} \alpha)$, respectively (Rottman et al. 1991; Hargrove et al. 1999). Although retinoids activate apoA-I gene expression, thyroids have dual effects on apoA-I promoter activity, whereas bile acids inhibit apoA-I gene expression (Taylor et al. 1996; Tzameli and Zannis 1996; Srivastava et al. 2000; Claudel et al. 2002). As shown in Fig. 1, in response to bile acids, FXR downregulates apoA-I gene transcription by two complementary mechanisms: (a) a direct binding 
to the apoA-I HRE and (b) an indirect mechanism via the induction of small heterodimer partner (Bavner et al. 2005) which, in turn, represses the activity of LRH-1 (Delerive et al. 2004).

The nuclear receptor constitutive androstane receptor (CAR) regulates the detoxification of xenobiotics and endogenous molecules. In mice, the specific CAR agonist 1,4-bis[2-(3,5-dichloropyridyloxy)]benzene (TCPOBOP) decreased HDL cholesterol and plasma apoA-I levels in a CAR-specific manner (Masson et al. 2008). In transient transfections, CAR decreased the activity of the human apoA-I promoter in the presence of TСРОВOP, but the mechanism by which this repression is facilitated remains unknown (Masson et al. 2008).

Ligands of the vitamin D receptor (VDR) were also shown to affect negatively apoA-I gene expression in hepatic cells (Wehmeier et al. 2005). In VDR KO mice, serum HDL-C levels were $22 \%$ higher and the mRNA levels of apoA-I were $49.2 \%$ higher compared with WT mice. The mechanisms by which VDR ligands affect HDL levels remain unclear (Wang et al. 2009).

\subsubsection{The Role of the Distal Enhancer in apoA-I Gene Transcription}

In addition to its own promoter, optimal expression of the human apoA-I gene in hepatic and intestinal cells requires the presence of a $200 \mathrm{bp}$ transcriptional enhancer element located downstream of the apoA-I gene, $500 \mathrm{bp}$ upstream of the first exon of the adjacent apoC-III gene. This regulatory region, which coordinates the expression of all three genes of the apoA-I/C-III/A-IV cluster, contains two hormone response elements that bind HNF-4 and different combinations of ligand-dependent nuclear receptors as well as two binding sites for the ubiquitous transcription factor specificity protein 1 (Sp1) (Kardassis et al. 1997; Lavrentiadou et al. 1999). The mutagenesis of the HREs and of the $\mathrm{Sp} 1$ sites reduced the activity of the apoA-I promoter/C-III enhancer cassette in cell cultures and abolished the binding of the corresponding factors (Kardassis et al. 1997; Lavrentiadou et al. 1999).

The contribution of the HREs and the Sp1 binding sites to the tissue-specific expression of the apoA-I gene in vivo was addressed using transgenic mice bearing the WT apoA-I/apoC-III gene cluster under the control of their regulatory regions or the same cluster bearing mutations in different regulatory elements (Georgopoulos et al. 2000; Kan et al. 2000, 2004). It was shown that mutations in one of the two HREs of the enhancer (element I4) abolished the intestinal expression and reduced the hepatic expression of the adjacent apoA-I gene to $20 \%$ of the control. Mutations in the two HREs of the proximal apoA-I promoter reduced the hepatic and intestinal expression of the apoA-I gene to approximately $15 \%$ of the control, whereas combined mutations in all three HREs totally eliminated the intestinal and hepatic expression of the apoA-I gene (Kan et al. 2000). Studies in cell cultures established that HNF-4 and Sp1 factors are both required for the synergy between the apoA-I promoter and the enhancer by physically interacting with each other and forming transcriptional complexes in order to facilitate the recruitment of the basal transcriptional machinery (Kardassis et al. 2002). The aforementioned mouse model that expresses human apoA-I under its own promoter 
and enhancer (Kan et al. 2000) is very useful for the in vivo characterization of the mechanisms that regulate the expression of the apoA-I gene under physiological or pathological conditions as well as for the identification and validation of novel compounds that are designed to upregulate human apoA-I gene transcription and serve as HDL-raising drugs. This is especially important in light of the differences between the mouse and the human apoA-I promoters. For instance, the mouse gene cannot be upregulated by fibrates due to a three base pair difference in the PPRE compared to the human promoter which responds to $0.2 \%$ fibrates but not to $0.03 \%$ fibrates as mentioned above.

\subsubsection{Other Factors Regulating apoA-I Gene Transcription}

Further upstream from the two apoA-I HREs, an insulin response core element (IRCE) was identified and shown to bind Sp1 (Murao et al. 1998). Insulin-activated signaling pathways including the Ras/raf and the phosphatidylinositol 3-kinase (PI3K) have been shown to posttranslationally modify Sp1, and this leads to increased apoA-I promoter activity (Mooradian et al. 2004).

Early growth response protein 1 (EGR-1) is another transcription factor that regulates apoA-I expression via the proximal HREs (Kilbourne et al. 1995; Cui et al. 2002). Mice with experimental nephrotic syndrome are characterized by a fivefold increase in the levels of EGR-1, and these changes were associated with high plasma apoA-I and HDL-C levels as well as apoA-I gene transcription in the liver (Zaiou et al. 1998). In line with these findings, mice deficient in EGR-1 have reduced plasma HDL-C and apoA-I as well as hepatic apoA-I mRNA levels (Zaiou et al. 1998). EGR-1 was shown to mediate the response of the apoA-I promoter to estrogens (Hargrove et al. 1999).

The proximal apoA-I promoter also contains one element that binds the basic leucine zipper (bZip) factor CCAAT/enhancer-binding protein (C/EBP) and nuclear factor Y (NFY) and another element that binds hepatocyte nuclear factor3ß/FOXA2 (Papazafiri et al. 1991; Novak and Bydlowski 1997). Nuclear factor HNF-3 $\beta$ was shown to mediate the response of the apoA-I promoter to glucocorticoids (Hargrove et al. 1999).

Several natural compounds with antioxidant, pro-estrogenic, or other activities were shown to affect apoA-I and HDL-C levels, and these studies are summarized in Haas and Mooradian (2010).

Pro-inflammatory cytokines including tumor necrosis factor $\alpha(\mathrm{TNF} \alpha)$ and interleukin-1 $\beta$ (IL-1 $\beta$ ) were previously shown to inhibit apoA-I gene expression both in cell cultures and in animals (Ettinger et al. 1994; Song et al. 1998). Furthermore, plasma levels of HDL-C and apoA-I were shown to be highly increased in mice deficient in the p50 subunit of the pro-inflammatory transcription factor NF- $\mathrm{KB}$ (Morishima et al. 2003). In agreement with this observation, the activation of NF- $\mathrm{KB}$ by lipopolysaccharide (LPS) caused a reduction in apoA-I mRNA and protein levels in HepG2 cells, whereas the inhibition of NF- $\kappa$ B via adenovirus-mediated overexpression of $\mathrm{I} \kappa \mathrm{B} \alpha$ abolished the reduction (Morishima et al. 2003). This IкB $\alpha$-induced apoA-I increase was blocked by preincubation with MK886, a selective inhibitor of peroxisome proliferator-activated receptor $\alpha$, and 
mutations in the PPAR $\alpha$ binding site in the apoA-I promoter abrogated these changes (Morishima et al. 2003). In a recent study, it was shown that apoA-I promoter activity in HepG 2 cells is inhibited by TNF $\alpha$ in a c-Jun-dependent manner but no AP1-responsive element within the apoA-I promoter was reported to mediate this effect (Parseghian et al. 2013). The inhibition of the expression of apoA-I and other HDL genes in hepatocytes during inflammation could also be mediated by HNF-4 which was previously shown to be negatively regulated by the $\mathrm{TNF} \alpha / \mathrm{NF}-\kappa \mathrm{B}$ signaling pathway by physically interacting with NF- $\kappa \mathrm{B}$ (NikolaidouNeokosmidou et al. 2006).

\subsection{Transcriptional Regulation of the ABCA1 Gene}

The gene encoding the ATP-binding cassette transporter A1 (ABCA1) is expressed in the liver, small intestine, macrophages, kidney, and various other tissues (Langmann et al. 1999, 2003; Kielar et al. 2001; Wellington et al. 2002). ABCA1 is an important regulator of HDL biogenesis in the liver and facilitates the removal of excess cholesterol from macrophages.

ABCA1 is particularly abundant in macrophages (Langmann et al. 1999). ABCA1 expression in macrophages has little influence on HDL-C plasma levels (Haghpassand et al. 2001) but is an important factor in the prevention of cholesterol accumulation in the macrophages found in the atherosclerotic plaque and their transformation into foam cells (Aiello et al. 2002). ABCA1 mRNA and protein are very unstable, having a half-life of 1-2 $\mathrm{h}$ in murine macrophages (Wang and Oram 2002). Fine-tuning regulatory mechanisms (transcriptional regulation as well as posttranscriptional and posttranslational modifications) are involved to ensure the constant and inducible ABCA1 expression in macrophages. In this section, we will focus on the transcriptional regulation of the ABCA1 gene with emphasis on macrophages. Posttranscriptional and posttranslational regulation of this gene will be discussed in later sections.

The human ABCA1 gene mapped to chromosome 9q31.1 is composed of 50 exons, which encode 2261-amino-acid residues (Santamarina-Fojo et al. 2000). The ABCA1 gene promoter contains a TATA box localized $24 \mathrm{bp}$ upstream of the transcription initiation site, essential for promoter activity in macrophages as well as in hepatocytes (Langmann et al. 2002). The engagement of alternative promoters and transcription initiation sites localized upstream of the first exon or inside the first intron of the gene enables the inducible and tissuespecific expression regulation of ABCA1 gene (Huuskonen et al. 2003; Singaraja et al. 2005). In addition, other transcriptional response elements of the promoter influence the constitutive and tissue-specific expression of ABCA1 (Fig. 2).

\subsubsection{Upregulatory Mechanisms of ABCA1 Gene Expression}

The major transcription factors that upregulate ABCA1 gene expression in macrophages are the nuclear receptors liver $\mathrm{X}$ receptors $\alpha$ and $\beta(\operatorname{LXR} \alpha$ and $\operatorname{LXR} \beta$ ), both expressed by this cell type. LXRs heterodimerize with the retinoic 


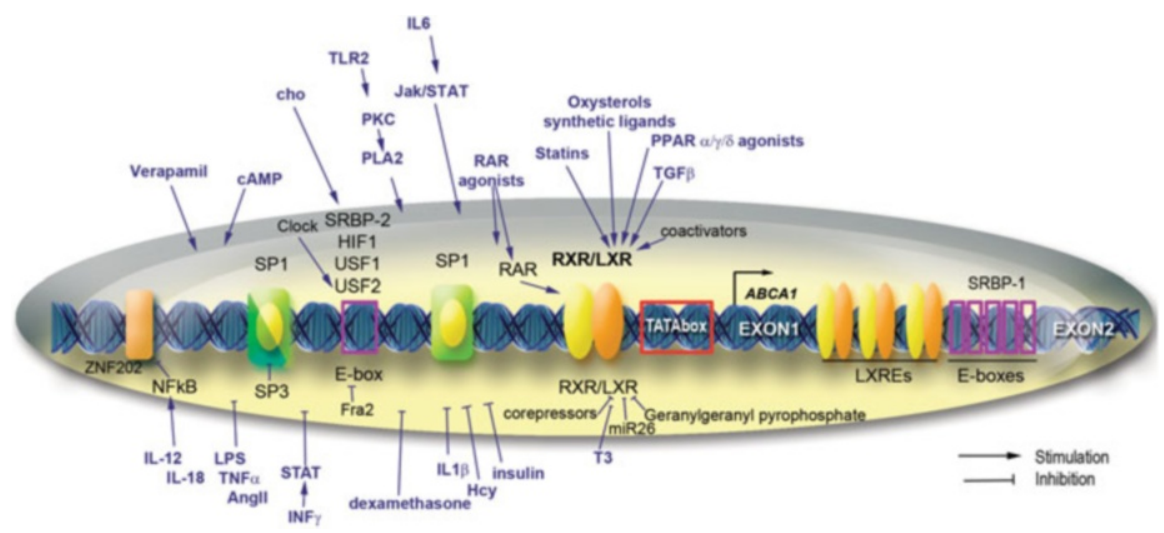

Fig. 2 Regulatory regions, transcription factors, and signaling molecules (cytokines, growth factors, metabolites, drugs) that modulate the expression of the ABCA1 gene in macrophages and other tissues. Arrows and block lines denote activation and repression, respectively. The mechanisms are described in detail in the text. Abbreviations: retinoic acid receptor (RAR); retinoid $\mathrm{X}$ receptor $(\mathrm{RXR})$; liver $\mathrm{X}$ receptor (LXR); sterol regulatory element-binding protein (SREBP); specificity protein 1 (Sp1); tumor necrosis factor $\alpha$ (TNF $\alpha$ ), interleukin (IL); lipopolysaccharide (LPS); interferon $\gamma$ (IFN $\gamma$ ); angiotensin II (AngII); nuclear factor kappa beta (NF-kB); upstream stimulatory factor (USF); hypoxia-inducible factor (HIF); transforming growth factor $\beta$ (TGF $\beta$ ); peroxisome proliferator-activated receptor (PPAR); Janus kinase (Jak); signal transducer and activator of transcription (STAT)

$\mathrm{X}$ receptor $(\mathrm{RXR} \alpha)$ to bind to the direct repeats separated by four nucleotides (direct repeat 4; DR4 elements) found at position $-62 /-47$ of the ABCA1 promoter (Costet et al. 2000). Additional but not well-characterized LXREs are present at the intron 1 promoter of the ABCA1 gene (Singaraja et al. 2001). Since the LXR $\alpha$ promoter is subject to autoregulation, the LXR-mediated gene expression is autoamplified (Laffitte et al. 2001a). The natural ligands of LXR are several hydroxylated derivatives of cholesterol (oxysterols) and include 27-hydroxycholesterol (Schwartz et al. 2000; Fu et al. 2001), 22(R)hydroxycholesterol (Costet et al. 2000), 20(S)-hydroxycholesterol (Schwartz et al. 2000), and desmosterol (Yang et al. 2006). Among these ligands, 27-hydroxycholesterol which is endogenously produced by the action of CYP27A1 enzyme represents the sensor of cholesterol loading in macrophages. In addition to these natural ligands, synthetic LXR ligands such as TO901317 have also been developed. These synthetic LXR agonists upregulate ABCA1 in cultured macrophages more efficiently than cholesterol loading via modified LDL particles (Sparrow et al. 2002).

LXR tissue-selective gene transcription is dependent on co-regulatory proteins. For example, data showed that the activation of the ABCA1 promoter by LXR $\alpha$ / $\mathrm{RXR} \alpha$ heterodimers and their ligands require Sp1 (Thymiakou et al. 2007). The overexpression of Sp1 increased ABCA1 mRNA level in HeLa cells and enhanced cellular cholesterol and phospholipid efflux in RAW 246.7 macrophages. Gel shift experiments revealed in vitro binding of $\mathrm{Sp} 1$ to $-85 /-91$ and $-151 /-156 \mathrm{GC}$ 
boxes. Moreover, it was shown that $\mathrm{Sp} 3$ competed with $\mathrm{Sp} 1$ for binding to the latter GC box, acting as a repressor (Langmann et al. 2002). Physical interactions between $\mathrm{Sp} 1$ and $\mathrm{LXR} \alpha$ require the $\mathrm{N}$-terminal region of $\mathrm{LXR} \alpha$, which includes the DNA-binding domain and two different domains of Sp1: the transactivation domain B and the DNA-binding domain (Thymiakou et al. 2007). LXR agonists, such as the natural steroidal ligand 22(R)-hydroxycholesterol and the weak nonsteroidal ligand GSK418224, differentially recruit coactivators and corepressors compared with full LXR agonists, such as the nonsteroidal ligand T0901317 (Albers et al. 2006; Peng et al. 2008, 2011; Phelan et al. 2008). The synthetic oxysterol N, $\mathrm{N}$-dimethyl-3 $\beta$-hydroxycholenamide (DMHCA) caused a differential induction of the ABCA1 and the sterol regulatory element-binding protein (SREBP)-1c genes in hepatic and macrophage cell lines, as well as in mice (Quinet et al. 2004). In cholesterol-loaded or unloaded peritoneal macrophages, DMHCA increased ABCA1 mRNA, whereas SREBP-1c mRNA levels were downregulated (Quinet et al. 2004). Cineole, a small aromatic compound found in teas and herbs, considerably stimulated the transactivation potential of $\operatorname{LXR} \alpha$ and $\operatorname{LXR} \beta$ and induced ABCA1 expression in macrophages but significantly reduced the expression of LXR $\alpha$ - and LXR $\alpha$-responsive genes in hepatocytes (Jun et al. 2013). Another LXR agonist, ATI-111, had a strong effect on ABCA1 expression in macrophages as well as in the intestine and small effect on ABCA1 expression in the liver. ATI-111 significantly stimulated SREBP-1c mRNA in some tissues but inhibited the conversion of SREBP-1c precursor form into its active form (Peng et al. 2011).

These findings revealed that LXR agonists have a promising potential for the upregulation of the ABCA1 transporter and the promotion of the cellular lipid efflux capacity of macrophages. Due to the concomitant LXR-mediated upregulation of two genes involved in the fatty acid biosynthesis, fatty acid synthase (Joseph et al. 2002a), and SREBP-1c (Yoshikawa et al. 2001), the development of LXR agonists for therapeutic uses has been limited by their adverse effects that include hepatic steatosis and hypertriglyceridemia. In order to dissociate the positive effects of LXR agonists on cholesterol homeostasis from the adverse effects on fatty acid metabolism, the next step will be the discovery of new LXR $\beta$-selective agonists and the synthesis of novel tissue-specific LXR ligands with weaker transcriptional effects on SREBP-1c. SREBP-1a, a different member of the SREBP family of proteins, binds to several sites present inside intron 1 ; however, the role of these elements in ABCA1 gene regulation is still unknown (Thymiakou et al., unpublished observations) (Fig. 2).

Besides LXR, other nuclear receptors and transcription factors are involved in ABCA1 gene regulation in macrophages. Retinoic acid receptor (RAR) activators such as all-trans-retinoic acid and 4-[(E)-2-(5,6,7,8-tetrahydro-5,5,8,8-tetramethyl2-naphthalenyl)-1-propenyl]benzoic acid (arotinoid acid) were found to increase ABCA1 mRNA and protein levels in macrophages (Costet et al. 2003). Co-transfection experiments showed that the same DR4 promoter element of the ABCA1 promoter binds RXR heterodimers in the following order: $\operatorname{RAR} \gamma / \mathrm{RXR} \alpha$ bound stronger and activated the human ABCA1 promoter, and RAR $\alpha / \operatorname{RXR} \alpha$ bound weaker, while no $\operatorname{RAR} \beta / \operatorname{RXR} \alpha$ binding was detected. However, in 
macrophages from $\mathrm{RAR} \gamma^{-l-}$ mice, arotinoid acid still induced ABCA1 gene expression and caused marked upregulation of $\mathrm{RAR} \alpha$, suggesting that high levels of RAR $\alpha$ can compensate for the absence of RAR $\gamma$ (Costet et al. 2003).

Peroxisome proliferator-activated receptors $\alpha(\operatorname{PPAR} \alpha)$ and $\gamma(\operatorname{PPAR} \gamma)$ are both expressed in human macrophages where they exert anti-inflammatory effects. The hydroxylated derivative of linoleic acid, 13-hydroxy linoleic acid, a natural PPAR agonist, and pioglitazone (PPAR $\gamma$ agonist) increased PPAR transcriptional activity and induced ABCA1 gene expression in macrophages (Kammerer et al. 2011; Ozasa et al. 2011). However, data suggest that these effects are indirect and most probably are mediated by LXR $\alpha$ (Chinetti et al. 2001). PPAR $\delta$ activators appeared to induce ABCA1 gene expression and cholesterol efflux moderately and to increase HDL levels in an obese-monkey model (Oliver et al. 2001).

Recent data showed that Clock, a key transcription factor that controls circadian rhythm, is involved in ABCA1 regulation in macrophages (Pan et al. 2013). The dominant-negative Clock mutant protein (Clock $\Delta 19 / \Delta 19)$ enhanced plasma cholesterol and atherosclerosis. Mutant Clock $\Delta 19 / 19 / \mathrm{apoE}^{-/-}$mice had macrophage dysfunction, expressed low levels of ABCA1, and had higher levels of scavenger receptors. Molecular studies revealed that Clock regulated ABCA1 expression in macrophages by modulating the activity of upstream stimulatory factor 2 (Pan et al. 2013).

Experimental data showed that signaling molecules upregulate ABCA1 expression in macrophages, but the fine-tuning mechanism of modulation and the regulatory regions involved remain to be elucidated. Transforming growth factor $\beta 1$ (TGF $\beta 1$ ) increased ABCA1 mRNA levels in cholesterol-loaded macrophages (Argmann et al. 2001; Panousis et al. 2001). It was demonstrated that in THP-1 macrophage-derived foam cells, the LXR $\alpha$ pathway is involved in TGF $\beta$-mediated upregulation of ABCA1 expression (Hu et al. 2010b). Interleukin-6 (IL-6) significantly increased ABCA1 at both the mRNA and protein levels. This effect was abolished by selective inhibition of the JAK2/STAT3 signaling pathway (Frisdal et al. 2011). ABCA1 mRNA levels were significantly increased by estradiol treatment of macrophages for a short period of time, suggesting a direct activation of the ABCA1 promoter via the estrogen receptor $\beta$ (Schmitz and Langmann 2005). Membrane-permeable analogues of cyclic adenosine monophosphate (cAMP) induced the ABCA1 mRNA in macrophages and other cells by an unknown mechanism (Lin and Bornfeldt 2002). Inhibitors that are able to block the action of phosphodiesterase 4 on cAMP have been found to increase ABCA1 mRNA and cellular cholesterol efflux (Lin and Bornfeldt 2002). Verapamil, a calcium channel blocker, enhanced ABCA1 transcription by an LXR-independent process (Suzuki et al. 2004). Toll-like receptor 2 agonist $\operatorname{Pam(3)CSK(4)~upregulated~ABCA1~gene~}$ expression in RAW 264.7 macrophages via the activation of the PKC $\eta$ phospholipase D2 signaling pathway (Park et al. 2013). S-Allylcysteine, the most abundant organosulfur compound in aged garlic extract, also elevated ABCA1 content in human THP-1 macrophages (Malekpour-Dehkordi et al. 2013). The data showed that stimulation with CXCL5 that has a protective role in atherosclerosis (Rousselle 
et al. 2013) induced ABCA1 expression in alternatively activated (M2) macrophages but not in classically activated (M1) macrophages.

\subsubsection{Negative Regulation of ABCA1 Gene Transcription}

The thyroid hormone T3 strongly suppressed ABCA1 gene transcription (Huuskonen et al. 2004). It was demonstrated that T3 significantly inhibited the ability of oxysterols to activate LXR. Moreover, the TR/RXR heterodimers competed with LXR/RXR for the DR4 element in the ABCA1 promoter (Huuskonen et al. 2004). A reciprocal negative cross talk exists between LXRs and STAT1 based on the competition for CREB-binding protein (Pascual-Garcia et al. 2013). This may explain the IFN $\gamma$-mediated downregulation of ABCA1 in cholesterol-loaded macrophages (Panousis and Zuckerman 2000; Argmann et al. 2001; Ma et al. 2013). Moreover, TNF $\alpha$ downregulates ABCA1 as well as $\mathrm{LXR} \alpha$ expression in macrophages via a PKC $\theta$-dependent pathway (Ma et al. 2013).

Unsaturated fatty acids decrease the expression of ABCA1 in RAW 264.7 macrophages by a mechanism that involves LXR/RXR binding to the promoter (Uehara et al. 2007) and by modulation of the histone acetylation state (Ku et al. 2012). In MCSF-activated human monocytes, linoleic acid decreases ABCA1 gene expression (Mauerer et al. 2009). Geranylgeranyl pyrophosphate, a product of the mevalonate pathway that is used for protein isoprenylation, suppresses LXR-induced ABCA1 synthesis in two ways: as an antagonist of the LXR interaction with the steroid receptor coactivator-1 (SRC-1) and as an activator of Rho GTP-binding proteins (Gan et al. 2001).

Among the transcription factors that downregulate ABCA1 expression in macrophages in an LXR-independent manner is the SCAN domain-containing zinc finger transcription factor ZNF202 which binds to a GnT motif in the region $-234 /-215$ of the ABCA1 promoter (Porsch-Ozcurumez et al. 2001). High intracellular levels of ZNF202 prevented LXR/RXR-mediated induction of the ABCA1 promoter in response to oxysterols (Porsch-Ozcurumez et al. 2001).

The conserved E-box at position -140 binds transcription factors that modulate the ABCA1 gene expression. Experimental data indicated that upstream stimulatory factors (USF) 1 and 2, hepatocyte nuclear factor-1 $\alpha$ (HNF-1 $\alpha$ ), and fos-related antigen (Fra) 2 bind to the intact E-box of the human ABCA1 promoter and differentially modulate the gene expression: USF1 and USF2 enhanced and Fra2 repressed ABCA1 promoter activity (Langmann et al. 2002; Yang et al. 2002). The same E-box element also binds the sterol regulatory element-binding protein 2 (SREBP-2), a key regulator of cholesterol metabolism, which suppresses ABCA1 gene transcription in response to cholesterol depletion (73).

ABCA1 gene expression was severely decreased in the liver and peritoneal macrophages of diabetic mice (Uehara et al. 2002). This observation was explained using in vitro models in which it was revealed that acetoacetate downregulates ABCA1 mRNA and protein in HepG2 hepatocytes and RAW 264.7 macrophages (Uehara et al. 2002) and thus high glucose concentration decreases ABCA1 gene expression in MCSF-activated monocytes (Mauerer et al. 2009). Data showed that 
the treatment of THP-1 macrophages with $100 \mathrm{nM}$ dexamethasone, a potent synthetic ligand of the glucocorticoid receptor, decreases the expression of the ABCA1 gene (Sporstol et al. 2007).

LPS downregulates ABCA1 in macrophages; this inhibition was reverted by the treatment with betulinic acid acting via the downregulation of miR-33 and suppression of NF- $\kappa$ B pathway (Zhao et al. 2013). IL-18 and IL-12 synergistically decrease ABCA1 levels in THP-1 macrophage-derived foam cells through the IL-18 recep-

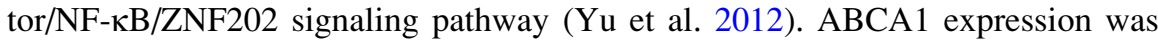
strongly suppressed by angiotensin (Ang) II at both mRNA and protein levels in a dose-dependent manner in THP-1-derived macrophages, whereas ABCG1 expression was not affected. The effect of Ang II on ABCA1 expression could be mediated by the angiotensin II type 1 (AT1) receptor (Chen et al. 2012a). It was demonstrated that clinically relevant concentrations of homocysteine (Hcy) decreased the mRNA and protein expression levels of ABCA1 in macrophages. It was revealed that mRNA expression and the activity of DNA methyltransferase were increased by Hcy, which may explain the higher DNA methylation level of ABCA1 gene in macrophages incubated with Hcy (Liang et al. 2013).

\subsection{Transcriptional Regulation of the ABCG1 Gene}

ABCG1 mediates cholesterol removal from macrophages to HDL particles, but not to lipid-free apoA-I (Kennedy et al. 2005; Fitzgerald et al. 2010). Although recent data showed that the combined macrophage deficiency of ABCA1/G1 is pro-atherogenic, probably by promoting plaque inflammation (Westerterp et al. 2013), the data concerning the role of ABCG1 expression in macrophages is controversial. Two independent groups reported that $\mathrm{LDLR}^{-/-}$mice lacking macrophage ABCG1 show decreased atherosclerotic lesions (Baldan et al. 2006; Ranalletta et al. 2006), while others reported that the absence of macrophage ABCG1 causes a modest increase in atherosclerotic lesions (Out et al. 2006). These contradictory results may be explained by recent data showing that the absence of ABCG1 leads to increased lesions in early stages of atherosclerosis but causes retarded lesion progression in more advanced stages of atherosclerosis in $\mathrm{LDLR}^{-1-}$ mice, suggesting that the influence of ABCG1 deficiency on lesion development depends on the stage of atherogenesis (Meurs et al. 2012).

The human ABCG1 gene has been mapped to chromosome 21q22.3 and encodes for a 678-amino-acid protein of $75.5 \mathrm{kDa}$ molecular mass (Chen et al. 1996). The ABCG1 gene spans more than $70 \mathrm{~kb}$ and includes 15 exons, each containing between 30 and 1,081 bp, while the intron size is between $137 \mathrm{bp}$ and more than $45 \mathrm{~kb}$. All exon-intron boundaries display the canonical GT/AG sequences. In contrast to the ABCA1 gene, the ABCG1 gene does not contain a canonical TATA box in the promoter (Langmann et al. 2000). 


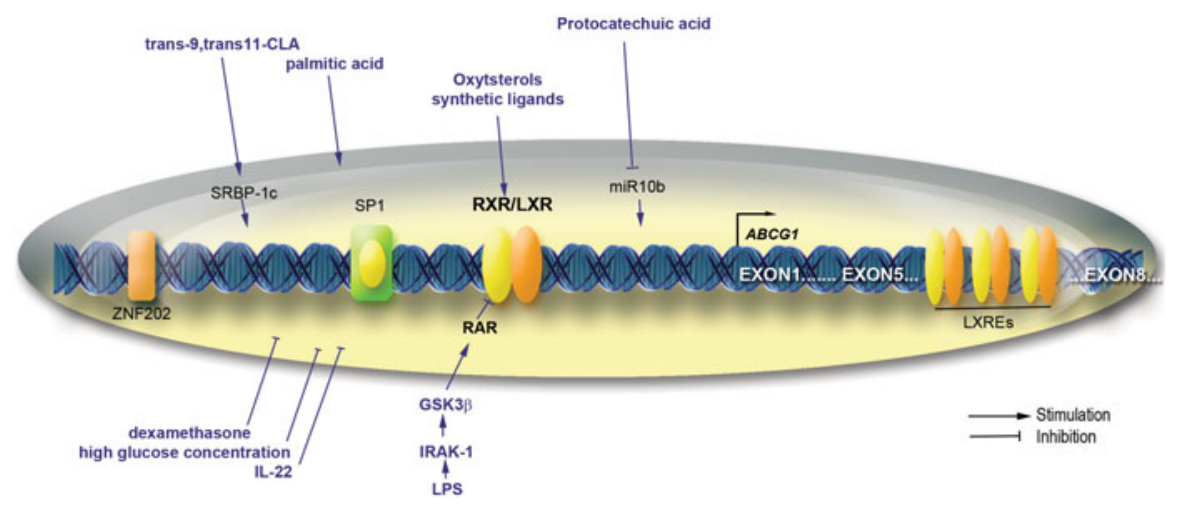

Fig. 3 Regulatory regions, transcription factors, and signaling molecules (cytokines, growth factors, metabolites, drugs) that modulate the expression of the ABCG1 gene. Arrows and block lines denote activation and repression, respectively. The mechanisms are described in detail in the text. Abbreviations: conjugated linoleic acid (CLA); glycogen synthase kinase $3 \beta$ (GSK3 $\beta$ ); sterol regulatory element-binding protein (SREBP); specificity protein 1 (Sp1)

The regulation of ABCG1 expression has similarities with that of ABCA1 (Fig. 3). Thus, LXR plays an important role in ABCG1 promoter activation. Experimental data indicated that various LXR ligands upregulate ABCG1 expression. ATI-111, a novel steroidal LXR agonist, induces ABCG1 mRNA expression in peritoneal macrophages more potently than T0901317 and inhibits its expression in the liver, suggesting tissue selectivity (Peng et al. 2011). Different natural compounds, such as cineole and fucosterol that are LXR activators, are able to increase ABCG1 levels in macrophages (Hoang et al. 2012; Jun et al. 2013). Recent data showed that the knockdown of LXR $\alpha$ impaired cholesterol efflux in human primary macrophages, while LXR $\beta$ silencing had no detectable impact on the expression of LXR target genes such as ABCA1 and ABCG1 and did not affect cholesterol efflux (Ishibashi et al. 2013). The indirect effects of LXR in ABCG1 regulation were recently shown. Adiponectin treatment significantly increased ABCG1 mRNA and protein levels in macrophages from diabetic patients, whereas the pharmacological or genetic inhibition of LXR abrogated this enhancement; these data demonstrated that the mechanism of adiponectin-mediated upregulation of ABCG1 includes LXR $\alpha$ (Wang et al. 2013b). Similar with ABCA1, TGF $\beta$ upregulates the expression of ABCG1, while unsaturated fatty acids suppress ABCG1 expression via the LXR pathway (Uehara et al. 2007; Hu et al. 2010b).

The analysis of potential regulatory elements in the promoter region carried out using the MatInspector program identified multiple Sp1 sites at positions -184, -382 , and -566 , an AP2 binding site at position -222 , a NF- $\mathrm{KB}$ site at position -338 , an E-box motif at position -233, a sterol regulatory element at position -660 , and the NFY binding site at position -198 in ABCG1 proximal promoter (Langmann et al. 2000). A functional genetic variant of the ABCG1 promoter associated with an increased risk of myocardial infarction and ischemic heart disease in the general population was revealed (Schou et al. 2012). This study 
showed that the ABCG1 expression was decreased by approximately $40 \%$ in g.-376C $>$ T heterozygotes versus noncarriers. This gene polymorphism is included in a Sp1 binding site located at position $-382 /-373$ in the ABCG1 promoter. Thus, the presence of the $-376 \mathrm{~T}$ allele reduced the binding and transactivation of the promoter by Sp1, leading to a decreased ABCG1 expression (Schou et al. 2012).

ZNF202 was identified as a transcriptional repressor of ABCG1 gene which binds at position -560 in the ABCG1 promoter (Porsch-Ozcurumez et al. 2001).

Recently, microbiotic and dietary factors were shown to regulate the ABCG1 expression. Protocatechuic acid (PCA), a gut microbiota metabolite of cyanidin-3 formed by $0-\beta$-glucoside, exerts an anti-atherogenic effect partially through the inhibition of miR-10b-mediated downregulation of ABCG1 expression (Wang et al. 2012a). Extra-virgin olive oil intake has been shown to improve the capacity of HDL to mediate cholesterol efflux and increased ABCG1 and ABCA1 expression in human macrophages (Helal et al. 2013). Conjugated linoleic acids (CLAs) are minor components of the diet with many reported biological activities. It was revealed that in MCSF-differentiated monocytes, trans-9,trans-11-CLA, but not cis-9,trans-11-CLA and trans-10,cis-12-CLA, activated ABCG1 via SREBP-1c (Ecker et al. 2007). In addition, it was demonstrated that palmitic acid upregulates the ABCG1 gene, while high glucose concentration decreased ABCG1 gene expression in MCSF-activated human monocytes (Mauerer et al. 2009).

Among the downregulators of ABCG1, low doses of LPS strongly reduce the expression of ABCG1 in bone marrow-derived macrophages through IL-1 receptorassociated kinase 1 (IRAK-1)/glycogen synthase kinase $3 \beta$ (GSK3 $\beta$ )/retinoic acid receptor $\alpha(\operatorname{RAR} \alpha)$ signaling pathway (Maitra and Li 2013). HMG-CoA reductase inhibitors, simvastatin and atorvastatin, decreased ABCG1-mediated cholesterol efflux in human macrophages, despite the fact that the protein expression remained unaltered (Wang et al. 2013c). In THP-1 monocytes, $100 \mathrm{nM}$ dexamethasone, a synthetic glucocorticoid, inhibited the mRNA expression of ABCG1, although the glucocorticoid receptor expression was very low in this cell line (Sporstol et al. 2007). IL-22, a member of the IL-10 cytokine family secreted primarily by Th17 and Th22 subsets of T lymphocytes, was induced by S100/calgranulin and impaired cholesterol efflux in macrophages by downregulation of ABCG1 (Chellan et al. 2013).

\subsection{Transcriptional Regulation of the Apolipoprotein E Gene}

Apolipoprotein E (apoE), a glycoprotein of $35 \mathrm{kDa}$, plays an important role in plasma cholesterol level regulation and in cholesterol efflux, as documented by studies in patients and animal models with apoE deficiency or mutated apoE genes (Nakashima et al. 1994; Linton et al. 1995; von Eckardstein 1996; Van Eck et al. 1997; Grainger et al. 2004; Ali et al. 2005; Davignon 2005; Raffai et al. 2005). ApoE is mainly synthesized by the liver but also by various cells and peripheral tissues (Zannis et al. 2001b). ApoE is a marker for the developmental state of macrophages; the culture of mouse bone marrow cells in vitro showed that 
mature macrophages, but not their monocytic precursors, synthesized apoE (Werb and Chin 1983c). At the site of atherosclerotic lesion, apoE is provided by infiltrated macrophages. Transgenic mice expressing apoE only in macrophages are protected against atherosclerosis, even though the plasma levels of apoE are exceedingly low and the animals are hypercholesterolemic (Bellosta et al. 1995). In contrast, transgenic mice with normal levels of apoE in plasma, but not in macrophages, are more susceptible to atherosclerosis (Fazio et al. 1997). ApoE secreted by macrophages within the atherosclerotic plaque facilitates the cholesterol efflux to exogenous acceptors (such as HDL), thus assisting the reverse cholesterol transport to the liver. The uptake of acetylated LDL or cholesterol ester-rich $\beta$-VLDL into peritoneal macrophages stimulates apoE synthesis and secretion (Basu et al. 1981).

The human apoE gene is located on chromosome 19 at the $5^{\prime}$ end of a cluster containing also apoC-I, apoC-IV, and apoC-II genes (Myklebost and Rogne 1988; Smit et al. 1988; Allan et al. 1995a, b). The regulation of apolipoprotein E gene transcription is a highly complex process and requires the interaction of transcription factors with the proximal promoters but also with the distal regulatory regions (Fig. 4).

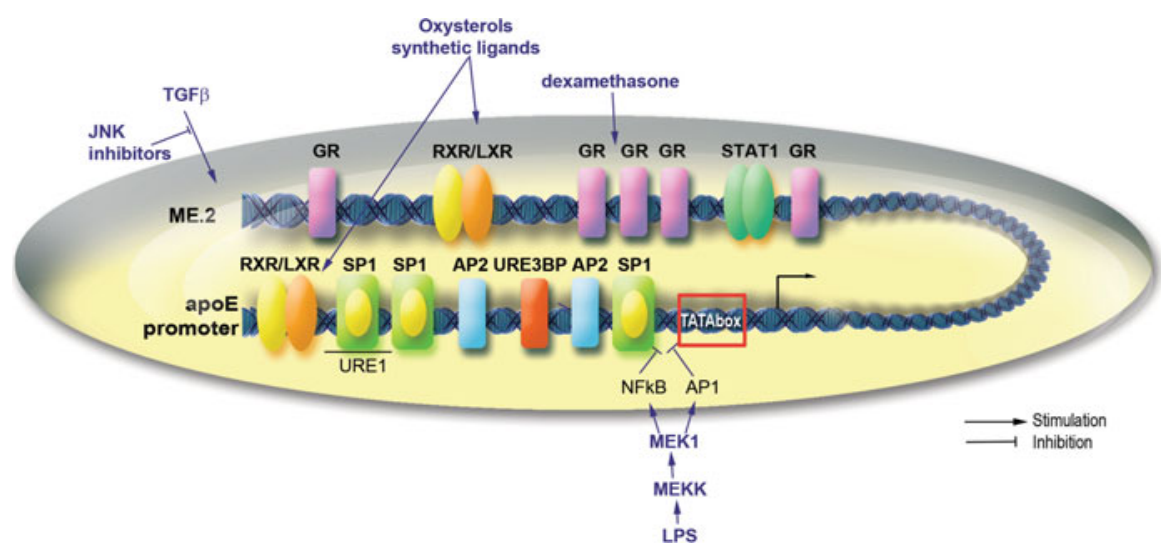

Fig. 4 Regulatory regions, transcription factors, and signaling molecules (cytokines, growth factors, metabolites, drugs) that modulate the expression of the apoE gene. Arrows and block lines denote activation and repression, respectively. The mechanisms are described in detail in the text. Abbreviations: glucocorticoid receptor (GR); signal transducer and activator of transcription (STAT); Jun N-terminal kinase (JNK); retinoid X receptor (RXR); liver X receptor (LXR); specificity protein 1 (Sp1); activator protein 2 (AP2); nuclear factor kappa beta (NF- $\mathrm{KB})$; upstream regulatory region 3 binding protein (URE3BP); lipopolysaccharide (LPS); multienhancer 2 (ME.2); transforming growth factor $\beta$ (TGF $\beta$ ) 


\subsubsection{Proximal Regulatory Binding Sites Involved in the apoE Gene Expression}

The proximal apoE promoter is well conserved in humans and mice, having the same localization of TATA box and GC box (Rajavashisth et al. 1985; Horiuchi et al. 1989). Multiple positive and negative elements that modulate apoE gene expression have been detected on the apoE promoter, using different in vitro systems (Larkin et al. 2000; Zannis et al. 2001b). Smith et al. analyzed the apoE promoter in both expressing (HepG2) and non-expressing (HeLa) cells (Smith et al. 1988). Within the proximal 5'-flanking sequence and the first intron, eight regions were identified which had a positive effect and three regions with a negative effect on apoE expression, in both HepG2 and HeLa cells (Smith et al. 1988). The proximal apoE promoter contains a GC box transcriptional control element at -59 / -45 , a nonspecific enhancer element at $-366 /-246$, an upstream regulatory element (URE1) at $-193 /-124$, and a downstream regulatory element at $+44 /+262$ (Paik et al. 1988). Within URE1, a sequence spanning -161/-141, defined as a positive element for transcription, has the ability to act alone as an enhancer element (Chang et al. 1990). This element interacts with Sp1 transcription factor that constitutively binds the GC box motif, suggesting that Sp1 may play an important role in the basal level of apoE expression, as well as in the activity of this enhancer element. Another regulatory element, termed URE3, was identified at position $-101 /-89$ and found to bind a $300 \mathrm{kDa}$ protein from placental nuclear extracts termed URE3 BP (Jo et al. 1995). DNase I footprinting revealed the existence of two binding sites for recombinant AP2 in the regions from -48/-74 and from $-107 /-135$ of the apoE promoter (Olaisen et al. 1982; Smith et al. 1988; Garcia et al. 1996; Salero et al. 2001, 2003). Gel mobility-shift assays showed the direct binding of $\mathrm{LXR} \alpha / \mathrm{RXR} \alpha$ and $\mathrm{LXR} \beta / \mathrm{RXR} \alpha$ to a low-affinity $\mathrm{LXRE}$ present in the region $-494 /-465$ of the proximal promoter (Laffitte et al. 2001b). Other studies revealed that USF binds to an atypical E-box located in the $-101 /-91$ region of the apoE promoter (Salero et al. 2003). The same group found that Zic1 and Zic2 transcription factors can bind to three binding sites located at $-65 /-54$, $-136 /-125$, and $-185 /-174$ in the apoE promoter and stimulate apoE gene expression (Salero et al. 2001).

Bacterial endotoxin and other inflammatory agents decrease apoE production (Werb and Chin 1983a, b; Gafencu et al. 2007). The apoE downregulation in macrophages impaired the local beneficial effect of apoE during the plaque development. As a result, despite the fact that macrophages are present in the lesion, their ability to regress atherosclerosis is seriously compromised. We have previously reported the mechanisms of apoE downregulation in macrophages exposed to inflammatory conditions, similar to those found at the atherosclerotic site (Gafencu et al. 2007). Tumor progression locus 2 (Tpl2) and mitogen-activated protein kinase/ERK kinase kinase 1 (MEKK1) were identified as the kinases that are primarily responsible for the downregulation of apoE promoter activity by LPS. Tpl2 and MEKK1 signaling pathways converge to NF- $\mathrm{BB}$ and AP1, acting on the apoE core promoter -55/+73 (Gafencu et al. 2007). 


\subsubsection{Distal Regulatory Binding Sites That Modulate apoE Gene Expression in Macrophages}

Despite this complex transcription factor machinery that may be targeted to the apoE promoter, the promoter itself lacks the ability to direct gene transcription in vivo in any cells, in the absence of the distal enhancers (Shih et al. 2000). In many tissues, cell-specific distal enhancers regulate the expression of genes in the apoE/apoC-I/apoC-I'/apoC-IV/apoC-II gene cluster (Shih et al. 2000). The expression of apoE in macrophages is controlled by two homologous enhancers $(95 \%$ identical in sequence), designated as multienhancer 1 (ME.1) and multienhancer 2 (ME.2), containing 620 and 619 nucleotides, respectively (Shih et al. 2000). These enhancers are located at 3.3 and $15.9 \mathrm{~kb}$ downstream of the apoE gene, respectively. We demonstrated by chromosome conformational capture (3C) and transient transfections that both ME. 1 and ME. 2 can interact with the apoE promoter only in phorbol 12-myristate 13-acetate (PMA)-differentiated macrophages, but not in undifferentiated monocytes (Trusca et al. 2011). The results showed that the interactions take place in antisense orientation of the promoter and ME.1/2. Our data obtained using a series of deletion mutants of the promoter or of the ME.2 identified the fragment $-100 /+73$ as the minimal region of the apoE promoter that is activated by the ME.2. We showed that the entire sequence of ME.2 is necessary for an optimal interaction with the apoE promoter, but the $5^{\prime}$ region of ME. 2 is more important than $3^{\prime}$ region for enhancing apoE promoter activity (Trusca et al. 2011). The interaction of the apoE promoter with ME.1/2 facilitates the transcriptional enhancement of the apoE gene by various transcription factors.

$\mathrm{LXR} \alpha$ and LXR $\beta$ and their oxysterol ligands are key regulators of apoE expression in macrophages (Laffitte et al. 2001b; Joseph et al. 2002b; Mak et al. 2002b). The ability of oxysterols and synthetic ligands to regulate apoE expression in peritoneal macrophages as well as in adipose tissue is reduced in $\mathrm{LXR} \alpha^{-1-}$ or LXR $\beta^{-1-}$ mice and abolished in double knockouts. However, basal expression of apoE is not compromised in LXR null mice, suggesting that LXRs mediate lipidinducible expression rather than tissue-specific expression of this gene (Laffitte et al. 2001b). Data revealed that LXR/RXR binds to a low-affinity LXRE present in the apoE promoter as well as a high-affinity site conserved in both human ME.1 and ME.2 (Laffitte et al. 2001b). Experimental data revealed that the ligand activation of the LXR/RXR heterodimer enhanced the activity of the reporter constructs under the control of human ME.1 or ME.2 fused to the apoE proximal promoter (Laffitte et al. 2001b). Oxysterol-binding protein-related protein 1S (ORP1S) translocates from the cytoplasm to the nucleus in response to sterol binding and then binds to LXRs, promoting the binding of LXRs to LXREs. Thus, ORP1S mediates the LXR-dependent transcription via the ME.1 and ME.2 of the apoE gene (Lee et al. 2012). An interesting finding was that the induction of apoE gene expression by LXR agonists is attenuated by inhibitors of JNK and PI3K pathways (Huwait et al. 2011). A similar inhibition was noticed in the case of TGF $\beta$-induced expression of apoE, which was prevented by pharmacological inhibitors of JNK, p38 kinase, and casein kinase 2 (Singh and Ramji 2006). 
The synthetic glucocorticoid receptor (GR) ligand, dexamethasone, increased apoE mRNA levels in mature macrophages up to sixfold over basal levels (Zuckerman et al. 1993). In silico analysis of the ME.1 and ME.2 revealed some transcription factor binding motifs for the GR (Shih et al. 2000). The presence of these GR binding sites in the multienhancers may explain the apoE upregulation by GR ligands, but the biological activity of these GR biding sites remains to be revealed.

TRANSFAC analysis of the apoE promoter, ME.1, and ME.2 showed that STAT1 transcription factor has a binding site only on the ME.2. Our data showed that this binding site is biologically active and STAT1 specifically upregulates apoE gene expression via ME.2, in macrophages, but not in hepatocytes. The STAT1 binding site was located in the 174/182 region of ME.2 (Trusca et al. 2011). Interestingly, a simultaneous increase in the expression of apoE and STAT1 was recorded after monocyte differentiation with PMA treatment (for $4 \mathrm{~h}$ ). Our model proposed that after DNA bending, which probably takes place during monocyte differentiation, STAT1 bound on ME.2 interacts with the transcription initiation complex, leading to the activation of apoE expression. In addition, STAT1 can interact and cooperate with other transcription factors bound on the ME. 2 or on the apoE promoter, for the modulation of apoE gene expression. Recently, we have revealed that STAT1 can interact with RXR and modulate gene expression of the apoC-II gene (Trusca et al. 2012). Since RXR $\alpha$ binds to the ME.2, we can speculate that apoE expression in macrophages may be modulated by the STAT1-RXR $\alpha$ interactions, similarly with apoC-II.

\subsection{Transcriptional Regulation of the Human apoM Gene in the Liver}

Apolipoprotein M (apoM) belongs to the lipocalin protein superfamily and differs from typical water-soluble apolipoproteins by its tertiary structure (Dahlback and Nielsen 2009; Nielsen et al. 2009). ApoM is secreted primarily by the liver and associates with HDL particles through its retained N-terminal signal peptide (Axler et al. 2008; Christoffersen et al. 2008). The silencing of the endogenous apoM gene in mice showed a loss of pre- $\beta$-HDL particles and formation of large HDL particles (Wolfrum et al. 2005). In addition to its role in HDL remodeling, it was shown that apoM is the sole carrier of the bioactive lipid sphingosine 1 phosphate (S1P) in HDL, thus mediating many of the atheroprotective properties of HDL in the endothelium (Christoffersen et al. 2011; Arkensteijn et al. 2013; Christoffersen and Nielsen 2013).

The expression of apoM in the liver is primarily controlled by hepatocyte nuclear factor-1 $\alpha$ (HNF-1 $\alpha)$ (Richter et al. 2003). HNF-1 $\alpha^{-/-}$mice are characterized by the complete absence of apoM from plasma. The plasma concentrations of other apolipoproteins in HNF-1 $\alpha^{-/-}$mice were either similar (apoA-II, apoB, apoC) or increased (apoA-I, apoE) compared to wild-type mice. This was not due to the absence of apoM since restoration of apoM gene expression 
in the liver via adenovirus-mediated gene transfer could not rescue the abnormal apolipoprotein profile (Wolfrum et al. 2005). The analysis of the plasma lipoprotein profile of HNF-1 $\alpha^{-1-}$ mice showed that similar to the apoM gene-silenced mice, plasma cholesterol was primarily associated with the HDL fraction. In addition, an abnormal large apoE-enriched HDL fraction that was identified as HDLc or HDL1 was observed, suggesting that this abnormal lipid profile in HNF- $1 \alpha^{-/-}$mice may be caused by the lack of apoM (Shih et al. 2001). In humans, HNF-1 $\alpha$ regulates apoM gene expression through direct binding to a conserved DNA element located in the proximal apoM promoter region between nucleotides -55 and -41 (Richter et al. 2003).

ApoM gene expression in the liver is negatively regulated during inflammation or infection via pro-inflammatory cytokines such as TNF $\alpha$ or IL-1 $\beta$ (Feingold et al. 2008). The HNF-1 $\alpha$ binding element in the proximal human apoM promoter is a dual-specificity regulatory element that mediates the activation or repression of apoM promoter activity by HNF-1 and by activator protein 1 (AP1) proteins (c-Jun and JunB), respectively, in hepatic cells (Mosialou et al. 2011). Competition experiments showed that the binding of Jun proteins and HNF-1 $\alpha$ to the apoM promoter is mutually exclusive and chromatin immunoprecipitation assays established that AP1 activation leads to the recruitment of c-Jun and JunB proteins to the proximal apoM promoter with the simultaneous displacement of HNF-1 (Mosialou et al. 2011). A similar mechanism of transcriptional repression via dual-specificity AP1-/HNF-1-responsive elements has been demonstrated in the case of the promoter of the human apolipoprotein A-II gene (Mosialou et al. 2011). AP1 factors were shown to inhibit the promoters of the apolipoprotein C-III (Hadzopoulou-Cladaras et al. 1998) and ABCA1 (Mosialou and Kardassis unpublished) genes in hepatic cells suggesting a broader role of AP1 factors in lipoprotein metabolism in the liver during inflammation.

Besides HNF-1 $\alpha$, apoM gene transcription in the liver has been shown to be controlled positively by liver receptor homologue-1 (LRH-1) and forkhead box A2 (FOXA2) transcription factors which bind to distinct sites on the proximal apoM promoter (Venteclef et al. 2008; Wolfrum et al. 2008). Bile acids suppress apoM expression in vivo by inhibiting LRH-1 transcriptional activity via the recruitment of small heterodimer partner (SHP) to the apoM promoter (Venteclef et al. 2008).

Insulin, insulin-like growth factor I (IGF-I), and IGF-I potential peptide (IGF-IPP) were all shown to inhibit apoM gene expression in a dose- and timedependent manner in primary human and murine hepatocytes via a signal transduction pathway that involves the serial activation of phosphatidylinositol 3-kinase (PI3K) and protein kinase $\mathrm{B}$ (PKB) and the inactivation of Foxa2 (Xu et al. 2006). In HepG2 cells, glucose and insulin inhibited apoM gene expression in an additive manner, while in hyperglycemic rats, serum apoM concentrations and hepatic apoM mRNA levels were significantly reduced (Zhang et al. 2007).

The human apoM gene is under the control of various orphan- and liganddependent nuclear receptors (Mosialou et al. 2010). The overexpression via adenovirus and silencing via siRNA established that HNF-4 is an important regulator of apoM gene transcription in hepatic cells (Mosialou et al. 2010). In addition to 
HNF-4, homodimers of retinoid X receptor and heterodimers of retinoid X receptor with receptors for retinoic acid, thyroid hormone, fibrates (peroxisome proliferatoractivated receptor), and oxysterols (liver $\mathrm{X}$ receptor) were shown to bind with different affinities to the proximal HRE in vitro and in vivo (Mosialou et al. 2010). These findings provide novel insights into the role of apoM in the regulation of HDL by steroid hormones and into the development of novel HDL-based therapies for diseases such as diabetes, obesity, metabolic syndrome, and coronary artery disease that affect a large proportion of the population in Western countries.

\subsection{Transcriptional Regulation of the CETP Gene}

The gene encoding the cholesterol ester transfer protein (CETP) plays an important role in human HDL metabolism because it facilitates the transfer of cholesteryl esters from mature spherical HDL particles to VLDL/IDL lipoproteins in exchange of triglycerides and its activity determines the plasma levels of HDL cholesterol (von Eckardstein et al. 2005; Tall et al. 2008).

The CETP gene is expressed mainly in the liver, adipose tissue, and spleen and at lower levels in the small intestine, adrenal, kidneys, and heart (Jiang et al. 1991; Radeau et al. 1995). Atherogenic diets were shown to increase CETP mRNA levels in rabbits and in human CETP transgenic mice (Quinet et al. 1990; Jiang et al. 1992). Both LXRs and SREBPs were shown to bind to regulatory elements on the promoter of the CETP gene and regulate its transcription in response to intracellular cholesterol levels (Gauthier et al. 1999; Luo and Tall 2000). It was shown recently that synthetic LXR agonists enhanced plasma CETP activity and decreased HDL-C levels in cynomolgus monkeys and human CETP transgenic mice (Honzumi et al. 2010). The induction of CETP gene expression by the LXR agonist was significantly reduced by knocking down the expression of $\operatorname{LXR} \alpha$ but not LXR $\beta$ both ex vivo and in mice (Honzumi et al. 2010). In another study, it was shown that the LXR agonist T0901317 markedly increased CETP mRNA levels and CETP production in human differentiated macrophages but not in human peripheral blood monocytes (Lakomy et al. 2009). In inflammatory mouse and human macrophages, LXR-mediated CETP gene upregulation was inhibited and this inhibition was independent of lipid loading. It was concluded that LXR-mediated induction of human CETP expression is switched on during monocyte-to-macrophage differentiation and is abrogated in inflammatory macrophages (Lakomy et al. 2009).

Other factors that regulate CETP promoter activity include Yin Yang 1 (YY1) that binds to the same element as SREBPs (Gauthier et al. 1999), the LRH-1 that potentiates the sterol-mediated induction of the CETP gene by LXRs (Luo et al. 2001), the orphan nuclear receptor ARP-1 (Gaudet and Ginsburg 1995) that inhibits CETP promoter activity, the retinoic acid receptor (RAR) which regulates CETP gene expression in response to all-trans-retinoic acid (Jeoung et al. 1999), and the CCAAT/enhancer-binding protein $(\mathrm{C} / \mathrm{EBP})$ which is an activator of CETP 
gene expression (Agellon et al. 1992). Binding sites for the ubiquitous transcription factors SP1 and SP3 have been identified on the CETP promoter at positions -690 , -623 , and -37 and seem to be essential for the basal CETP promoter activity (Le Goff et al. 2003).

CETP gene expression was shown recently to be under regulation by bile acids and their nuclear receptor farnesoid X receptor (FXR) (Gautier et al. 2013). It was shown that plasma CETP activity and mass was higher in patients with cholestasis than controls and this was associated with lower HDL-C levels (Gautier et al. 2013). In agreement with this observation, bile acid feeding of APOE3*Leiden mice expressing the human CETP transgene controlled by its endogenous promoter decreased HDL-C and increased plasma CETP activity and mass. An FXR response element (FXRE) was identified in the first intron of the human CETP gene which could be responsible for the upregulation of CETP gene expression in response to bile acids (Gautier et al. 2013). In another study, it was shown that FXR $\alpha$ binds to DR4 LXRE that is present in the proximal CETP promoter and represses LXR-mediated transactivation of the CETP promoter by a competition mechanism (Park et al. 2008).

\subsection{Transcriptional Regulation of the PLTP Gene}

Phospholipid transfer protein (PLTP) belongs to the lipopolysaccharide (LPS) binding/lipid transfer gene family that includes the LPS-binding protein (LBP), the neutrophil bactericidal/permeability-increasing protein (BPI), and the cholesteryl ester transfer protein (CETP). PLTP is essential in the transfer of very low-density lipoprotein phospholipids into HDL (Jiang et al. 2012).

PLTP is expressed ubiquitously, but the highest expression levels in human tissues were observed in the ovary, thymus, placenta, and lung (Day et al. 1994). Taking into account the organ size involved, the liver and small intestine appear to be important sites for the overall PLTP expression. A high-fat, high-cholesterol diet causes a significant increase in PLTP activity and in mRNA levels. Plasma PLTP activity and PLTP mRNA levels in the liver and adipose tissues were significantly decreased following LPS administration (Jiang and Bruce 1995).

An FXR-responsive element (FXRE) has been found in the proximal PLTP promoter that binds $\mathrm{FXR} \alpha / \mathrm{RXR} \alpha$ heterodimers and mediates the response of the PLTP promoter to bile acids (Urizar et al. 2000). Fibrates were shown to increase PLTP gene expression by activating PPARs which bind to three PPAR-responsive elements on the PLTP promoter (Tu and Albers 1999; Bouly et al. 2001). Two of these PPAR-responsive elements also seem to be responsible for the induction of PLTP expression by high glucose (Tu and Albers 2001).

The human PLTP promoter contains at least two LXR-responsive elements, one in the proximal and one in the distal region, that were shown to mediate PLTP gene regulation by oxysterols ex vivo and in vivo (Cao et al. 2002; Mak et al. 2002a; Laffitte et al. 2003). It was recently demonstrated that LXR agonists activate triglyceride synthesis and PLTP gene transcription by activating SREBP-1c 
(Okazaki et al. 2010). In concert with the increase in triglyceride synthesis, the increased PLTP caused triglyceride incorporation into abnormally large VLDL particles which were removed from plasma by LDL receptors, whereas in the absence of LDL receptors, the large VLDLs accumulated and caused massive hypertriglyceridemia (Okazaki et al. 2010).

Recently, microarray analysis following alteration of p53 status in several human- and mouse-derived cells identified a group of 341 genes whose expression was induced by p53 in the liver-derived cell line HepG2 (Goldstein et al. 2012). Twenty of these genes encode proteins involved in many aspects of lipid homeostasis including PLTP (Goldstein et al. 2012).

\subsection{Transcriptional Regulation of the Bile Acid Transporters ABCG5/ABCG8}

ATP-binding cassette half-transporters G5 and G8 (ABCG5 and ABCG8) play important roles in the control of sterol excretion from the liver (Fitzgerald et al. 2010; Tarling and Edwards 2012; Li et al. 2013; Yu et al. 2014). Mutations in either of these transporters leads to $\beta$-sitosterolemia, an autosomal recessive disease characterized by premature coronary atherosclerosis and elevated levels of phytosterols in plasma (Fitzgerald et al. 2010; Tarling and Edwards 2012; Li et al. 2013; Yu et al. 2014). Mice lacking ABCG5 and ABCG8 proteins have decreased ability to secrete sterols into the bile (Yu et al. 2002a). The overexpression of ABCG5 and ABCG8 in the liver increases biliary cholesterol secretion and decreases dietary cholesterol absorption (Yu et al. 2002b). The human ABCG5 and ABCG8 genes are oriented in a head-to-head configuration, they are transcribed in opposite directions, and their transcription is coordinated by a short $374 \mathrm{bp}$ bidirectional promoter in the intergenic region (Remaley et al. 2002).

The bidirectional promoter of ABCG5/ABCG8 genes contains a binding site for LRH-1 at positions 134-142 which is required for the activity of both the ABCG5 and ABCG8 promoters (Freeman et al. 2004). Mutating this LRH-1 binding site reduced promoter activity of the human ABCG5/ABCG8 intergenic region in HepG2 and Caco2 cells. Bile acids such as deoxycholic acid repressed ABCG5 and ABCG8 promoters via the FXR-SHP-LXR pathway that was described above (Sumi et al. 2007).

Dietary cholesterol feeding was shown to increase duodenal, jejunal, and hepatic expression levels of ABCG5 and ABCG8 mRNA in wild-type mice (Berge et al. 2000). The increase in ABCG5 or ABCG8 gene expression by diet was compromised in mice lacking either $\operatorname{LXR} \alpha$ or both $\operatorname{LXR} \alpha$ and $\operatorname{LXR} \beta$ (Repa et al. 2002). Both the RXR-specific agonist LG268 and the LXR-specific agonist T0901317 caused upregulation of ABCG5 and ABCG8 mRNA expression in the liver and intestine of wild-type mice but not in $\mathrm{LXR} \alpha / \beta^{-1-}$ mice (Repa et al. 2002). To identify functional LXREs that control the expression of the ABCG5/ABCG8 genes in response to oxysterols, a recent study searched for evolutionarily conserved regions (ECRs) between the human and the mouse genes and identified 
23 ECRs which were studied by luciferase assays for LXR responsiveness (Back et al. 2013). Two ECRs were found to be responsive to the LXR and binding of LXR $\alpha$ to these regions was verified (Back et al. 2013).

The bidirectional promoter of the ABCG5/G8 genes was shown to bind HNF-4 and GATA transcription factors and to be regulated by these factors in a cooperative manner and independent of the orientation of the bidirectional promoter (Sumi et al. 2007).

It was shown that the expression of both ABCG5 and ABCG8 genes is upregulated in the livers of mice with genetic ablation of the insulin receptor gene (LIRKO mice) both at the mRNA and the protein levels (Biddinger et al. 2008). In agreement with these findings, insulin suppressed the expression of ABCG5 and ABCG8 genes at subnanomolar concentrations and in a doseresponsive manner in rat hepatoma cells (Biddinger et al. 2008). The observation that the short intergenic region responded to insulin in both the ABCG5 and ABCG8 orientations suggested the presence of an element in the intragenic region of the ABCG5 and ABCG8 genes that responds to insulin. Using ex vivo and in vivo approaches, it was shown that insulin resistance leads to the activation of the forkhead box 1 (FOXO1) transcription factor which binds to the bidirectional promoter and activates the transcription of both genes severalfold (Biddinger et al. 2008).

\subsection{Transcriptional Regulation of the HDL Receptor SR-BI}

The gene encoding the HDL receptor scavenger receptor class B type I (SR-BI) is expressed at high levels in the liver and steroidogenic tissues. Several transcription factors have been shown to bind to the human or rodent SR-BI promoter and to regulate SR-BI gene transcription in a positive or negative manner.

The steroidogenic factor-1 (SF-1) has been shown to regulate both the human and rat SR-BI promoters and to serve as mediator of the cAMP-dependent regulation of the SR-BI gene in response to steroidogenic hormones (Lopez et al. 1999).

Liver X receptors $\alpha$ and $\beta$ and PPAR $\alpha$ and $\gamma$ were shown to bind to distal LXRE and PPARE, respectively, on the human and rat SR-BI promoters and regulate the expression of the human SR-BI gene in response to oxysterols and fibrates (Lopez and McLean 1999; Malerod et al. 2002, 2003), whereas HNF-4 enhances the PPAR $\gamma$-mediated SR-BI gene transcription (Malerod et al. 2003; Zhang et al. 2011). As discussed above, conditional inactivation of the HNF-4 gene in the liver of adult mice was associated with a significant increase in hepatic SR-BI mRNA levels and a decrease in plasma HDL-C levels, suggesting that HNF-4 influences negatively the expression of the HDL receptor (Hayhurst et al. 2001).

LRH-1 binds to a proximal response element on the human SR-BI promoter in an overlapping manner with SF-1 and activates the SR-BI promoter (Schoonjans et al. 2002). Retrovirus-mediated overexpression of LRH-1 in hepatic cells induced SR-BI gene expression, and this was associated with histone $\mathrm{H} 3$ acetylation on the SR-BI promoter. In agreement with these findings, the SR-BI mRNA levels were 
decreased in the livers of LRH-1(+/-) animals providing evidence that LRH-1 regulates SR-BI gene expression in vivo (Schoonjans et al. 2002).

Estrogens regulate the activity of the rat SR-BI promoter via estrogen receptors $\alpha$ and $\beta$ (ER $\alpha$ and $\beta$ ) which bind to three different estrogen response elements (ERE) on the SR-BI promoter (Lopez et al. 2002; Lopez and McLean 2006). In endothelial cells, 17beta-estradiol (E2) increased the mRNA levels of the human SR-BI gene and the activity of the hSR-BI promoter, and this upregulation was protein kinase $\mathrm{C}$ (PKC) dependent since it was blocked by the PKC inhibitor bisindolylmaleimide I and a dominant-negative mutant of PKC (Fukata et al. 2013).

The mRNA levels of the mouse SR-BI gene were decreased in mice lacking the FXR nuclear receptor (FXR ${ }^{-/-}$mice) (Lambert et al. 2003). When WT mice were placed on a diet containing $0.4 \%$ of the FXR agonist cholic acid, the hepatic SR-BI mRNA and protein levels increased in the wild-type but not in the $\mathrm{FXR}^{-1-}$ mice, indicating that bile acids positively regulate SR-BI gene expression via FXRs (Lambert et al. 2003). In agreement with these findings, treatment of human hepatoma HepG2 cells with FXR ligands resulted in the upregulation of SR-BI both at the mRNA and protein levels via FXR binding to a novel FXRE, a direct repeat 8 at position $-703 /-684$ of the promoter (Chao et al. 2010). A natural ligand of FXR administered to mice increased hepatic SR-BI expression (Chao et al. 2010). However, in another study, it was reported that bile acids inhibit SR-BI gene expression in the liver of mice and reduce the SR-BI promoter activity (Malerod et al. 2005). It was proposed that this inhibition was due to the FXR-mediated activation of SHP, which repressed the activity of LRH-1 that binds to the proximal SR-BI promoter (Malerod et al. 2005).

The zinc finger transcription factor Kruppel-like factor 4 (KLF4) was shown to bind to a putative KLF4 element on the SR-BI promoter at position -342/-329 and upregulate its activity in peripheral blood mononuclear cells and PMA-differentiated THP-1 cells treated with HDL (Yang et al. 2010).

Using high-throughput screening of 6,000 microbial secondary metabolite crude extracts for the identification of compounds that upregulate the SR-BI promoter in HepG2 cells, several putative SR-BI upregulators were identified: hoxyl-3',5,7hydroxyl isoflavone; (9R,13S)-7-deoxy-13-dihydrodaunomycinone; pratensein; the isoflavones formononetin, genistein, and daidzein; and the histone deacetylase inhibitor trichostatin A (Yang et al. 2007, 2009; Bao et al. 2009). Some of these compounds were shown to increase the uptake of DiI-labeled HDL and the efflux of cholesterol to HDL by cells.

In steroidogenic tissues, SR-BI supplies the cells with exogenous cholesterol for storage or for the synthesis of steroid hormones. In these tissues, SR-BI expression was shown to be upregulated by adrenocorticotropic hormone (ACTH) (Sun et al. 1999). The suppression of ACTH by the synthetic corticosteroid dexamethasone (which inhibits the hypothalamic-pituitary axis and decreases ACTH secretion) decreased SR-BI levels. However, the mechanism by which ACTH and glucocorticoid regulate the expression of the SR-BI gene in steroidogenic tissues is unclear. It was shown that the transcription of the human SR-BI gene is subject to feedback inhibition by glucocorticoids in adrenal and ovarian cells. SR-BI mRNA 
levels were increased in adrenals from corticosterone-insufficient $\mathrm{Crh}^{-1-}$ mice, whereas corticosterone replacement by oral administration inhibited SR-BI gene expression in these mice (Mavridou et al. 2010). The glucocorticoid-mediated inhibition of SR-BI gene transcription required de novo protein synthesis and the glucocorticoid receptor (GR). No direct binding of GR to the SR-BI promoter could be demonstrated in vitro and in vivo, suggesting an indirect mechanism of repression of SR-BI gene transcription by GR in adrenal cells (Mavridou et al. 2010).

In the rat ovary, the uptake of cholesterol by the theca-interstitial cells is mediated by SR-BI. It was shown that insulin and the trophic hormone $\mathrm{LH} / \mathrm{cGH}$ stimulate the expression of SR-BI in theca-interstitial cells and increase intracellular cholesterol, which is subsequently mobilized for androgen biosynthesis (Li et al. 2001; Towns et al. 2005).

In the adrenocortical cell line Y-1, adenovirus-mediated overexpression of prolactin regulatory element-binding (PREB) protein, a transcription factor that regulates prolactin expression in the anterior pituitary and is induced by cAMP, increased the levels of SR-BI protein and the activity of the SR-BI promoter by binding to a PREB-responsive cis-element of the SR-BI promoter. Using small interfering RNA against PREB in Y-1 cells, the effects of cAMP on SR-BI expression were attenuated. It was concluded that in the adrenal gland under conditions of cAMP increase, PREB regulates the transcription of the SR-BI gene (Murao et al. 2008).

Intracellular sterol levels regulate SR-BI gene expression via SREBP-1a which binds to two sterol-responsive elements (SREs) present on the rat SR-BI promoter (Cao et al. 1997; Lopez and McLean 1999). The ubiquitous transcription factors SP1 and SP3 bind to several GC-rich boxes present on the proximal SR-BI promoter and have been shown to be important for the basal activity as well as the SREBP-1a-mediated transactivation of the SR-BI promoter (Shea-Eaton et al. 2001).

The expression of the SR-BI gene is also subject to negative regulation by transcription factors including the orphan nuclear receptor dorsal-sensitive sex adrenal hypoplasia congenital critical region on the $\mathrm{X}$ chromosome gene 1 (DAX-1), which was shown to repress the rat SR-BI promoter by interfering with the SF-1- and SREBP-1a-mediated transactivation of the this promoter (Lopez et al. 2001). In addition, YY1 transcription factor binds directly to two sites on the SR-BI promoter and downregulates its activity by interfering with the binding of SREBP-1a to the SR-BI promoter (Shea-Eaton et al. 2001).

\section{Posttranscriptional Regulation of HDL Genes by Noncoding RNAs and microRNAs}

According to the Encyclopedia of DNA Elements (ENCODE project), $76 \%$ of the human genome is transcribed (Bernstein et al. 2012; Djebali et al. 2012). While novel promoter and enhancer regions have been described (Bernstein et al. 2012; Sanyal et al. 2012), some of the newly described genes encode for noncoding RNAs 
including microRNAs (miRNAs), small interfering RNAs (siRNAs), piwiinteracting RNAs (piRNAs), circular RNAs (circRNAs), long noncoding RNAs (lncRNAs), trans-acting siRNAs (tasiRNAs), and several other noncoding RNAs. Their abundance and their recognized roles in transcriptional and epigenetic gene regulation and their involvement in several diseases suggest the existence of an extensive regulatory network on the basis of RNA signaling (Mattick and Makunin 2005). An important class of these endogenous noncoding RNAs is miRNAs. miRNAs are small noncoding RNAs ( 22 nt) that have emerged as important posttranscriptional regulators of different protein-coding genes (Bartel 2009) including those related to HDL metabolism (Davalos and Fernandez-Hernando 2013).

\section{1 miRNAs: Biogenesis and Function}

Although originally described as regulators of developmental timing in Caenorhabditis elegans (Lee et al. 1993; Wightman et al. 1993), miRNAs did not receive special attention until their widespread identification in different species (Lagos-Quintana et al. 2002; Reinhart et al. 2002) and their role in human diseases was uncovered (Calin et al. 2002). miRNAs are important posttranscriptional regulators of gene expression through sequence-specific complementary binding to the $3^{\prime}$ untranslated region (UTR) of the target mRNA (Bartel 2009), even though certain miRNAs can interact with other target mRNA regions including the $5^{\prime}$ UTR, coding region, or intron-exon junction and even increase rather than decrease target mRNA expression (Vasudevan et al. 2007; Orom et al. 2008; Tay et al. 2008; Schnall-Levin et al. 2010). The interaction of a miRNA with its target mRNA results in the inhibition of translation and/or degradation of mRNAs (Guo et al. 2010; Krol et al. 2010).

miRNA biogenesis and function have been intensively studied in recent years (Bartel 2009; Krol et al. 2010). Briefly, in most mammals, these small RNAs are transcribed by RNA polymerase II into a primary long miRNA (pri-miRNA). The pri-miRNA is then processed in the nucleus into an $\sim 70$ nucleotide precursor hairpin (pre-miRNA) by a multiprotein complex containing different cofactors and two core components, a ribonuclease III (Drosha) and a double-stranded RNA-binding domain protein (DGCR8/Pasha). Some intronic miRNAs that bypass Drosha-mediated processing are produced by splicing and debranching (miRtrons). Pre-miRNAs are transported to the cytoplasm by Exportin 5 in a Ran-GTP-dependent manner (Lund et al. 2004) where they are further cleaved by an RNAse III enzyme called Dicer, generating the mature 22 nt long miRNA/miRNA* duplex. Dicer-independent miRNA biogenesis has also been described (Cifuentes et al. 2010). The duplex miRNA is separated and one of the strands associates with an argonaute protein (Ago) within the RNA-induced silencing complex (RISC), guiding the complex to the complementary sites within the $3^{\prime}$ UTR of the target mRNA to induce mRNA repression and/or degradation. Although the miRNA/miRNA* duplex is initially produced in equal amounts, the miRNA* 
strand (passenger strand) is usually degraded. However, it also contains target recognition sites and is thus functional (Yang et al. 2011). Argonaute proteins are major players in miRNA-mediated gene regulation (Meister 2013). Although several aspects of miRNA biogenesis and function are well characterized, the different factors that regulate their decay or turnover are not well known (Krol et al. 2010).

Sequencing studies have identified $\sim 2,000$ miRNAs encoded in our human genome, and prediction algorithms suggest that $60 \%$ of human protein-coding genes have conserved targets for pairing with miRNAs within their $3^{\prime}$ UTR (Friedman et al. 2009). Factors that influence miRNA target selection include the "seed" sequence which consists of nucleotides 2-8 at the $5^{\prime}$ end of the mature miRNA (Bartel 2009) and tissue distribution or developmental stage, as certain miRNAs are highly expressed or even restricted to certain cell types and can only target their mRNA target if they are co-expressed in the same tissue at the same time (Lagos-Quintana et al. 2002; Small and Olson 2011). In contrast to most plant miRNAs, which bind with near perfect complementarity to their targets, most mammalian miRNAs bind with mismatches and bulges and the mode of binding determines the type of posttranscriptional repression (Carthew and Sontheimer 2009). Recent experimental data suggest that around $60 \%$ of seed interactions are noncanonical, containing bulged or mismatched nucleotides which are accompanied by specific, non-seed base pairing (Helwak et al. 2013). Some miRNA-mRNA interactions also involve the $3^{\prime}$ end of the miRNA (Helwak et al. 2013). Moreover, pseudogenes (Poliseno et al. 2010), long noncoding RNAs (lncRNAs) (Cesana et al. 2011), and circular RNAs (Hansen et al. 2013) that contain miRNA binding sites also influence miRNA activity, acting as competing endogenous RNAs (ceRNAs) and thus sequestering miRNAs and preventing them from binding to their mRNA targets (Salmena et al. 2011).

While the primary role of miRNAs seems to be the "fine-tuning" of gene expression, their capacity to simultaneously bind and repress multiple target genes and similarly the possibility of a single mRNA to be targeted by multiple miRNAs provide a mechanism to synchronize the coordinated regulation of a large number of transcripts that govern an entire biological process, thus resulting in strong phenotypic output (Mendell and Olson 2012). The high redundancy among related and non-related miRNAs in regulating gene expression reduces the importance of a particular miRNA under conditions of normal cellular homeostasis. However, compelling evidence suggests that under conditions of stress the function of miRNAs become especially pronounced (Mendell and Olson 2012) and their pharmacological modulation represents a novel approach to treat disease by modulating entire biological pathways as described in Davalos and Chroni (2014).

Compelling evidences have shown that miRNAs are present in the systemic circulation and other human biological fluids associate with extracellular microvesicles, exosomes (Valadi et al. 2007; Hunter et al. 2008), Ago2 complex (Arroyo et al. 2011), or HDL (Vickers et al. 2011). Even exogenous miRNAs have been described in our circulating plasma (Wang et al. 2012b; Zhang et al. 2012). Although several circulating miRNAs have been implicated as disease biomarkers 
in several diseases (Allegra et al. 2012; Kinet et al. 2013) or secreted for intercellular communication (Chen et al. 2012b), the biological significance, the factors that modulate their extracellular secretion, and the mechanisms by which they reach the target tissue still remain elusive. HDL has been shown to transport and deliver endogenous miRNAs to recipient cells with functional targeting capabilities (Vickers et al. 2011). Although the HDL miRNA signature from normal subjects was found to be different from hypercholesterolemic subjects (Vickers et al. 2011), the extent by which HDL-bound miRNAs contribute to total circulating miRNAs and thus regulate target cell gene function is not clear (Wagner et al. 2013).

In summary, miRNAs play a major role in almost every aspect of cellular function by posttranscriptional regulation of gene expression. Whether other noncoding RNAs (that modulate miRNA activity) or circulating or extracellular miRNAs might modulate HDL metabolism is not known. However, it seems obvious that by modulating miRNA activity, they might also have a role in HDL metabolism.

\subsection{Posttranscriptional Modulation of HDL Metabolism by miRNAs}

For normal function, mammalian cells must maintain cellular cholesterol levels within tight limits. Thus, complex mechanisms have been evolutionarily developed to control both cellular input from endogenous cholesterol biosynthesis or the uptake from circulating lipoproteins and cellular output by controlling cholesterol efflux. miRNAs have emerged as important regulators of HDL and cholesterol metabolism, and their functions are summarized in Fig. 5 and described in detail below. Although miRNAs have increased the complexity of HDL metabolism regulation, our understanding of every single step in their regulation will provide better opportunities to develop novel targets for their therapeutic modulation.

\subsubsection{Targeting ABCA1 and ABCG1}

$\mathrm{ABCA} 1$ is one of the most important proteins directly involved in the elimination of excess cholesterol from cells (cholesterol efflux). As described in this chapter, $\mathrm{ABCA} 1$ is regulated at the transcriptional, posttranscriptional, and posttranslational level. Its regulation is in accordance with the cellular need to handle cholesterol levels within tight limits, as excess of free cholesterol is deleterious to cells. ABCA1 mRNA contains a particularly long $3^{\prime}$ UTR $(>3.3 \mathrm{~kb})$ as compared to other common genes involved in cholesterol and HDL metabolism including LCAT (20 bp), apoA-I (55 bp), ApoA-II (112 bp), CETP (178 bp), apoB (301 bp), PDZK1 (583 bp), ABCG1 (852 bp), SR-BI (959 bp), PCSK9 (1,269 bp), IDOL (1,496 bp), CAV-1 (1,898 bp), LIPG (2,386 bp), and LDLR (2,513 bp) (Davalos and Fernandez-Hernando 2013). This unusually long $3^{\prime}$ UTR of ABCA1 clearly raises the probability of posttranscriptional regulation by miRNAs (and probably other noncoding RNAs). Different prediction algorithms indicate that ABCA1 can potentially be targeted by $\sim 100$ miRs. Some of them have been experimentally validated 


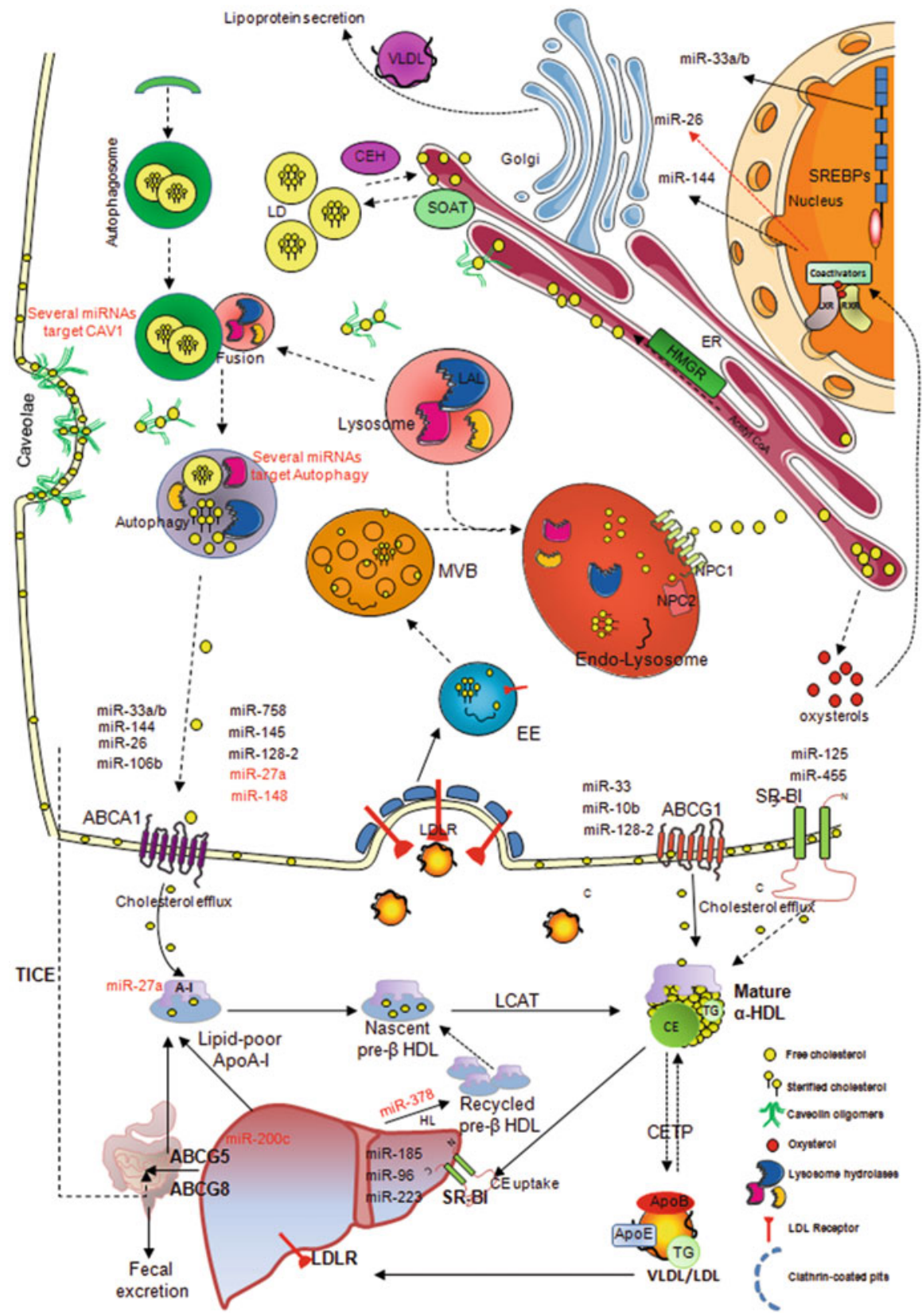

Fig. 5 Overview of posttranscriptional regulation by miRNAs of proteins involved in cholesterol efflux, RCT, and HDL metabolism. HDL metabolism and the role of individual proteins such as plasma enzymes, membrane transporters, and receptors are described in the text and more extensively in other chapters. Autophagy, the cell catabolism process through the lysosomal machinery, has been proposed to participate in cholesterol efflux. The induction of SREBPs induces the expression of miR-33 family. The induction of LXR induces the expression of miR-144 and represses miR-26. The induction of FXR also induces miR-144. miRNAs in black 
for their importance in cholesterol efflux, reverse cholesterol transport, and cardiovascular disease, whereas other miRNAs still remain to be elucidated. Validated miRNAs that directly target ABCA1 are miR-33 family, miR-758, miR-106b, miR-26, miR-144, miR-10b, miR-128-2, and miR-145 (Fig. 5).

miR-33a and miR-33b play a crucial role in controlling cholesterol efflux and HDL function in concert with their host genes, the SREBP transcription factors (Najafi-Shoushtari et al. 2010; Horton et al. 2002; Horie et al. 2010; Marquart et al. 2010; Rayner et al. 2010). While both mature miRNAs only differ in two nucleotides, they are predicted to have largely overlapping sets of target genes in rodents (Rayner et al. 2011b; Horie et al. 2012) and nonhuman primates (Rayner et al. 2011a; Rottiers et al. 2013). The inhibition of the two miR-33 isoforms, either genetically or therapeutically, resulted in increased cholesterol efflux, increased HDL levels, increased reverse cholesterol transport, reduced atherosclerosis, and reduced VLDL triglyceride levels. Although miR-33a and miR-33b target different genes involved in lipid homeostasis, fatty acid $\beta$-oxidation, insulin signaling, and biliary transporters (Gerin et al. 2010; Davalos et al. 2011; Rayner et al. 2011a; Allen et al. 2012; Horie et al. 2013), their effects are mediated mainly by ABCA1. The human $3^{\prime}$ UTR of ABCA1 has three functional binding sites for miR-33. While most of the studies have been performed in tissues/cells directly related to lipoprotein metabolism and CVD (i.e., hepatocytes, macrophages), it is possible that from these $\sim 100$ miRs that potentially target ABCA1 3' UTR, some of them might be relevant to other cells and tissues as well.

Regarding other tissues, miR-106b (Kim et al. 2012) and miR-758 (Ramirez et al. 2011) were found to regulate neuronal cholesterol excess. While miR-758 expression is particularly high in the brain and its expression is mediated by high cholesterol levels, the expression of miR-106 in brain tissues is low. However, their role in neuronal cholesterol efflux suggests that these miRNAs may contribute to the regulation of cholesterol levels in the brain. miR-758 and miR-106 directly target the $3^{\prime}$ UTR of ABCA1 by binding to two sites and one site, respectively. Moreover, miR-758 has other targets involved in neurological functions (Ramirez et al. 2011). miR-106b also targets the amyloid precursor protein (APP) and increases the amyloid $\beta$ (A $\beta$ ) peptide secretion and clearance (Kim et al. 2012).

HDL metabolism is regulated by the LXRs which control the transcription of several genes related to lipid metabolism in response to hydroxylated products of cholesterol as described above (Calkin and Tontonoz 2012). Recent data suggest that LXRs also regulate HDL metabolism posttranscriptionally (Sun et al. 2012; de Aguiar Vallim et al. 2013; Ramirez et al. 2013; Vickers and Rader 2013). The induction of LXR resulted in the repression of miR-26 and induction of miR-26-a-1,

Fig. 5 (continued) labels are validated miRNAs for HDL metabolism. miRNAs in red labels are suggested miRNAs, but not fully validated, in HDL metabolism. All biological processes may not necessarily happen in the same cell type. Abbreviations: endoplasmic reticulum (ER); early endosome (EE); cholesterol ester hydrolase (CEH); multivesicular bodies (MVB); lysosomal acid lipase (LAL) (Figure courtesy of Dr. Alberto Canfrán-Duque) 
and miR-144 that directly target the $3^{\prime}$ UTR of ABCA1 and thus regulate cholesterol efflux, RCT, and HDL levels. While having one binding site for miR-26-a-1 (Sun et al. 2012), the human $3^{\prime}$ UTR of ABCA1 has several (up to seven) predicted binding sites for miR-144 (Ramirez et al. 2013). miR-26-a-1 also targets the ADP-ribosylation factor-like 7 (Arl7), which participates in cellular cholesterol efflux (Engel et al. 2004). miR-144 expression is also induced by the nuclear receptor FXR (Vickers and Rader 2013). By controlling bile acid levels, FXR activation will not only repress the expression of ABCA1 posttranscriptionally but will also induce the expression of SR-BI, thereby resulting in an increased uptake of plasma HDL cholesterol and increased cholesterol biliary excretion via ABCG5/ABCG8 (de Aguiar Vallim et al. 2013).

Evolutionarily, the dual effect of LXR activation on miR-144 induction and mR-26-a-1 repression seems obvious, as cells must maintain cellular cholesterol levels within tight limits and these miRNAs might work as buffers against deleterious variation in gene expression programs.

Other miRNAs including miR-10b, miR-128-2, and miR-145 also regulate cellular cholesterol efflux by directly targeting the $3^{\prime}$ UTR of ABCA1. Protocatechuic acid, an intestinal microbiota metabolite of cyanidin-3-O-glucoside, was found to repress miR-10b and thus regulate cholesterol efflux (Wang et al. 2012a). While in hepatocytes the inhibition of miR145 increases cholesterol efflux, in pancreatic islet beta cells it improves glucose-stimulated insulin secretion (Kang et al. 2013). The proapoptotic miRNA miR-128-2 was also found to regulate cholesterol efflux by targeting (one binding site) the $3^{\prime}$ UTR of ABCA1 (Adlakha et al. 2013). Recent data suggest that this miRNA family governs neuronal excitability and motor behavior in mice (Tan et al. 2013) and that miR-1282 might control neuronal cholesterol levels. RXR $\alpha$ is also a direct target of miR-128-2 (Adlakha et al. 2013). miR-27a and miR-148 were found to repress an ABCA1 3' UTR luciferase reporter construct; however, their physiological role in regulating cholesterol efflux has not been described (Kang et al. 2013).

ABCG1, the other member of the ATP-binding cassette transporter family, which also participates in cellular cholesterol efflux to HDL, was found to be directly regulated by some of these miRNAs. miR-33, miR-10b, and miR-1282 regulate cholesterol efflux by posttranscriptionally regulating ABCG1 through binding to its 3' UTR (Rayner et al. 2010; Wang et al. 2012a; Adlakha et al. 2013).

\subsubsection{Targeting SR-BI}

Liver regulation of SR-BI is primarily achieved posttranslationally through a PDZ domain-containing adaptor protein (PDZK1) (Kocher et al. 2003; Kocher and Krieger 2009) as described in detail in a later section of this chapter. Increasing evidence suggests that other posttranscriptional mechanisms, such as targeting by miRNAs, also regulate SR-BI protein levels. Prediction miRNA analysis (www. targetscan.org) suggests that $\sim 25$ miRNA families might target SR-BI, most of which are poorly conserved among mammals and vertebrates. miR-125a and miR-455 were found to repress the lipoprotein-supported steroidogenesis by directly targeting the $3^{\prime}$ UTR of SR-BI (Hu et al. 2012). In hepatic cells, where 
SR-BI is expressed at higher levels, the expression of miR-125a was also high and its overexpression resulted in a reduced SR-BI-mediated selective cholesterol ester uptake. In contrast, miR-455 did not show any effect on hepatic SR-BI expression (Hu et al. 2012). miR-185, miR-96, and miR-223 were also found to directly target the $3^{\prime}$ UTR of SR-BI and to repress HDL cholesterol uptake in hepatic cells (Wang et al. 2013a).

\subsubsection{Targeting Other miRNAs Related to HDL Biogenesis and Function}

miR-27a was suggested to regulate apoA-I plasma levels, but the direct interaction to its $3^{\prime}$ UTR was not evaluated (Shirasaki et al. 2013). Several other miRNAs were proposed to regulate genes involved in cholesterol efflux, RCT, or HDL metabolism, including ABCG5 (Liu et al. 2012) or endothelial lipase (Kulyte et al. 2013), but either their direct interaction with the $3^{\prime}$ UTR of these genes or their physiological effects on HDL metabolism were not directly assessed.

Autophagy is the catabolic process by which unnecessary or dysfunctional cellular components are degraded in the lysosome. During starvation, this breakdown of cellular components contributes to the maintenance of cellular energy levels. The hydrolysis of cytoplasmic cholesteryl ester of lipid droplets is normally mediated by the action of neutral cholesteryl ester hydrolases. It has been recently recognized that lipid droplets can also be delivered to lysosomes via autophagy, where lysosomal acid lipase can hydrolyze lipid droplet cholesteryl esters to generate free cholesterol for cholesterol efflux (Ouimet et al. 2011).

Several miRNAs have been described that regulate different targets in autophagy (Frankel and Lund 2012). miRNAs that target key pathways in lipidloaded macrophage autophagy genes and/or cholesterol ester hydrolases might be promising targets to promote cholesterol efflux (Davalos and Fernandez-Hernando 2013). Caveolin, the major protein coat of caveolae, has been proposed to contribute to cellular cholesterol efflux (Truong et al. 2010; Kuo et al. 2011). There is accumulating evidence that several miRNAs including miR-103, miR-107, miR-133a, miR-192, miR-802, and others target caveolin (Nohata et al. 2011; Trajkovski et al. 2011) but their contribution to cholesterol efflux, RCT, and HDL metabolism and their real physiological contribution to HDL function remain to be elucidated.

\section{Posttranslational Mechanisms of HDL Regulation}

\subsection{ABCA1}

In addition to the transcriptional and posttranscriptional mechanisms described above, the expression of ABCA1 is also regulated at the posttranslational level. Following its synthesis, ABCA1 is inserted into the ER where it undergoes proper folding, N-glycosylation, dimerization, and disulfide bond formation and transport to the plasma membrane via the ER-Golgi system (Fig. 6) (Kang et al. 2010). 


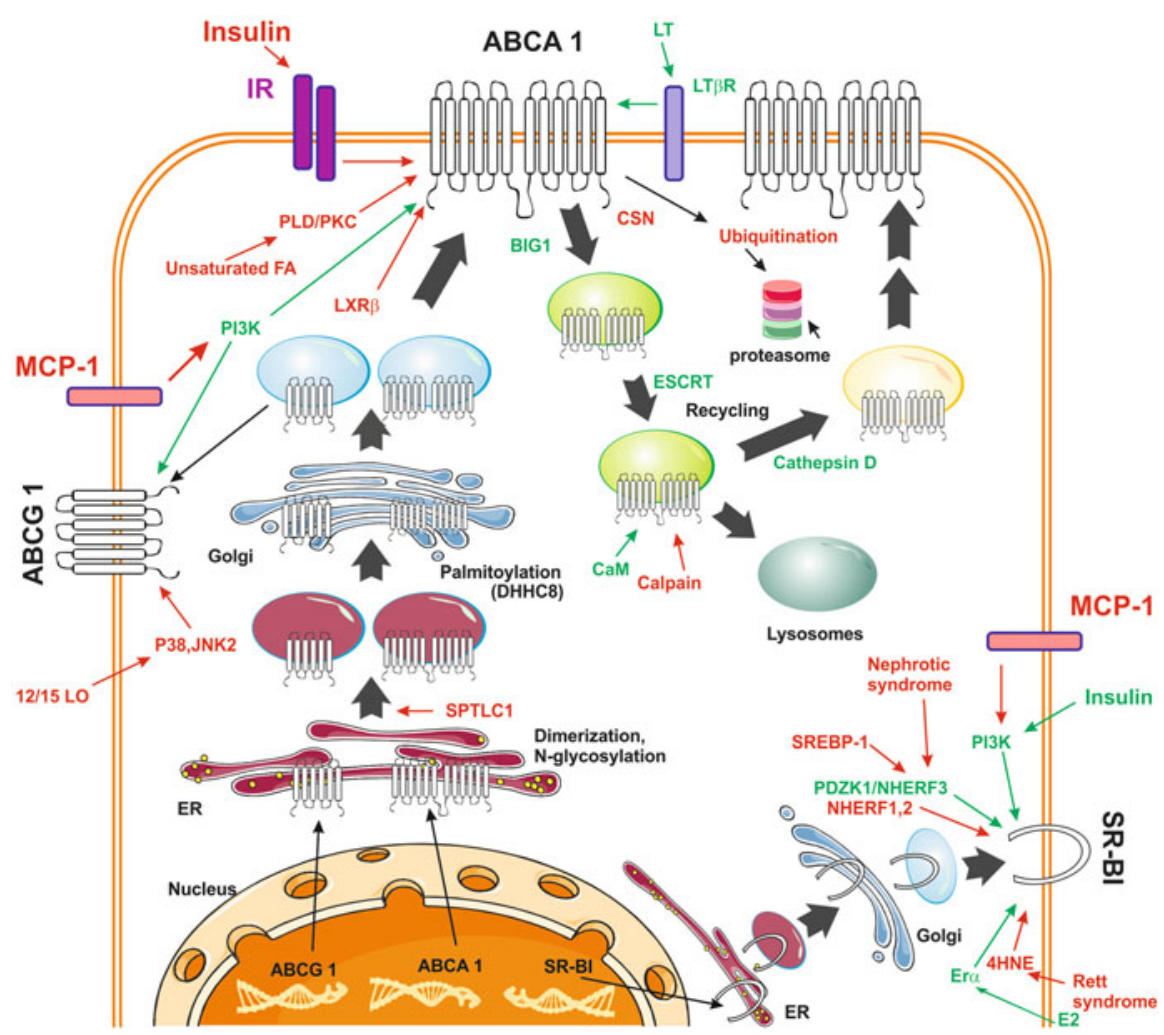

Fig. 6 Overview of the mechanisms that regulate the expression of ABCA1, ABCG1, and SR-BI genes at the posttranslational level. The mechanisms are described in the text. Abbreviations: endoplasmic reticulum (ER); Asp-His-His-Cys 8 (DHHC8); serine palmitoyltransferase 1 (SPTLC1); guanine nucleotide-exchange protein 1 (BIG1); endosomal sorting complex required for transport (ESCRT); Pro-GLu-Ser-Thr (PEST); calmodulin (Cam); lymphotoxin (LT); LT- $\beta$ receptor (LT $\beta R$ ); phospholipase D (PLD); protein kinase $\mathrm{C} \delta$ (PKCס); insulin receptor (IR); phosphatidylinositol 3-kinase (PI3K); 12/15-lipoxygenase (12/15LO); PDZ-containing kidney protein 1 (PDZK1); $\mathrm{Na}^{+} / \mathrm{H}^{+}$exchanger regulator factor-3 (NHERF3); 4-hydroxy-2-nonenal (4HNE); monocyte chemoattractant protein-1 (MCP-1)

Transport from the ER to the Golgi is prevented when ABCA1 interacts with the enzyme serine palmitoyltransferase 1 (SPTLC1) which participates in the biosynthetic pathway of sphingomyelin, a major phospholipid component of membranes. The ABCA1/SCPTL1 interaction may regulate the levels of intracellular pools of sphingolipids when the cellular demands for these lipids are high. Pharmacological inhibition of SPTLC1 with myriocin, an atypical amino acid and antibiotic derived from thermophilic fungi (Miyake et al. 1995), increases both the ABCA1 levels at the plasma membrane and the ABCA1-mediated cholesterol efflux (Tamehiro et al. 2008). Mutations in ABCA1 that prevent normal glycosylation cause failure 
of ABCA1 to exit the ER (Singaraja et al. 2006). In the Golgi compartment, ABCA1 undergoes palmitoylation at cysteine residues 3, 23, 1110, and 1111 by the palmitoyltransferase Asp-His-His-Cys 8 (DHHC8) (Singaraja et al. 2009). Inhibiting this enzyme by drugs or preventing ABCA1 palmitoylation by sitespecific mutagenesis reduced ABCA1 levels at the plasma membrane and decreased efflux to apoA-I (Singaraja et al. 2009). The gene encoding cathepsin D, a lysosomal protease, was identified by comparative transcriptomic analysis to be associated with low HDL-C levels in humans (Haidar et al. 2006). Blocking the activity or expression of cathepsin D reduced ABCA1 expression and protein abundance as well as apoA-I-mediated lipid efflux by more than $70 \%$ and caused retention of ABCA1 in lysosomal compartments (Haidar et al. 2006). Very recently, BIG1 (brefeldin A-inhibited guanine nucleotide-exchange protein 1) was found to modulate ABCA1 trafficking and functions in the liver cells (Lin et al. 2013). BIG1 depletion reduced surface ABCA1 on HepG2 cells and inhibited by $60 \%$ cholesterol efflux, whereas BIG1 overexpression had the opposite effects. RNA interference with BIG1 dramatically decreased the internalization and recycling of ABCA1. This novel function of BIG1 was dependent on the guanine nucleotide-exchange activity and achieved through the activation of ADP-ribosylation factor 1 (Lin et al. 2013).

The transport of ABCA1 to the plasma membrane is also facilitated by certain members of the family of small GTPase including Rab8, Rab4A, and Rab4B (Linder et al. 2009) (Jean and Kiger 2012).

Calpain, a cysteine protease, cleaves ABCA1 at the PEST (proline, glutamic acid, serine, threonine) sequence (amino acids 1283-1306) that is located in the cytosolic loop of the molecule, and this cleavage takes place at the early endosomes (Fig. 6) (Yokoyama et al. 2012; Miyazaki et al. 2013). The deletion of the PEST sequence increases ABCA1 levels on the plasma membrane and apoA-I binding (Chen et al. 2005). The interaction with apoA-I stabilizes ABCA1 against this degradation (Arakawa and Yokoyama 2002; Wang et al. 2003; Arakawa et al. 2004). Importantly, the inhibition of calpain was shown to increase HDL biogenesis in cultured cells, indicating that the inhibition of proteolytic degradation of ABCA1 could be a promising strategy for increasing HDL ( $\mathrm{Lu}$ et al. 2008). The phosphorylation of the PEST sequence of ABCA1 at Thr-1286 and Thr-1305 regulates calpain-mediated proteolysis of ABCA1 since the ABCA1-T1286A/ T1305A mutant could not be degraded by calpain (Martinez et al. 2003). The interaction of ABCA1 with apoA-I results in the dephosphorylation of the ABCA1 PEST sequence and inhibition of calpain degradation, leading to an increase of ABCA1 cell-surface expression (Martinez et al. 2003). Calmodulin was also shown to interact with ABCA1 in the presence of $\mathrm{Ca}^{2+}$ and to protect from calpain-mediated degradation (Iwamoto et al. 2010).

In addition to the calpain-mediated proteolytic degradation of ABCA1 described above, ABCA1 is subject to ubiquitin-mediated proteolysis. The presence of ubiquitinated ABCA1 in the plasma membrane of several cell lines was recently demonstrated (Mizuno et al. 2011). In HuH-7 cells, the degradation of cell-surfaceresident $\mathrm{ABCA} 1$ was inhibited by the overexpression of a dominant-negative form 
of ubiquitin. Moreover, the disruption of the endosomal sorting complex required for transport (ESCRT) pathway by the knockdown of hepatocyte growth factorregulated tyrosine kinase substrate (HRS) delayed the degradation of ABCA1 (Mizuno et al. 2011). These findings suggested that ubiquitination mediates the lysosomal degradation of plasma membrane $\mathrm{ABCA} 1$ and thereby regulates the expression and cholesterol efflux functions of ABCA1 independently of the calpain-mediated pathway.

Unsaturated fatty acids such as oleate and linoleate were shown to destabilize $\mathrm{ABCA} 1$ protein and to inhibit $\mathrm{ABCA1-mediated} \mathrm{cholesterol} \mathrm{efflux} \mathrm{in} \mathrm{macrophages}$ by a mechanism that depends on the activity of the enzyme acyl-CoA synthetase 1 which is responsible for their activation to their CoA derivatives (Kanter et al. 2012). At the same time, unsaturated fatty acids increase the Ser phosphorylation of ABCA1 via a phospholipase $\mathrm{D}$ (PLD)/protein kinase $\mathrm{C} \delta$ pathway which contributes to ABCA1 destabilization (Fig. 6) (Wang and Oram 2007).

Two additional proteins that were identified by two-hybrid screen to physically interact with $\mathrm{ABCA} 1$ and to regulate $\mathrm{ABCA} 1$ intracellular localization and turnover by interacting with its PDZ (PSD-95, Dlg, ZO-1) domain are the a1 and b1 syntrophins (Munehira et al. 2004). Given the short half-life of ABCA1 $\left(t_{1 / 2}=1-2 \mathrm{~h}\right)$ (Wang et al. 2003), interfering with the accessory proteins or the enzymes that posttranslationally modify ABCA1 may prove a valuable strategy to regulate ABCA1-mediated HDL biogenesis in the liver and the intestine or to enhance cholesterol efflux in peripheral cells.

Insulin enhances ABCA1 protein degradation in HepG2 cells via PI3K. In addition, it inhibits ABCA1 activity by phosphorylation at Tyr1206 (Nonomura et al. 2011). The kinase that is responsible for this Tyr phosphorylation of ABCA1 is not known, but it was hypothesized that it is the insulin receptor itself.

TNF $\alpha$ and lymphotoxin $\alpha$ (LT) are key inflammatory mediators which also contribute to the atherogenic process (Schreyer et al. 1996, 2002; Pamir et al. 2012). TNF induces ABCA1 mRNA and protein levels as well as cholesterol efflux from cultured macrophages to apoA-I (Gerbod-Giannone et al. 2006). The induction of ABCA1 by TNF $\alpha$ depended primarily on NF- $\mathrm{\kappa B}$ (Gerbod-Giannone et al. 2006). It was also shown that the expression of the two TNF receptors is required to mediate full ABCA1 induction by TNF $\alpha$. In addition, LT increased ABCA1 protein levels by inhibiting protein degradation through the LT- $\beta$ receptor (LTßR) (Edgel et al. 2010).

ABCA1-mediated cholesterol efflux and ABCA1 protein levels were shown to be decreased by interferon $\gamma$ (IFN $\gamma$ ) in murine macrophages and macrophagederived foam cells (Panousis and Zuckerman 2000). This ABCA1 downregulation was an early event in IFN $\gamma$-mediated activation of macrophages (Alfaro Leon et al. 2005) and was dependent on signal transducer and activator of transcription 1 (STAT1) since similar effects were not observed in macrophages from STAT1 KO mice (Wang et al. 2002).

Additional protein kinases were shown to affect the activity and stability of ABCA1 at the posttranslational level including protein kinase A (PKA), protein kinase C (PKC), Janus kinase 2 (JAK2), and casein kinase (CK2) (Tang et al. 2004). 
ABCA1 activity was shown to be regulated by the nuclear receptor $\operatorname{LXR} \beta$ by a mechanism that is distinct from the transcriptional induction of the ABCA1 gene caused by cholesterol accumulation. It was shown that at low cholesterol levels, LXR $\beta$ binds to ABCA1 and the ABCA1-LXR $\beta$ complex is stably localized at the plasma membrane but is unable to facilitate apoA-I-mediated cholesterol efflux. Exogenously added LXR ligands, which mimic cholesterol accumulation, cause LXR $\beta$ to dissociate from ABCA1, thus freeing ABCA1 for apoA-I binding and subsequent cholesterol efflux (Hozoji et al. 2008; Hozoji-Inada et al. 2011).

\subsection{ABCG1}

Similar to ABCA1, the levels of ABCG1 transporter were shown to be subject to regulation at the posttranslational level (Fig. 6) (Tarling and Edwards 2012). Recent studies showed that the presence of additional 12 amino acids between the Walker B motif and the first transmembrane domain of ABCG1 can affect ABCG1 protein stability (Engel et al. 2006). It was shown that stable overexpression of 12/15lipoxygenase $(12 / 15 \mathrm{LO})$ in macrophages was associated with a $30 \%$ reduction in HDL-mediated cholesterol efflux and reduced ABCG1 protein expression (Nagelin et al. 2008). Treatment of macrophages with the 12/15LO eicosanoid product 12SHETE increased serine phosphorylation of ABCG1 and affected the stability of the protein (Nagelin et al. 2008). Proteasomal inhibitors blocked the downregulation of ABCG1 and resulted in the accumulation of phosphorylated ABCG1 (Nagelin et al. 2009). Macrophages that lack 12/15LO had enhanced ABCG1 expression, reduced ABCG1 phosphorylation, and increased cholesterol efflux. Conversely, macrophages that overexpress 12/15LO have reduced ABCG1 expression, increased transporter phosphorylation, and reduced cholesterol efflux (Nagelin et al. 2009). It was also shown that 12/15LO regulates ABCG1 expression and function through p38- and JNK2-dependent mechanisms (Nagelin et al. 2009).

The activation of adenosine monophosphate-activated protein kinase (AMPK) in human aortic endothelial cells resulted in increased levels of ABCG1 protein via a posttranscriptional mechanism that involved increased stability of ABCG1 mRNA (Li et al. 2010a, b). The aminoimidazole carboxamide ribonucleotide (AICAR)dependent induction of ABCG1 was associated with increased efflux of cellular cholesterol and 7-ketocholesterol to HDL and protected nitric oxide synthase activity and vascular reactivity (Li et al. 2010a, b).

The protein levels of ABCG1 were shown to be controlled by palmitoylation in both human embryonic kidney 293 cells and in mouse macrophage, J774 (Gu et al. 2013). Five cysteine residues located at positions 26, 150, 311, 390, and 402 in the NH2-terminal cytoplasmic region of ABCG1 were shown to be palmitoylated. The removal of palmitoylation at Cys311 by mutating the residue to Ala (C311A) or Ser significantly decreased ABCG1-mediated cholesterol efflux. On the other hand, the removal of palmitoylation at sites 26, 150, 390, and $402 \mathrm{had}$ no significant effect (Gu et al. 2013). 


\subsection{SR-BI}

The stability of the HDL receptor SR-BI in the hepatocyte plasma membrane is very important for its functions and is subject to posttranscriptional regulation (Fig. 6). SR-BI stability is primarily controlled by its adapter protein, PDZ-containing kidney protein 1 (PDZK1 or NHERF3 for $\mathrm{Na}^{+} / \mathrm{H}^{+}$exchanger regulator factor-3), since PZK1-knockout mice exhibit a $>95 \%$ reduction in hepatic SR-BI protein (but not mRNA) and are characterized by hypercholesterolemia and the presence of large cholesterol-rich HDL particles in the plasma (Kocher et al. 2003). In adrenal cells where the PDZK1 levels are very low, additional members of the NHERF family such as NHERF1 and NHERF2 (but not NHERF4) were shown to specifically interact with SR-BI and reduce its protein levels (Hu et al. 2013). The data showed that the downregulation of SR-BI by these NHERF1/2 factors significantly inhibits both HDL-CE uptake and steroid hormone production by adrenal cells. It was concluded that the PDZK1 homologues act as physiological translational/posttranslational regulators of the functional expression of SR-BI (Hu et al. 2013).

Feeding mice with an atherogenic diet was accompanied by a threefold posttranslational downregulation of hepatic SR-BI at the protein level (Niemeier et al. 2009). A similar SR-BI downregulation was observed in transgenic mice overexpressing SREBP-1a and SREBP-1c on chow diet, and it was associated with a decrease in the expression levels of PDZK1 (Niemeier et al. 2009).

The levels of SR-BI protein were shown to be affected in two syndromes: the nephrotic syndrome and the Rett syndrome. It was shown that animals with nephrotic syndrome which is characterized by dyslipidemia, impaired high-density lipoprotein (HDL)-mediated reverse cholesterol transport, and atherosclerosis (Vaziri et al. 2003) exhibited severe hypercholesterolemia, hypertriglyceridemia, reduced HDL/total cholesterol ratio, significant upregulation of the endocytic HDL receptor ATP synthase mRNA and protein, and significant reduction of SR-BI protein despite its normal mRNA abundance. The reduction in SR-BI protein levels in animals with NS was accompanied by parallel reductions in PDZK1 mRNA and protein levels (Vaziri et al. 2011). Rett syndrome, a genetic form of infantile autism, is the second most common cause of mental retardation in women (Amir et al. 1999). When compared to healthy subjects, patients with Rett syndrome present with significant increases in total cholesterol $(12 \%)$, LDL cholesterol (15\%), and HDL-C (18\%) (Sticozzi et al. 2013). Skin fibroblasts isolated from patients with Rett syndrome exhibited low levels of SR-BI as a consequence of its association with 4-hydroxy-2-nonenal (4HNE), a product of lipid peroxidation that is increased in patients with Rett syndrome, and increased ubiquitination (Sticozzi et al. 2013). The role of the proteasome in SR-BI stability was confirmed using the proteasomal inhibitor (MG132). When Rett syndrome fibroblasts were pretreated with MG132, the loss of SR-BI was reversed demonstrating that SR-BI is degraded via the proteasome machinery (Sticozzi et al. 2013).

In hepatic cells and fibroblasts, SR-BI protein levels and SR-BI-mediated cholesterol transport (export and uptake) were shown to be affected by the Ras/MEK/ ERK signaling cascade. This effect was mediated via PPAR $\alpha$-inducible 
degradation pathways (Wood et al. 2011). Metabolic labeling experiments in primary hepatocytes from mice demonstrated that fenofibrate enhances the degradation of SR-BI in a post-endoplasmic reticulum compartment (Lan and Silver 2005). Moreover, fenofibrate-induced degradation of SR-BI was independent of the proteasome, the calpain protease, or the lysosome (Lan and Silver 2005).

In primary macrophages and cell lines derived from female but not from male mice, tamoxifen and 4-hydroxytamoxifen increased SR-BI protein expression via the estrogen receptor $\alpha$ (Dong et al. 2011). Because SR-BI mRNA expression and promoter activity were not influenced by tamoxifen and 4-hydroxytamoxifen, it was demonstrated that the regulation of SR-BI by these substances takes place at the level of protein stability (Dong et al. 2011).

The phosphatidylinositol 3-kinase (PI3K) pathway was shown to affect positively the SR-BI-mediated HDL selective cholesterol ester uptake into human HepG 2 cells as this process was compromised in the presence of the PI3K inhibitors wortmannin and LY294002 (Shetty et al. 2006). These inhibitors also blocked the positive effect of insulin on the SR-BI-dependent selective uptake. HDL cellsurface binding, receptor biotinylation studies, and confocal fluorescence microscopy of HepG2 cells expressing green fluorescent protein-tagged SR-BI demonstrated changes in SR-BI subcellular localization and cell-surface expression as a result of PI3K activation (Shetty et al. 2006). These data indicate that PI3K activation stimulates hepatic SR-BI function posttranslationally by regulating the subcellular localization of SR-BI. It was recently shown that monocyte chemoattractant protein-1 (MCP-1), a protein expressed by endothelial cells under inflammatory conditions, decreases the cell-surface protein expression of ABCA1, ABCG1, and SR-BI in a dose-dependent and time-dependent manner (Huang et al. 2013). It was shown that PI3K activation corrected the MCP-1-induced decreases in the cell-surface protein expression of the three transporters. MCP-1 decreased the lipid uptake by HepG2 cells and the ABCA1-mediated cholesterol efflux to apoA-I, and this was reversed by the activation of PI3K. These data suggested that MCP-1 impairs RCT activity in HepG2 cells by a PI3K-/AKTmediated posttranslational regulation of ABCA1, ABCG1, and SR-BI cell-surface expression (Huang et al. 2013).

Finally, it was shown that hormones such as triiodothyronine (T3) and thyromimetics and some pharmacological agents such as probucol increase SR-BI levels posttranscriptionally (Leiva et al. 2011).

\section{Conclusions}

As discussed earlier in this chapter as well as in other chapters of this handbook, plasma HDL cholesterol levels are determined by the relative rates of HDL biogenesis and HDL catabolism which in turn are mediated by several lipidcarrying proteins, plasma enzymes, and membrane transporters. The deregulation of the activity or the expression of these proteins by mutations or during diseases is associated with non-physiological levels of HDL cholesterol, HDL dysfunction, and predisposition to coronary heart disease. Epidemiological studies as well as experiments in genetically modified animals have provided unequivocal proof that raising HDL cholesterol levels may be therapeutic. Drugs 
that could specifically increase the rates of HDL biogenesis by inducing the levels of apoA-I, ABCA1, or LCAT are anticipated to be of great clinical benefit. Other HDL proteins such as ABCG1, ABCG5/G8, CETP, and LPL could also provide useful targets for HDL-based therapies that will interfere with HDL maturation or catabolism without compromising HDL functionality. The development of novel HDL-raising drugs that will capitalize on HDL biogenesis will certainly require a thorough understanding of the mechanisms and the molecules that are involved in HDL regulation at the transcriptional, posttranscriptional, or posttranslational level in hepatic cells as well as in other physiologically relevant cells such as the macrophages. For instance, understanding ABCA1 gene regulation in the macrophage has led to the elucidation of the important role of LXRs and their ligands in the reverse cholesterol transport and the development of novel LXR ligands which however have severe lipogenic effects in the liver and are thus of no clinical value today so the challenge here is to develop more specific drugs that will avoid lipogenesis. Novel single- or dual-specificity agonists of peroxisome proliferator-activated receptor isoforms are also anticipated. Understanding how the levels of HDL proteins and their functionality are affected by inflammatory factors will enable us to develop novel drugs to restore HDL levels and functionality and thus reduce the atherosclerotic burden in patients with chronic inflammatory diseases.

In summary, the current challenges in the HDL field are to develop novel therapies that would raise HDL cholesterol levels without compromising HDL functionality and to identify novel HDL-based biomarkers. The advances in the field of HDL regulation may provide crucial insights and tools to achieve this goal.

Acknowledgments This work was supported by the European Cooperation in Science and Technology (COST) Action BM0904; by grants from the Greek Secretariat for Research and Technology (SYNERGASIA-09 and THALIS MIS377286) to Dimitris Kardassis; by grants from the Spanish Instituto de Salud Carlos III (FIS, PI11/00315) to Alberto Dávalos; by a grant of the Romanian National Authority for Scientific Research, CNCS - UEFISCDI, project number PN-IIID-PCE-2011-3-0591, and the Romanian Academy to Anca Gafencu; and by an NIH grant HL-48739 to Vassilis I. Zannis. We thank Dr. Ovidiu Croitoru for the graphic design.

Open Access This chapter is distributed under the terms of the Creative Commons Attribution Noncommercial License, which permits any noncommercial use, distribution, and reproduction in any medium, provided the original author(s) and source are credited.

\section{References}

Adcock IM, Caramori G (2001) Cross-talk between pro-inflammatory transcription factors and glucocorticoids. Immunol Cell Biol 79:376-384

Adlakha YK, Khanna S, Singh R, Singh VP, Agrawal A, Saini N (2013) Pro-apoptotic miRNA128-2 modulates ABCA1, ABCG1 and RXRalpha expression and cholesterol homeostasis. Cell Death Dis 4:e780 
Agellon LB, Zhang P, Jiang XC, Mendelsohn L, Tall AR (1992) The CCAAT/enhancer-binding protein trans-activates the human cholesteryl ester transfer protein gene promoter. J Biol Chem 267:22336-22339

Aiello RJ, Brees D, Bourassa PA, Royer L, Lindsey S, Coskran T et al (2002) Increased atherosclerosis in hyperlipidemic mice with inactivation of ABCA1 in macrophages. Arterioscler Thromb Vasc Biol 22:630-637

Albers M, Blume B, Schlueter T, Wright MB, Kober I, Kremoser C et al (2006) A novel principle for partial agonism of liver $\mathrm{X}$ receptor ligands. Competitive recruitment of activators and repressors. J Biol Chem 281:4920-4930

Alfaro Leon ML, Evans GF, Farmen MW, Zuckerman SH (2005) Post-transcriptional regulation of macrophage ABCA1, an early response gene to IFN-gamma. Biochem Biophys Res Commun 333:596-602

Ali K, Middleton M, Pure E, Rader DJ (2005) Apolipoprotein E suppresses the type I inflammatory response in vivo. Circ Res 97:922-927

Allan CM, Walker D, Segrest JP, Taylor JM (1995a) Identification and characterization of a new human gene (APOC4) in the apolipoprotein E, C-I, and C-II gene locus. Genomics 28:291-300

Allan CM, Walker D, Taylor JM (1995b) Evolutionary duplication of a hepatic control region in the human apolipoprotein $\mathrm{E}$ gene locus. Identification of a second region that confers high level and liver-specific expression of the human apolipoprotein E gene in transgenic mice. J Biol Chem 270:26278-26281

Allegra A, Alonci A, Campo S, Penna G, Petrungaro A, Gerace D et al (2012) Circulating microRNAs: new biomarkers in diagnosis, prognosis and treatment of cancer (review). Int $\mathrm{J}$ Oncol 41:1897-1912

Allen RM, Marquart TJ, Albert CJ, Suchy FJ, Wang DQ, Ananthanarayanan M et al (2012) miR-33 controls the expression of biliary transporters, and mediates statin- and diet-induced hepatotoxicity. EMBO Mol Med 4:882-895

Amir RE, Van den Veyver IB, Wan M, Tran CQ, Francke U, Zoghbi HY (1999) Rett syndrome is caused by mutations in X-linked MECP2, encoding methyl-CpG-binding protein 2. Nat Genet 23:185-188

Arakawa R, Yokoyama S (2002) Helical apolipoproteins stabilize ATP-binding cassette transporter A1 by protecting it from thiol protease-mediated degradation. J Biol Chem 277: 22426-22429

Arakawa R, Hayashi M, Remaley AT, Brewer BH, Yamauchi Y, Yokoyama S (2004) Phosphorylation and stabilization of ATP binding cassette transporter A1 by synthetic amphiphilic helical peptides. J Biol Chem 279:6217-6220

Argmann CA, Van Den Diepstraten CH, Sawyez CG, Edwards JY, Hegele RA, Wolfe BM et al (2001) Transforming growth factor-betal inhibits macrophage cholesteryl ester accumulation induced by native and oxidized VLDL remnants. Arterioscler Thromb Vasc Biol 21: 2011-2018

Arkensteijn BW, Berbee JF, Rensen PC, Nielsen LB, Christoffersen C (2013) The apolipoprotein m-sphingosine-1-phosphate axis: biological relevance in lipoprotein metabolism, lipid disorders and atherosclerosis. Int J Mol Sci 14:4419-4431

Arroyo JD, Chevillet JR, Kroh EM, Ruf IK, Pritchard CC, Gibson DF et al (2011) Argonaute2 complexes carry a population of circulating microRNAs independent of vesicles in human plasma. Proc Natl Acad Sci USA 108:5003-5008

Axler O, Ahnstrom J, Dahlback B (2008) Apolipoprotein M associates to lipoproteins through its retained signal peptide. FEBS Lett 582:826-828

Back SS, Kim J, Choi D, Lee ES, Choi SY, Han K (2013) Cooperative transcriptional activation of ATP-binding cassette sterol transporters ABCG5 and ABCG8 genes by nuclear receptors including Liver-X-Receptor. BMB Rep 46:322-327

Baldan A, Pei L, Lee R, Tarr P, Tangirala RK, Weinstein MM et al (2006) Impaired development of atherosclerosis in hyperlipidemic Ldlr-/- and ApoE-/- mice transplanted with Abcg1-/bone marrow. Arterioscler Thromb Vasc Biol 26:2301-2307 
Bao Y, Yang Y, Wang L, Gao L, Jiang W, Wang L et al (2009) Identification of trichostatin A as a novel transcriptional up-regulator of scavenger receptor BI both in HepG2 and RAW 264.7 cells. Atherosclerosis 204:127-135

Bartel DP (2009) MicroRNAs: target recognition and regulatory functions. Cell 136:215-233

Basu SK, Brown MS, Ho YK, Havel RJ, Goldstein JL (1981) Mouse macrophages synthesize and secrete a protein resembling apolipoprotein E. Proc Natl Acad Sci USA 78:7545-7549

Bavner A, Sanyal S, Gustafsson JA, Treuter E (2005) Transcriptional corepression by SHP: molecular mechanisms and physiological consequences. Trends Endocrinol Metab 16: 478-488

Belalcazar LM, Merched A, Carr B, Oka K, Chen KH, Pastore L et al (2003) Long-term stable expression of human apolipoprotein A-I mediated by helper-dependent adenovirus gene transfer inhibits atherosclerosis progression and remodels atherosclerotic plaques in a mouse model of familial hypercholesterolemia. Circulation 107:2726-2732

Bellosta S, Mahley RW, Sanan DA, Murata J, Newland DL, Taylor JM et al (1995) Macrophagespecific expression of human apolipoprotein $\mathrm{E}$ reduces atherosclerosis in hypercholesterolemic apolipoprotein E-null mice. J Clin Invest 96:2170-2179

Berge KE, Tian H, Graf GA, Yu L, Grishin NV, Schultz J et al (2000) Accumulation of dietary cholesterol in sitosterolemia caused by mutations in adjacent ABC transporters. Science 290: $1771-1775$

Bernstein BE, Birney E, Dunham I, Green ED, Gunter C, Snyder M (2012) An integrated encyclopedia of DNA elements in the human genome. Nature 489:57-74

Biddinger SB, Haas JT, Yu BB, Bezy O, Jing E, Zhang W et al (2008) Hepatic insulin resistance directly promotes formation of cholesterol gallstones. Nat Med 14:778-782

Blumberg B, Evans RM (1998) Orphan nuclear receptors - new ligands and new possibilities. Genes Dev 12:3149-3155

Bouly M, Masson D, Gross B, Jiang XC, Fievet C, Castro G et al (2001) Induction of the phospholipid transfer protein gene accounts for the high density lipoprotein enlargement in mice treated with fenofibrate. J Biol Chem 276:25841-25847

Bourguet W, Germain P, Gronemeyer H (2000) Nuclear receptor ligand-binding domains: threedimensional structures, molecular interactions and pharmacological implications. Trends Pharmacol Sci 21:381-388

Calin GA, Dumitru CD, Shimizu M, Bichi R, Zupo S, Noch E et al (2002) Frequent deletions and down-regulation of micro-RNA genes miR15 and miR16 at 13q14 in chronic lymphocytic leukemia. Proc Natl Acad Sci USA 99:15524-15529

Calkin AC, Tontonoz P (2012) Transcriptional integration of metabolism by the nuclear sterolactivated receptors LXR and FXR. Nat Rev Mol Cell Biol 13:213-224

Cao G, Garcia CK, Wyne KL, Schultz RA, Parker KL, Hobbs HH (1997) Structure and localization of the human gene encoding SR-BI/CLA-1. Evidence for transcriptional control by steroidogenic factor 1. J Biol Chem 272:33068-33076

Cao G, Beyer TP, Yang XP, Schmidt RJ, Zhang Y, Bensch WR et al (2002) Phospholipid transfer protein is regulated by liver X receptors in vivo. J Biol Chem 277:39561-39565

Carthew RW, Sontheimer EJ (2009) Origins and mechanisms of miRNAs and siRNAs. Cell 136:642-655

Cesana M, Cacchiarelli D, Legnini I, Santini T, Sthandier O, Chinappi M et al (2011) A long noncoding RNA controls muscle differentiation by functioning as a competing endogenous RNA. Cell 147:358-369

Chang DJ, Paik YK, Leren TP, Walker DW, Howlett GJ, Taylor JM (1990) Characterization of a human apolipoprotein $\mathrm{E}$ gene enhancer element and its associated protein factors. J Biol Chem 265:9496-9504

Chao F, Gong W, Zheng Y, Li Y, Huang G, Gao M et al (2010) Upregulation of scavenger receptor class B type I expression by activation of FXR in hepatocyte. Atherosclerosis 213:443-448 
Chellan B, Yan L, Sontag TJ, Reardon CA, Hofmann Bowman MA (2013) IL-22 is induced by S100/calgranulin and impairs cholesterol efflux in macrophages by down regulating ABCG1. J Lipid Res 55:443-454

Chen JD, Li H (1998) Coactivation and corepression in transcriptional regulation by steroid/ nuclear hormone receptors. Crit Rev Eukaryot Gene Expr 8:169-190

Chen WS, Manova K, Weinstein DC, Duncan SA, Plump AS, Prezioso VR et al (1994) Disruption of the HNF-4 gene, expressed in visceral endoderm, leads to cell death in embryonic ectoderm and impaired gastrulation of mouse embryos. Genes Dev 8:2466-2477

Chen H, Rossier C, Lalioti MD, Lynn A, Chakravarti A, Perrin G et al (1996) Cloning of the cDNA for a human homologue of the Drosophila white gene and mapping to chromosome 21q22.3. Am J Hum Genet 59:66-75

Chen W, Wang N, Tall AR (2005) A PEST deletion mutant of ABCA1 shows impaired internalization and defective cholesterol efflux from late endosomes. J Biol Chem 280:29277-29281

Chen HY, Xu Z, Chen LF, Wang W, Fang Q, Yan XW (2012a) Valsartan and telmisartan abrogate angiotensin II-induced downregulation of ABCA1 expression via AT1 receptor, rather than AT2 receptor or PPARgamma activation. J Cardiovasc Pharmacol 59:570-575

Chen X, Liang H, Zhang J, Zen K, Zhang CY (2012b) Secreted microRNAs: a new form of intercellular communication. Trends Cell Biol 22:125-132

Chinetti G, Lestavel S, Bocher V, Remaley AT, Neve B, Torra IP et al (2001) PPAR-alpha and PPAR-gamma activators induce cholesterol removal from human macrophage foam cells through stimulation of the ABCA1 pathway. Nat Med 7:53-58

Christoffersen C, Nielsen LB (2013) Apolipoprotein M: bridging HDL and endothelial function. Curr Opin Lipidol 24:295-300

Christoffersen C, Ahnstrom J, Axler O, Christensen EI, Dahlback B, Nielsen LB (2008) The signal peptide anchors apolipoprotein $\mathrm{M}$ in plasma lipoproteins and prevents rapid clearance of apolipoprotein M from plasma. J Biol Chem 283:18765-18772

Christoffersen C, Obinata H, Kumaraswamy SB, Galvani S, Ahnstrom J, Sevvana M et al (2011) Endothelium-protective sphingosine-1-phosphate provided by HDL-associated apolipoprotein M. Proc Natl Acad Sci USA 108:9613-9618

Christova R (2013) Detecting DNA-protein interactions in living cells-ChIP approach. Adv Protein Chem Struct Biol 91:101-133

Churko JM, Mantalas GL, Snyder MP, Wu JC (2013) Overview of high throughput sequencing technologies to elucidate molecular pathways in cardiovascular diseases. Circ Res 112: $1613-1623$

Cifuentes D, Xue H, Taylor DW, Patnode H, Mishima Y, Cheloufi S et al (2010) A novel miRNA processing pathway independent of Dicer requires Argonaute2 catalytic activity. Science 328: $1694-1698$

Claudel T, Sturm E, Duez H, Torra IP, Sirvent A, Kosykh V et al (2002) Bile acid-activated nuclear receptor FXR suppresses apolipoprotein A-I transcription via a negative FXR response element. J Clin Invest 109:961-971

Costet P, Luo Y, Wang N, Tall AR (2000) Sterol-dependent transactivation of the ABC1 promoter by the liver X receptor/retinoid X receptor. J Biol Chem 275:28240-28245

Costet P, Lalanne F, Gerbod-Giannone MC, Molina JR, Fu X, Lund EG et al (2003) Retinoic acid receptor-mediated induction of ABCA1 in macrophages. Mol Cell Biol 23:7756-7766

Cui L, Schoene NW, Zhu L, Fanzo JC, Alshatwi A, Lei KY (2002) Zinc depletion reduced Egr-1 and HNF-3beta expression and apolipoprotein A-I promoter activity in Hep G2 cells. Am J Physiol Cell Physiol 283:C623-C630

Dahlback B, Nielsen LB (2009) Apolipoprotein M affecting lipid metabolism or just catching a ride with lipoproteins in the circulation? Cell Mol Life Sci 66:559-564

Davalos A, Chroni A (2014) Antisense oligonucleotides, microRNAs and antibodies. In: von Eckardstein A, Kardassis D (eds) High density lipoproteins - from biological understanding to clinical exploitation. Springer, Heidelberg 
Davalos A, Fernandez-Hernando C (2013) From evolution to revolution: miRNAs as pharmacological targets for modulating cholesterol efflux and reverse cholesterol transport. Pharmacol Res 75:60-72

Davalos A, Goedeke L, Smibert P, Ramirez CM, Warrier NP, Andreo U et al (2011) miR-33a/b contribute to the regulation of fatty acid metabolism and insulin signaling. Proc Natl Acad Sci USA 108:9232-9237

Davignon J (2005) Apolipoprotein E and atherosclerosis: beyond lipid effect. Arterioscler Thromb Vasc Biol 25:267-269

Day JR, Albers JJ, Lofton-Day CE, Gilbert TL, Ching AF, Grant FJ et al (1994) Complete cDNA encoding human phospholipid transfer protein from human endothelial cells. J Biol Chem 269: 9388-9391

de Aguiar Vallim TQ, Tarling EJ, Kim T, Civelek M, Baldan A, Esau C et al (2013) MicroRNA144 regulates hepatic ATP binding cassette transporter A1 and plasma high-density lipoprotein after activation of the nuclear receptor farnesoid X receptor. Circ Res 112:1602-1612

del Castillo-Olivares A, Gil G (2000) Alpha 1-fetoprotein transcription factor is required for the expression of sterol 12alpha-hydroxylase, the specific enzyme for cholic acid synthesis. Potential role in the bile acid-mediated regulation of gene transcription. J Biol Chem 275: 17793-17799

Delerive P, Galardi CM, Bisi JE, Nicodeme E, Goodwin B (2004) Identification of liver receptor homolog-1 as a novel regulator of apolipoprotein AI gene transcription. Mol Endocrinol 18: $2378-2387$

Djebali S, Davis CA, Merkel A, Dobin A, Lassmann T, Mortazavi A et al (2012) Landscape of transcription in human cells. Nature 489:101-108

Dong P, Xie T, Zhou X, Hu W, Chen Y, Duan Y et al (2011) Induction of macrophage scavenger receptor type BI expression by tamoxifen and 4-hydroxytamoxifen. Atherosclerosis 218:435-442

Duez H, Lefebvre B, Poulain P, Torra IP, Percevault F, Luc G et al (2005) Regulation of human apoA-I by gemfibrozil and fenofibrate through selective peroxisome proliferator-activated receptor alpha modulation. Arterioscler Thromb Vasc Biol 25:585-591

Durrington PN, Mackness MI, Bhatnagar D, Julier K, Prais H, Arrol S et al (1998) Effects of two different fibric acid derivatives on lipoproteins, cholesteryl ester transfer, fibrinogen, plasminogen activator inhibitor and paraoxonase activity in type IIb hyperlipoproteinaemia. Atherosclerosis 138:217-225

Ecker J, Langmann T, Moehle C, Schmitz G (2007) Isomer specific effects of Conjugated Linoleic Acid on macrophage ABCG1 transcription by a SREBP-1c dependent mechanism. Biochem Biophys Res Commun 352:805-811

Edgel KA, Leboeuf RC, Oram JF (2010) Tumor necrosis factor-alpha and lymphotoxin-alpha increase macrophage $\mathrm{ABCA} 1$ by gene expression and protein stabilization via different receptors. Atherosclerosis 209:387-392

Engel T, Lueken A, Bode G, Hobohm U, Lorkowski S, Schlueter B et al (2004) ADP-ribosylation factor (ARF)-like 7 (ARL7) is induced by cholesterol loading and participates in apolipoprotein AI-dependent cholesterol export. FEBS Lett 566:241-246

Engel T, Bode G, Lueken A, Knop M, Kannenberg F, Nofer JR et al (2006) Expression and functional characterization of ABCG1 splice variant ABCG1(666). FEBS Lett 580:4551-4559

Ettinger WH, Varma VK, Sorci-Thomas M, Parks JS, Sigmon RC, Smith TK et al (1994) Cytokines decrease apolipoprotein accumulation in medium from Hep G2 cells. Arterioscler Thromb 14:8-13

Fayard E, Auwerx J, Schoonjans K (2004) LRH-1: an orphan nuclear receptor involved in development, metabolism and steroidogenesis. Trends Cell Biol 14:250-260

Fazio S, Babaev VR, Murray AB, Hasty AH, Carter KJ, Gleaves LA et al (1997) Increased atherosclerosis in mice reconstituted with apolipoprotein E null macrophages. Proc Natl Acad Sci USA 94:4647-4652 
Feingold KR, Shigenaga JK, Chui LG, Moser A, Khovidhunkit W, Grunfeld C (2008) Infection and inflammation decrease apolipoprotein M expression. Atherosclerosis 199:19-26

Fitzgerald ML, Mujawar Z, Tamehiro N (2010) ABC transporters, atherosclerosis and inflammation. Atherosclerosis 211:361-370

Frankel LB, Lund AH (2012) MicroRNA regulation of autophagy. Carcinogenesis 33:2018-2025

Freeman LA, Kennedy A, Wu J, Bark S, Remaley AT, Santamarina-Fojo S et al (2004) The orphan nuclear receptor LRH-1 activates the ABCG5/ABCG8 intergenic promoter. J Lipid Res 45: $1197-1206$

Friedman RC, Farh KK, Burge CB, Bartel DP (2009) Most mammalian mRNAs are conserved targets of microRNAs. Genome Res 19:92-105

Frisdal E, Lesnik P, Olivier M, Robillard P, Chapman MJ, Huby T et al (2011) Interleukin-6 protects human macrophages from cellular cholesterol accumulation and attenuates the proinflammatory response. J Biol Chem 286:30926-30936

Fu X, Menke JG, Chen Y, Zhou G, MacNaul KL, Wright SD et al (2001) 27-hydroxycholesterol is an endogenous ligand for liver $\mathrm{X}$ receptor in cholesterol-loaded cells. J Biol Chem 276: 38378-38387

Fukata Y, Yu X, Imachi H, Nishiuchi T, Lyu J, Seo K et al (2013) 17ß-Estradiol regulates scavenger receptor class BI gene expression via protein kinase $\mathrm{C}$ in vascular endothelial cells. Endocrine 46:644-650

Gafencu AV, Robciuc MR, Fuior E, Zannis VI, Kardassis D, Simionescu M (2007) Inflammatory signaling pathways regulating ApoE gene expression in macrophages. J Biol Chem 282: 21776-21785

Gan X, Kaplan R, Menke JG, MacNaul K, Chen Y, Sparrow CP et al (2001) Dual mechanisms of ABCA1 regulation by geranylgeranyl pyrophosphate. J Biol Chem 276:48702-48708

Garcia MA, Vazquez J, Gimenez C, Valdivieso F, Zafra F (1996) Transcription factor AP-2 regulates human apolipoprotein $\mathrm{E}$ gene expression in astrocytoma cells. J Neurosci 16: $7550-7556$

Gaudet F, Ginsburg GS (1995) Transcriptional regulation of the cholesteryl ester transfer protein gene by the orphan nuclear hormone receptor apolipoprotein AI regulatory protein-1. J Biol Chem 270:29916-29922

Gauthier B, Robb M, Gaudet F, Ginsburg GS, McPherson R (1999) Characterization of a cholesterol response element (CRE) in the promoter of the cholesteryl ester transfer protein gene: functional role of the transcription factors SREBP-1a, -2, and YY1. J Lipid Res 40: 1284-1293

Gautier T, de Haan W, Grober J, Ye D, Bahr MJ, Claudel T et al (2013) Farnesoid X receptor activation increases cholesteryl ester transfer protein expression in humans and transgenic mice. J Lipid Res 54:2195-2205

Gavrilov A, Eivazova E, Priozhkova I, Lipinski M, Razin S, Vassetzky Y (2009) Chromosome conformation capture (from $3 \mathrm{C}$ to $5 \mathrm{C}$ ) and its ChIP-based modification. Methods Mol Biol 567:171-188

Georgopoulos S, Kan HY, Reardon-Alulis C, Zannis V (2000) The SP1 sites of the human apoCIII enhancer are essential for the expression of the apoCIII gene and contribute to the hepatic and intestinal expression of the apoA-I gene in transgenic mice. Nucleic Acids Res 28:4919-4929

Gerbod-Giannone MC, Li Y, Holleboom A, Han S, Hsu LC, Tabas I et al (2006) TNFalpha induces ABCA1 through NF-kappaB in macrophages and in phagocytes ingesting apoptotic cells. Proc Natl Acad Sci USA 103:3112-3117

Gerin I, Clerbaux LA, Haumont O, Lanthier N, Das AK, Burant CF et al (2010) Expression of miR-33 from an SREBP2 intron inhibits cholesterol export and fatty acid oxidation. J Biol Chem 285:33652-33661

Goldstein I, Ezra O, Rivlin N, Molchadsky A, Madar S, Goldfinger N et al (2012) p53, a novel regulator of lipid metabolism pathways. J Hepatol 56:656-662 
Grainger DJ, Reckless J, McKilligin E (2004) Apolipoprotein E modulates clearance of apoptotic bodies in vitro and in vivo, resulting in a systemic proinflammatory state in apolipoprotein E-deficient mice. J Immunol 173:6366-6375

Gronemeyer H, Gustafsson JA, Laudet V (2004) Principles for modulation of the nuclear receptor superfamily. Nat Rev Drug Discov 3:950-964

Gu HM, Li G, Gao X, Berthiaume LG, Zhang DW (2013) Characterization of palmitoylation of ATP binding cassette transporter G1: effect on protein trafficking and function. Biochim Biophys Acta 1831:1067-1078

Guo H, Ingolia NT, Weissman JS, Bartel DP (2010) Mammalian microRNAs predominantly act to decrease target mRNA levels. Nature 466:835-840

Haas MJ, Mooradian AD (2010) Therapeutic interventions to enhance apolipoprotein A-Imediated cardioprotection. Drugs 70:805-821

Hadzopoulou-Cladaras M, Lavrentiadou SN, Zannis VI, Kardassis D (1998) Transactivation of the ApoCIII promoter by ATF-2 and repression by members of the Jun family. Biochemistry 37 : $14078-14087$

Haghpassand M, Bourassa PA, Francone OL, Aiello RJ (2001) Monocyte/macrophage expression of ABCA1 has minimal contribution to plasma HDL levels. J Clin Invest 108:1315-1320

Haidar B, Kiss RS, Sarov-Blat L, Brunet R, Harder C, McPherson R et al (2006) Cathepsin D, a lysosomal protease, regulates ABCA1-mediated lipid efflux. J Biol Chem 281:39971-39981

Hansen TB, Jensen TI, Clausen BH, Bramsen JB, Finsen B, Damgaard CK et al (2013) Natural RNA circles function as efficient microRNA sponges. Nature 495:384-388

Hargrove GM, Junco A, Wong NC (1999) Hormonal regulation of apolipoprotein AI. J Mol Endocrinol 22:103-111

Hayhurst GP, Lee YH, Lambert G, Ward JM, Gonzalez FJ (2001) Hepatocyte nuclear factor 4alpha (nuclear receptor 2A1) is essential for maintenance of hepatic gene expression and lipid homeostasis. Mol Cell Biol 21:1393-1403

Helal O, Berrougui H, Loued S, Khalil A (2013) Extra-virgin olive oil consumption improves the capacity of HDL to mediate cholesterol efflux and increases ABCA1 and ABCG1 expression in human macrophages. Br J Nutr 109:1844-1855

Helsen C, Kerkhofs S, Clinckemalie L, Spans L, Laurent M, Boonen S et al (2012) Structural basis for nuclear hormone receptor DNA binding. Mol Cell Endocrinol 348:411-417

Helwak A, Kudla G, Dudnakova T, Tollervey D (2013) Mapping the human miRNA interactome by CLASH reveals frequent noncanonical binding. Cell 153:654-665

Hoang MH, Jia Y, Jun HJ, Lee JH, Lee BY, Lee SJ (2012) Fucosterol is a selective liver X receptor modulator that regulates the expression of key genes in cholesterol homeostasis in macrophages, hepatocytes, and intestinal cells. J Agric Food Chem 60:11567-11575

Honzumi S, Shima A, Hiroshima A, Koieyama T, Ubukata N, Terasaka N (2010) LXRalpha regulates human CETP expression in vitro and in transgenic mice. Atherosclerosis 212: 139-145

Horie T, Ono K, Horiguchi M, Nishi H, Nakamura T, Nagao K et al (2010) MicroRNA-33 encoded by an intron of sterol regulatory element-binding protein 2 (Srebp2) regulates HDL in vivo. Proc Natl Acad Sci USA 107:17321-17326

Horie T, Baba O, Kuwabara Y, Chujo Y, Watanabe S, Kinoshita M et al (2012) MicroRNA-33 deficiency reduces the progression of atherosclerotic plaque in ApoE-/- mice. J Am Heart Assoc 1:e003376

Horie T, Nishino T, Baba O, Kuwabara Y, Nakao T, Nishiga M et al (2013) MicroRNA-33 regulates sterol regulatory element-binding protein 1 expression in mice. Nat Commun 4:2883

Horiuchi K, Tajima S, Menju M, Yamamoto A (1989) Structure and expression of mouse apolipoprotein E gene. J Biochem 106:98-103

Horton JD, Goldstein JL, Brown MS (2002) SREBPs: activators of the complete program of cholesterol and fatty acid synthesis in the liver. J Clin Invest 109:1125-1131 
Hozoji M, Munehira Y, Ikeda Y, Makishima M, Matsuo M, Kioka N et al (2008) Direct interaction of nuclear liver X receptor-beta with ABCA1 modulates cholesterol efflux. J Biol Chem 283: 30057-30063

Hozoji-Inada M, Munehira Y, Nagao K, Kioka N, Ueda K (2011) Liver X receptor beta (LXRbeta) interacts directly with ATP-binding cassette A1 (ABCA1) to promote high density lipoprotein formation during acute cholesterol accumulation. J Biol Chem 286:20117-20124

Hu Y, Ren X, Wang H, Ma Y, Wang L, Shen Y et al (2010a) Liver-specific expression of an exogenous gene controlled by human apolipoprotein A-I promoter. Int J Pharm 398:161-164

Hu YW, Wang Q, Ma X, Li XX, Liu XH, Xiao J et al (2010b) TGF-beta1 up-regulates expression of ABCA1, ABCG1 and SR-BI through liver $\mathrm{X}$ receptor alpha signaling pathway in THP-1 macrophage-derived foam cells. J Atheroscler Thromb 17:493-502

$\mathrm{Hu}$ Z, Shen WJ, Kraemer FB, Azhar S (2012) MicroRNAs 125a and 455 repress lipoproteinsupported steroidogenesis by targeting scavenger receptor class B type I in steroidogenic cells. Mol Cell Biol 32:5035-5045

$\mathrm{Hu} \mathrm{Z}, \mathrm{Hu}$ J, Zhang Z, Shen WJ, Yun CC, Berlot CH et al (2013) Regulation of expression and function of scavenger receptor class $\mathrm{B}$, type $\mathrm{I}(\mathrm{SR}-\mathrm{BI})$ by $\mathrm{Na}^{+} / \mathrm{H}^{+}$exchanger regulatory factors (NHERFs). J Biol Chem 288:11416-11435

Huang CX, Zhang YL, Wang JF, Jiang JY, Bao JL (2013) MCP-1 impacts RCT by repressing ABCA1, ABCG1, and SR-BI through PI3K/Akt posttranslational regulation in HepG2 cells. J Lipid Res 54:1231-1240

Hunter MP, Ismail N, Zhang X, Aguda BD, Lee EJ, Yu L et al (2008) Detection of microRNA expression in human peripheral blood microvesicles. PLoS ONE 3:e3694

Huuskonen J, Abedin M, Vishnu M, Pullinger CR, Baranzini SE, Kane JP et al (2003) Dynamic regulation of alternative ATP-binding cassette transporter A1 transcripts. Biochem Biophys Res Commun 306:463-468

Huuskonen J, Vishnu M, Pullinger CR, Fielding PE, Fielding CJ (2004) Regulation of ATP-binding cassette transporter A1 transcription by thyroid hormone receptor. Biochemistry 43:1626-1632

Huwait EA, Greenow KR, Singh NN, Ramji DP (2011) A novel role for c-Jun N-terminal kinase and phosphoinositide 3-kinase in the liver $\mathrm{X}$ receptor-mediated induction of macrophage gene expression. Cell Signal 23:542-549

Ishibashi M, Filomenko R, Rebe C, Chevriaux A, Varin A, Derangere V et al (2013) Knock-down of the oxysterol receptor LXRalpha impairs cholesterol efflux in human primary macrophages: lack of compensation by LXRbeta activation. Biochem Pharmacol 86:122-129

Iwamoto N, Lu R, Tanaka N, Abe-Dohmae S, Yokoyama S (2010) Calmodulin interacts with ATP binding cassette transporter A1 to protect from calpain-mediated degradation and upregulates high-density lipoprotein generation. Arterioscler Thromb Vasc Biol 30:1446-1452

Jean S, Kiger AA (2012) Coordination between RAB GTPase and phosphoinositide regulation and functions. Nat Rev Mol Cell Biol 13:463-470

Jeoung NH, Jang WG, Nam JI, Pak YK, Park YB (1999) Identification of retinoic acid receptor element in human cholesteryl ester transfer protein gene. Biochem Biophys Res Commun 258: $411-415$

Jiang XC, Bruce C (1995) Regulation of murine plasma phospholipid transfer protein activity and mRNA levels by lipopolysaccharide and high cholesterol diet. J Biol Chem 270:17133-17138

Jiang XC, Moulin P, Quinet E, Goldberg IJ, Yacoub LK, Agellon LB et al (1991) Mammalian adipose tissue and muscle are major sources of lipid transfer protein mRNA. J Biol Chem 266:4631-4639

Jiang XC, Agellon LB, Walsh A, Breslow JL, Tall A (1992) Dietary cholesterol increases transcription of the human cholesteryl ester transfer protein gene in transgenic mice. Dependence on natural flanking sequences. J Clin Invest 90:1290-1295

Jiang XC, Jin W, Hussain MM (2012) The impact of phospholipid transfer protein (PLTP) on lipoprotein metabolism. Nutr Metab (Lond) 9:75 
Jo DW, Leren TP, Yang ZY, Chung YH, Taylor JM, Paik YK (1995) Characterization of an upstream regulatory element of the human apolipoprotein $\mathrm{E}$ gene, and purification of its binding protein from the human placenta. J Biochem 117:915-922

Joseph SB, Laffitte BA, Patel PH, Watson MA, Matsukuma KE, Walczak R et al (2002a) Direct and indirect mechanisms for regulation of fatty acid synthase gene expression by liver $\mathrm{X}$ receptors. J Biol Chem 277:11019-11025

Joseph SB, McKilligin E, Pei L, Watson MA, Collins AR, Laffitte BA et al (2002b) Synthetic LXR ligand inhibits the development of atherosclerosis in mice. Proc Natl Acad Sci USA 99: 7604-7609

Jun HJ, Hoang MH, Yeo SK, Jia Y, Lee SJ (2013) Induction of ABCA1 and ABCG1 expression by the liver X receptor modulator cineole in macrophages. Bioorg Med Chem Lett 23:579-583

Kammerer I, Ringseis R, Biemann R, Wen G, Eder K (2011) 13-hydroxy linoleic acid increases expression of the cholesterol transporters ABCA1, ABCG1 and SR-BI and stimulates apoA-Idependent cholesterol efflux in RAW264.7 macrophages. Lipids Health Dis 10:222

Kan HY, Georgopoulos S, Zannis V (2000) A hormone response element in the human apolipoprotein CIII (ApoCIII) enhancer is essential for intestinal expression of the ApoA-I and ApoCIII genes and contributes to the hepatic expression of the two linked genes in transgenic mice. J Biol Chem 275:30423-30431

Kan HY, Georgopoulos S, Zanni M, Shkodrani A, Tzatsos A, Xie HX et al (2004) Contribution of the hormone-response elements of the proximal ApoA-I promoter, ApoCIII enhancer, and $\mathrm{C} / \mathrm{EBP}$ binding site of the proximal ApoA-I promoter to the hepatic and intestinal expression of the ApoA-I and ApoCIII genes in transgenic mice. Biochemistry 43:5084-5093

Kang MH, Singaraja R, Hayden MR (2010) Adenosine-triphosphate-binding cassette transporter-1 trafficking and function. Trends Cardiovasc Med 20:41-49

Kang MH, Zhang LH, Wijesekara N, de Haan W, Butland S, Bhattacharjee A et al (2013) Regulation of ABCA1 protein expression and function in hepatic and pancreatic islet cells by miR-145. Arterioscler Thromb Vasc Biol 33:2724-2732

Kanter JE, Tang C, Oram JF, Bornfeldt KE (2012) Acyl-CoA synthetase 1 is required for oleate and linoleate mediated inhibition of cholesterol efflux through ATP-binding cassette transporter A1 in macrophages. Biochim Biophys Acta 1821:358-364

Kardassis D, Tzameli I, Hadzopoulou-Cladaras M, Talianidis I, Zannis V (1997) Distal apolipoprotein $\mathrm{C}$-III regulatory elements $\mathrm{F}$ to $\mathrm{J}$ act as a general modular enhancer for proximal promoters that contain hormone response elements. Synergism between hepatic nuclear factor-4 molecules bound to the proximal promoter and distal enhancer sites. Arterioscler Thromb Vasc Biol 17:222-232

Kardassis D, Falvey E, Tsantili P, Hadzopoulou-Cladaras M, Zannis V (2002) Direct physical interactions between HNF-4 and Sp1 mediate synergistic transactivation of the apolipoprotein CIII promoter. Biochemistry 41:1217-1228

Kardassis D, Drosatos C, Zannis V (2007) Regulation of genes involved in the biogenesis and the remodeling of HDL. In: Fielding CJ (ed) High-density lipoproteins from basic biology to clinical aspects. Wiley-VCH, Weinheim, pp 237-253

Kennedy MA, Barrera GC, Nakamura K, Baldan A, Tarr P, Fishbein MC et al (2005) ABCG1 has a critical role in mediating cholesterol efflux to HDL and preventing cellular lipid accumulation. Cell Metab 1:121-131

Kielar D, Dietmaier W, Langmann T, Aslanidis C, Probst M, Naruszewicz M et al (2001) Rapid quantification of human ABCA1 mRNA in various cell types and tissues by real-time reverse transcription-PCR. Clin Chem 47:2089-2097

Kilbourne EJ, Widom R, Harnish DC, Malik S, Karathanasis SK (1995) Involvement of early growth response factor Egr-1 in apolipoprotein AI gene transcription. J Biol Chem 270: 7004-7010

Kim J, Yoon H, Ramirez CM, Lee SM, Hoe HS, Fernandez-Hernando C (2012) MiR-106b impairs cholesterol efflux and increases $A \beta$ levels by repressing ABCA1 expression. Exp Neurol 235: $476-483$ 
Kinet V, Halkein J, Dirkx E, Windt LJ (2013) Cardiovascular extracellular microRNAs: emerging diagnostic markers and mechanisms of cell-to-cell RNA communication. Front Genet 4:214

Kir S, Zhang Y, Gerard RD, Kliewer SA, Mangelsdorf DJ (2012) Nuclear receptors HNF4alpha and LRH-1 cooperate in regulating Cyp7a1 in vivo. J Biol Chem 287:41334-41341

Kocher O, Krieger M (2009) Role of the adaptor protein PDZK1 in controlling the HDL receptor SR-BI. Curr Opin Lipidol 20:236-241

Kocher O, Yesilaltay A, Cirovic C, Pal R, Rigotti A, Krieger M (2003) Targeted disruption of the PDZK1 gene in mice causes tissue-specific depletion of the high density lipoprotein receptor scavenger receptor class B type I and altered lipoprotein metabolism. J Biol Chem 278: $52820-52825$

Krol J, Loedige I, Filipowicz W (2010) The widespread regulation of microRNA biogenesis, function and decay. Nat Rev Genet 11:597-610

Ku CS, Park Y, Coleman SL, Lee J (2012) Unsaturated fatty acids repress expression of ATP binding cassette transporter A1 and G1 in RAW 264.7 macrophages. J Nutr Biochem 23: $1271-1276$

Kulyte A, Lorente-Cebrian S, Gao H, Mejhert N, Agustsson T, Arner P et al (2013) MicroRNA profiling links miR-378 to enhanced adipocyte lipolysis in human cancer cachexia. Am J Physiol Endocrinol Metab 306:E267-E274

Kuo CY, Lin YC, Yang JJ, Yang VC (2011) Interaction abolishment between mutant caveolin-1 (Delta62-100) and ABCA1 reduces HDL-mediated cellular cholesterol efflux. Biochem Biophys Res Commun 414:337-343

Ladias JA, Karathanasis SK (1991) Regulation of the apolipoprotein AI gene by ARP-1, a novel member of the steroid receptor superfamily. Science 251:561-565

Laffitte BA, Joseph SB, Walczak R, Pei L, Wilpitz DC, Collins JL et al (2001a) Autoregulation of the human liver X receptor alpha promoter. Mol Cell Biol 21:7558-7568

Laffitte BA, Repa JJ, Joseph SB, Wilpitz DC, Kast HR, Mangelsdorf DJ et al (2001b) LXRs control lipid-inducible expression of the apolipoprotein $\mathrm{E}$ gene in macrophages and adipocytes. Proc Natl Acad Sci USA 98:507-512

Laffitte BA, Joseph SB, Chen M, Castrillo A, Repa J, Wilpitz D et al (2003) The phospholipid transfer protein gene is a liver $\mathrm{X}$ receptor target expressed by macrophages in atherosclerotic lesions. Mol Cell Biol 23:2182-2191

Lagos-Quintana M, Rauhut R, Yalcin A, Meyer J, Lendeckel W, Tuschl T (2002) Identification of tissue-specific microRNAs from mouse. Curr Biol 12:735-739

Lakomy D, Rebe C, Sberna AL, Masson D, Gautier T, Chevriaux A et al (2009) Liver X receptormediated induction of cholesteryl ester transfer protein expression is selectively impaired in inflammatory macrophages. Arterioscler Thromb Vasc Biol 29:1923-1929

Lambert G, Amar MJ, Guo G, Brewer HB Jr, Gonzalez FJ, Sinal CJ (2003) The farnesoid $\mathrm{X}$-receptor is an essential regulator of cholesterol homeostasis. J Biol Chem 278:2563-2570

Lan D, Silver DL (2005) Fenofibrate induces a novel degradation pathway for scavenger receptor B-I independent of PDZK1. J Biol Chem 280:23390-23396

Langmann T, Klucken J, Reil M, Liebisch G, Luciani MF, Chimini G et al (1999) Molecular cloning of the human ATP-binding cassette transporter 1 (hABC1): evidence for steroldependent regulation in macrophages. Biochem Biophys Res Commun 257:29-33

Langmann T, Porsch-Ozcurumez M, Unkelbach U, Klucken J, Schmitz G (2000) Genomic organization and characterization of the promoter of the human ATP-binding cassette transporter-G1 (ABCG1) gene. Biochim Biophys Acta 1494:175-180

Langmann T, Porsch-Ozcurumez M, Heimerl S, Probst M, Moehle C, Taher M et al (2002) Identification of sterol-independent regulatory elements in the human ATP-binding cassette transporter A1 promoter: role of Sp1/3, E-box binding factors, and an oncostatin M-responsive element. J Biol Chem 277:14443-14450

Langmann T, Mauerer R, Zahn A, Moehle C, Probst M, Stremmel W et al (2003) Real-time reverse transcription-PCR expression profiling of the complete human ATP-binding cassette transporter superfamily in various tissues. Clin Chem 49:230-238 
Larkin L, Khachigian LM, Jessup W (2000) Regulation of apolipoprotein E production in macrophages (review). Int J Mol Med 6:253-258

Lavrentiadou SN, Hadzopoulou-Cladaras M, Kardassis D, Zannis VI (1999) Binding specificity and modulation of the human ApoCIII promoter activity by heterodimers of ligand-dependent nuclear receptors. Biochemistry 38:964-975

Le Goff W, Guerin M, Petit L, Chapman MJ, Thillet J (2003) Regulation of human CETP gene expression: role of SP1 and SP3 transcription factors at promoter sites $-690,-629$, and -37 . J Lipid Res 44:1322-1331

Lee RC, Feinbaum RL, Ambros V (1993) The C. elegans heterochronic gene lin-4 encodes small RNAs with antisense complementarity to lin-14. Cell 75:843-854

Lee S, Wang PY, Jeong Y, Mangelsdorf DJ, Anderson RG, Michaely P (2012) Sterol-dependent nuclear import of ORP1S promotes LXR regulated trans-activation of apoE. Exp Cell Res 318:2128-2142

Leiva A, Verdejo H, Benitez ML, Martinez A, Busso D, Rigotti A (2011) Mechanisms regulating hepatic SR-BI expression and their impact on HDL metabolism. Atherosclerosis 217:299-307

Lemon B, Tjian R (2000) Orchestrated response: a symphony of transcription factors for gene control. Genes Dev 14:2551-2569

Li J, Ning G, Duncan SA (2000) Mammalian hepatocyte differentiation requires the transcription factor HNF-4alpha. Genes Dev 14:464-474

Li X, Peegel H, Menon KM (2001) Regulation of high density lipoprotein receptor messenger ribonucleic acid expression and cholesterol transport in theca-interstitial cells by insulin and human chorionic gonadotropin. Endocrinology 142:174-181

Li D, Wang D, Wang Y, Ling W, Feng X, Xia M (2010a) Adenosine monophosphate-activated protein kinase induces cholesterol efflux from macrophage-derived foam cells and alleviates atherosclerosis in apolipoprotein E-deficient mice. J Biol Chem 285:33499-33509

Li D, Zhang Y, Ma J, Ling W, Xia M (2010b) Adenosine monophosphate activated protein kinase regulates ABCG1-mediated oxysterol efflux from endothelial cells and protects against hypercholesterolemia-induced endothelial dysfunction. Arterioscler Thromb Vasc Biol 30: $1354-1362$

Li G, Gu HM, Zhang DW (2013) ATP-binding cassette transporters and cholesterol translocation. IUBMB Life 65:505-512

Liang Y, Yang X, Ma L, Cai X, Wang L, Yang C et al (2013) Homocysteine-mediated cholesterol efflux via ABCA1 and ACAT1 DNA methylation in THP-1 monocyte-derived foam cells. Acta Biochim Biophys Sin (Shanghai) 45:220-228

Lin G, Bornfeldt KE (2002) Cyclic AMP-specific phosphodiesterase 4 inhibitors promote ABCA1 expression and cholesterol efflux. Biochem Biophys Res Commun 290:663-669

Lin S, Zhou C, Neufeld E, Wang YH, Xu SW, Lu L et al (2013) BIG1, a brefeldin A-inhibited guanine nucleotide-exchange protein modulates ATP-binding cassette transporter A-1 trafficking and function. Arterioscler Thromb Vasc Biol 33:e31-e38

Linder MD, Mayranpaa MI, Peranen J, Pietila TE, Pietiainen VM, Uronen RL et al (2009) Rab8 regulates ABCA1 cell surface expression and facilitates cholesterol efflux in primary human macrophages. Arterioscler Thromb Vasc Biol 29:883-888

Linton MF, Atkinson JB, Fazio S (1995) Prevention of atherosclerosis in apolipoprotein E-deficient mice by bone marrow transplantation. Science 267:1034-1037

Liu C, Lin JD (2011) PGC-1 coactivators in the control of energy metabolism. Acta Biochim Biophys Sin (Shanghai) 43:248-257

Liu S, Tetzlaff MT, Cui R, Xu X (2012) miR-200c inhibits melanoma progression and drug resistance through down-regulation of BMI-1. Am J Pathol 181:1823-1835

Lopez D, McLean MP (1999) Sterol regulatory element-binding protein-1a binds to cis elements in the promoter of the rat high density lipoprotein receptor SR-BI gene. Endocrinology 140: $5669-5681$

Lopez D, McLean MP (2006) Estrogen regulation of the scavenger receptor class B gene: antiatherogenic or steroidogenic, is there a priority? Mol Cell Endocrinol 247:22-33 
Lopez D, Sandhoff TW, McLean MP (1999) Steroidogenic factor-1 mediates cyclic 3',5'-adenosine monophosphate regulation of the high density lipoprotein receptor. Endocrinology 140:3034-3044

Lopez D, Shea-Eaton W, Sanchez MD, McLean MP (2001) DAX-1 represses the high-density lipoprotein receptor through interaction with positive regulators sterol regulatory elementbinding protein-1a and steroidogenic factor-1. Endocrinology 142:5097-5106

Lopez D, Sanchez MD, Shea-Eaton W, McLean MP (2002) Estrogen activates the high-density lipoprotein receptor gene via binding to estrogen response elements and interaction with sterol regulatory element binding protein-1A. Endocrinology 143:2155-2168

Lu R, Arakawa R, Ito-Osumi C, Iwamoto N, Yokoyama S (2008) ApoA-I facilitates ABCA1 recycle/accumulation to cell surface by inhibiting its intracellular degradation and increases HDL generation. Arterioscler Thromb Vasc Biol 28:1820-1824

Lund E, Guttinger S, Calado A, Dahlberg JE, Kutay U (2004) Nuclear export of microRNA precursors. Science 303:95-98

Luo Y, Tall AR (2000) Sterol upregulation of human CETP expression in vitro and in transgenic mice by an LXR element. J Clin Invest 105:513-520

Luo Y, Liang CP, Tall AR (2001) The orphan nuclear receptor LRH-1 potentiates the sterolmediated induction of the human CETP gene by liver X receptor. J Biol Chem 276: 24767-24773

Ma AZ, Zhang Q, Song ZY (2013) TNFa alter cholesterol metabolism in human macrophages via PKC-theta-dependent pathway. BMC Biochem 14:20

Maitra U, Li L (2013) Molecular mechanisms responsible for the reduced expression of cholesterol transporters from macrophages by low-dose endotoxin. Arterioscler Thromb Vasc Biol 33:24-33

Mak PA, Kast-Woelbern HR, Anisfeld AM, Edwards PA (2002a) Identification of PLTP as an LXR target gene and apoE as an FXR target gene reveals overlapping targets for the two nuclear receptors. J Lipid Res 43:2037-2041

Mak PA, Laffitte BA, Desrumaux C, Joseph SB, Curtiss LK, Mangelsdorf DJ et al (2002b) Regulated expression of the apolipoprotein E/C-I/C-IV/C-II gene cluster in murine and human macrophages. A critical role for nuclear liver $\mathrm{X}$ receptors alpha and beta. J Biol Chem 277:31900-31908

Malekpour-Dehkordi Z, Javadi E, Doosti M, Paknejad M, Nourbakhsh M, Yassa N et al (2013) S-Allylcysteine, a garlic compound, increases ABCA1 expression in human THP-1 macrophages. Phytother Res 27:357-361

Malerod L, Juvet LK, Hanssen-Bauer A, Eskild W, Berg T (2002) Oxysterol-activated LXRalpha/ RXR induces hSR-BI-promoter activity in hepatoma cells and preadipocytes. Biochem Biophys Res Commun 299:916-923

Malerod L, Sporstol M, Juvet LK, Mousavi A, Gjoen T, Berg T (2003) Hepatic scavenger receptor class B, type I is stimulated by peroxisome proliferator-activated receptor gamma and hepatocyte nuclear factor 4alpha. Biochem Biophys Res Commun 305:557-565

Malerod L, Sporstol M, Juvet LK, Mousavi SA, Gjoen T, Berg T et al (2005) Bile acids reduce SR-BI expression in hepatocytes by a pathway involving FXR/RXR, SHP, and LRH-1. Biochem Biophys Res Commun 336:1096-1105

Marquart TJ, Allen RM, Ory DS, Baldan A (2010) miR-33 links SREBP-2 induction to repression of sterol transporters. Proc Natl Acad Sci USA 107:12228-12232

Martinez LO, Agerholm-Larsen B, Wang N, Chen W, Tall AR (2003) Phosphorylation of a pest sequence in ABCA1 promotes calpain degradation and is reversed by ApoA-I. J Biol Chem 278:37368-37374

Masson D, Qatanani M, Sberna AL, Xiao R, Pais de Barros JP, Grober J et al (2008) Activation of the constitutive androstane receptor decreases HDL in wild-type and human apoA-I transgenic mice. J Lipid Res 49:1682-1691 
Mataki C, Magnier BC, Houten SM, Annicotte JS, Argmann C, Thomas C et al (2007) Compromised intestinal lipid absorption in mice with a liver-specific deficiency of liver receptor homolog 1. Mol Cell Biol 27:8330-8339

Mattick JS, Makunin IV (2005) Small regulatory RNAs in mammals. Hum Mol Genet 14(Spec No 1):R121-R132

Mauerer R, Ebert S, Langmann T (2009) High glucose, unsaturated and saturated fatty acids differentially regulate expression of ATP-binding cassette transporters ABCA1 and ABCG1 in human macrophages. Exp Mol Med 41:126-132

Mavridou S, Venihaki M, Rassouli O, Tsatsanis C, Kardassis D (2010) Feedback inhibition of human scavenger receptor class B type I gene expression by glucocorticoid in adrenal and ovarian cells. Endocrinology 151:3214-3224

Meister G (2013) Argonaute proteins: functional insights and emerging roles. Nat Rev Genet 14: $447-459$

Mendell JT, Olson EN (2012) MicroRNAs in stress signaling and human disease. Cell 148: $1172-1187$

Meurs I, Lammers B, Zhao Y, Out R, Hildebrand RB, Hoekstra M et al (2012) The effect of ABCG1 deficiency on atherosclerotic lesion development in LDL receptor knockout mice depends on the stage of atherogenesis. Atherosclerosis 221:41-47

Mitchell PJ, Tjian R (1989) Transcriptional regulation in mammalian cells by sequence-specific DNA binding proteins. Science 245:371-378

Miyake Y, Kozutsumi Y, Nakamura S, Fujita T, Kawasaki T (1995) Serine palmitoyltransferase is the primary target of a sphingosine-like immunosuppressant, ISP-1/myriocin. Biochem Biophys Res Commun 211:396-403

Miyazaki T, Koya T, Kigawa Y, Oguchi T, Lei XF, Kim-Kaneyama JR et al (2013) Calpain and atherosclerosis. J Atheroscler Thromb 20:228-237

Mizuno T, Hayashi H, Naoi S, Sugiyama Y (2011) Ubiquitination is associated with lysosomal degradation of cell surface-resident ATP-binding cassette transporter A1 (ABCA1) through the endosomal sorting complex required for transport (ESCRT) pathway. Hepatology 54:631-643

Mooradian AD, Haas MJ, Wong NC (2004) Transcriptional control of apolipoprotein A-I gene expression in diabetes. Diabetes 53:513-520

Morishima A, Ohkubo N, Maeda N, Miki T, Mitsuda N (2003) NFkappaB regulates plasma apolipoprotein A-I and high density lipoprotein cholesterol through inhibition of peroxisome proliferator-activated receptor alpha. J Biol Chem 278:38188-38193

Mosialou I, Zannis VI, Kardassis D (2010) Regulation of human apolipoprotein m gene expression by orphan and ligand-dependent nuclear receptors. J Biol Chem 285:30719-30730

Mosialou I, Krasagakis K, Kardassis D (2011) Opposite regulation of the human apolipoprotein M gene by hepatocyte nuclear factor 1 and Jun transcription factors. J Biol Chem 286: 17259-17269

Munehira Y, Ohnishi T, Kawamoto S, Furuya A, Shitara K, Imamura M et al (2004) Alpha1syntrophin modulates turnover of ABCA1. J Biol Chem 279:15091-15095

Murao K, Wada Y, Nakamura T, Taylor AH, Mooradian AD, Wong NC (1998) Effects of glucose and insulin on rat apolipoprotein A-I gene expression. J Biol Chem 273:18959-18965

Murao K, Imachi H, Yu X, Cao WM, Muraoka T, Dobashi H et al (2008) The transcriptional factor prolactin regulatory element-binding protein mediates the gene transcription of adrenal scavenger receptor class B type I via $3^{\prime}, 5^{\prime}$-cyclic adenosine $5^{\prime}$-monophosphate. Endocrinology 149: 6103-6112

Myklebost O, Rogne S (1988) A physical map of the apolipoprotein gene cluster on human chromosome 19. Hum Genet 78:244-247

Nagelin MH, Srinivasan S, Lee J, Nadler JL, Hedrick CC (2008) 12/15-Lipoxygenase activity increases the degradation of macrophage ATP-binding cassette transporter G1. Arterioscler Thromb Vasc Biol 28:1811-1819 
Nagelin MH, Srinivasan S, Nadler JL, Hedrick CC (2009) Murine 12/15-lipoxygenase regulates ATP-binding cassette transporter G1 protein degradation through p38- and JNK2-dependent pathways. J Biol Chem 284:31303-31314

Najafi-Shoushtari SH, Kristo F, Li Y, Shioda T, Cohen DE, Gerszten RE et al (2010) MicroRNA33 and the SREBP host genes cooperate to control cholesterol homeostasis. Science 328: $1566-1569$

Nakashima Y, Plump AS, Raines EW, Breslow JL, Ross R (1994) ApoE-deficient mice develop lesions of all phases of atherosclerosis throughout the arterial tree. Arterioscler Thromb 14: $133-140$

Nakshatri H, Bhat-Nakshatri P (1998) Multiple parameters determine the specificity of transcriptional response by nuclear receptors HNF-4, ARP-1, PPAR, RAR and RXR through common response elements. Nucleic Acids Res 26:2491-2499

Nielsen LB, Christoffersen C, Ahnstrom J, Dahlback B (2009) ApoM: gene regulation and effects on HDL metabolism. Trends Endocrinol Metab 20:66-71

Niemeier A, Kovacs WJ, Strobl W, Stangl H (2009) Atherogenic diet leads to posttranslational down-regulation of murine hepatocyte SR-BI expression. Atherosclerosis 202:169-175

Nikolaidou-Neokosmidou V, Zannis VI, Kardassis D (2006) Inhibition of hepatocyte nuclear factor 4 transcriptional activity by the nuclear factor kappaB pathway. Biochem J 398:439-450

Nohata N, Hanazawa T, Kikkawa N, Mutallip M, Fujimura L, Yoshino H et al (2011) Caveolin-1 mediates tumor cell migration and invasion and its regulation by miR-133a in head and neck squamous cell carcinoma. Int J Oncol 38:209-217

Nonomura K, Arai Y, Mitani H, Abe-Dohmae S, Yokoyama S (2011) Insulin down-regulates specific activity of ATP-binding cassette transporter A1 for high density lipoprotein biogenesis through its specific phosphorylation. Atherosclerosis 216:334-341

Novak EM, Bydlowski SP (1997) NFY transcription factor binds to regulatory element AIC and transactivates the human apolipoprotein A-I promoter in HEPG2 cells. Biochem Biophys Res Commun 231:140-143

Okazaki H, Goldstein JL, Brown MS, Liang G (2010) LXR-SREBP-1c-phospholipid transfer protein axis controls very low density lipoprotein (VLDL) particle size. J Biol Chem 285: $6801-6810$

Olaisen B, Teisberg P, Gedde-Dahl T Jr (1982) The locus for apolipoprotein E (apoE) is linked to the complement component C3 (C3) locus on chromosome 19 in man. Hum Genet 62:233-236

Oliver WR Jr, Shenk JL, Snaith MR, Russell CS, Plunket KD, Bodkin NL et al (2001) A selective peroxisome proliferator-activated receptor delta agonist promotes reverse cholesterol transport. Proc Natl Acad Sci USA 98:5306-5311

Orom UA, Nielsen FC, Lund AH (2008) MicroRNA-10a binds the 5'UTR of ribosomal protein mRNAs and enhances their translation. Mol Cell 30:460-471

Ouimet M, Franklin V, Mak E, Liao X, Tabas I, Marcel YL (2011) Autophagy regulates cholesterol efflux from macrophage foam cells via lysosomal acid lipase. Cell Metab 13: 655-667

Out R, Hoekstra M, Hildebrand RB, Kruit JK, Meurs I, Li Z et al (2006) Macrophage ABCG1 deletion disrupts lipid homeostasis in alveolar macrophages and moderately influences atherosclerotic lesion development in LDL receptor-deficient mice. Arterioscler Thromb Vasc Biol 26:2295-2300

Out C, Hageman J, Bloks VW, Gerrits H, Sollewijn Gelpke MD, Bos T et al (2011) Liver receptor homolog-1 is critical for adequate up-regulation of Cyp7a1 gene transcription and bile salt synthesis during bile salt sequestration. Hepatology 53:2075-2085

Ozasa H, Ayaori M, Iizuka M, Terao Y, Uto-Kondo H, Yakushiji E et al (2011) Pioglitazone enhances cholesterol efflux from macrophages by increasing ABCA1/ABCG1 expressions via PPARgamma/LXRalpha pathway: findings from in vitro and ex vivo studies. Atherosclerosis 219:141-150 
Paik YK, Chang DJ, Reardon CA, Walker MD, Taxman E, Taylor JM (1988) Identification and characterization of transcriptional regulatory regions associated with expression of the human apolipoprotein E gene. J Biol Chem 263:13340-13349

Pamir N, McMillen TS, Edgel KA, Kim F, LeBoeuf RC (2012) Deficiency of lymphotoxin-alpha does not exacerbate high-fat diet-induced obesity but does enhance inflammation in mice. Am J Physiol Endocrinol Metab 302:E961-E971

Pan X, Jiang XC, Hussain MM (2013) Impaired cholesterol metabolism and enhanced atherosclerosis in clock mutant mice. Circulation 128:1758-1769

Panousis CG, Zuckerman SH (2000) Interferon-gamma induces downregulation of Tangier disease gene (ATP-binding-cassette transporter 1) in macrophage-derived foam cells. Arterioscler Thromb Vasc Biol 20:1565-1571

Panousis CG, Evans G, Zuckerman SH (2001) TGF-beta increases cholesterol efflux and ABC-1 expression in macrophage-derived foam cells: opposing the effects of IFN-gamma. J Lipid Res 42:856-863

Papazafiri P, Ogami K, Ramji DP, Nicosia A, Monaci P, Cladaras C et al (1991) Promoter elements and factors involved in hepatic transcription of the human ApoA-I gene positive and negative regulators bind to overlapping sites. J Biol Chem 266:5790-5797

Park SS, Choi H, Kim SJ, Kim OJ, Chae KS, Kim E (2008) FXRalpha down-regulates LXRalpha signaling at the CETP promoter via a common element. Mol Cells 26:409-414

Park DW, Lee HK, Lyu JH, Chin H, Kang SW, Kim YJ et al (2013) TLR2 stimulates ABCA1 expression via PKC-eta and PLD2 pathway. Biochem Biophys Res Commun 430:933-937

Parseghian S, Onstead-Haas LM, Wong NC, Mooradian AD, Haas MJ (2013) Inhibition of apolipoprotein A-I gene expression by tumor necrosis factor alpha in HepG2 cells: requirement for c-jun. J Cell Biochem 115:253-260

Pascual-Garcia M, Rue L, Leon T, Julve J, Carbo JM, Matalonga J et al (2013) Reciprocal negative cross-talk between liver X receptors (LXRs) and STAT1: effects on IFN-gamma-induced inflammatory responses and LXR-dependent gene expression. J Immunol 190:6520-6532

Paszty C, Maeda N, Verstuyft J, Rubin EM (1994) Apolipoprotein AI transgene corrects apolipoprotein E deficiency-induced atherosclerosis in mice. J Clin Invest 94:899-903

Peng D, Hiipakka RA, Dai Q, Guo J, Reardon CA, Getz GS et al (2008) Antiatherosclerotic effects of a novel synthetic tissue-selective steroidal liver $\mathrm{X}$ receptor agonist in low-density lipoprotein receptor-deficient mice. J Pharmacol Exp Ther 327:332-342

Peng D, Hiipakka RA, Xie JT, Dai Q, Kokontis JM, Reardon CA et al (2011) A novel potent synthetic steroidal liver $\mathrm{X}$ receptor agonist lowers plasma cholesterol and triglycerides and reduces atherosclerosis in LDLR(-/-) mice. Br J Pharmacol 162:1792-1804

Phelan CA, Weaver JM, Steger DJ, Joshi S, Maslany JT, Collins JL et al (2008) Selective partial agonism of liver $\mathrm{X}$ receptor alpha is related to differential corepressor recruitment. Mol Endocrinol 22:2241-2249

Poliseno L, Salmena L, Zhang J, Carver B, Haveman WJ, Pandolfi PP (2010) A codingindependent function of gene and pseudogene mRNAs regulates tumour biology. Nature 465:1033-1038

Porsch-Ozcurumez M, Langmann T, Heimerl S, Borsukova H, Kaminski WE, Drobnik W et al (2001) The zinc finger protein 202 (ZNF202) is a transcriptional repressor of ATP binding cassette transporter A1 (ABCA1) and ABCG1 gene expression and a modulator of cellular lipid efflux. J Biol Chem 276:12427-12433

Quinet EM, Agellon LB, Kroon PA, Marcel YL, Lee YC, Whitlock ME et al (1990) Atherogenic diet increases cholesteryl ester transfer protein messenger RNA levels in rabbit liver. J Clin Invest 85:357-363

Quinet EM, Savio DA, Halpern AR, Chen L, Miller CP, Nambi P (2004) Gene-selective modulation by a synthetic oxysterol ligand of the liver X receptor. J Lipid Res 45:1929-1942

Radeau T, Lau P, Robb M, McDonnell M, Ailhaud G, McPherson R (1995) Cholesteryl ester transfer protein (CETP) mRNA abundance in human adipose tissue: relationship to cell size and membrane cholesterol content. J Lipid Res 36:2552-2561 
Raffai RL, Loeb SM, Weisgraber KH (2005) Apolipoprotein E promotes the regression of atherosclerosis independently of lowering plasma cholesterol levels. Arterioscler Thromb Vasc Biol 25:436-441

Rajavashisth TB, Kaptein JS, Reue KL, Lusis AJ (1985) Evolution of apolipoprotein E: mouse sequence and evidence for an 11-nucleotide ancestral unit. Proc Natl Acad Sci USA 82: 8085-8089

Ramirez CM, Davalos A, Goedeke L, Salerno AG, Warrier N, Cirera-Salinas D et al (2011) MicroRNA-758 regulates cholesterol efflux through posttranscriptional repression of ATP-binding cassette transporter A1. Arterioscler Thromb Vasc Biol 31:2707-2714

Ramirez CM, Rotllan N, Vlassov AV, Davalos A, Li M, Goedeke L et al (2013) Control of cholesterol metabolism and plasma high-density lipoprotein levels by microRNA-144. Circ Res 112:1592-1601

Ranalletta M, Wang N, Han S, Yvan-Charvet L, Welch C, Tall AR (2006) Decreased atherosclerosis in low-density lipoprotein receptor knockout mice transplanted with Abcg1-/- bone marrow. Arterioscler Thromb Vasc Biol 26:2308-2315

Rayner KJ, Suarez Y, Davalos A, Parathath S, Fitzgerald ML, Tamehiro N et al (2010) MiR-33 contributes to the regulation of cholesterol homeostasis. Science 328:1570-1573

Rayner KJ, Esau CC, Hussain FN, McDaniel AL, Marshall SM, van Gils JM et al (2011a) Inhibition of miR-33a/b in non-human primates raises plasma HDL and lowers VLDL triglycerides. Nature 478:404-407

Rayner KJ, Sheedy FJ, Esau CC, Hussain FN, Temel RE, Parathath S et al (2011b) Antagonism of miR-33 in mice promotes reverse cholesterol transport and regression of atherosclerosis. J Clin Invest 121:2921-2931

Reinhart BJ, Weinstein EG, Rhoades MW, Bartel B, Bartel DP (2002) MicroRNAs in plants. Genes Dev 16:1616-1626

Remaley AT, Bark S, Walts AD, Freeman L, Shulenin S, Annilo T et al (2002) Comparative genome analysis of potential regulatory elements in the ABCG5-ABCG8 gene cluster. Biochem Biophys Res Commun 295:276-282

Repa JJ, Berge KE, Pomajzl C, Richardson JA, Hobbs H, Mangelsdorf DJ (2002) Regulation of ATP-binding cassette sterol transporters ABCG5 and ABCG8 by the liver X receptors alpha and beta. J Biol Chem 277:18793-18800

Richter S, Shih DQ, Pearson ER, Wolfrum C, Fajans SS, Hattersley AT et al (2003) Regulation of apolipoprotein M gene expression by MODY3 gene hepatocyte nuclear factor-1alpha: haploinsufficiency is associated with reduced serum apolipoprotein M levels. Diabetes 52: 2989-2995

Rochel N, Ciesielski F, Godet J, Moman E, Roessle M, Peluso-Iltis C et al (2011) Common architecture of nuclear receptor heterodimers on DNA direct repeat elements with different spacings. Nat Struct Mol Biol 18:564-570

Rodriguez-Ubreva J, Ballestar E (2014) Chromatin immunoprecipitation. Methods Mol Biol 1094: 309-318

Roeder RG (1998) Role of general and gene-specific cofactors in the regulation of eukaryotic transcription. Cold Spring Harb Symp Quant Biol 63:201-218

Roeder RG (2005) Transcriptional regulation and the role of diverse coactivators in animal cells. FEBS Lett 579:909-915

Rottiers V, Obad S, Petri A, McGarrah R, Lindholm MW, Black JC et al (2013) Pharmacological inhibition of a microRNA family in nonhuman primates by a seed-targeting 8-mer antimiR. Sci Transl Med 5:212ra162

Rottman JN, Widom RL, Nadal-Ginard B, Mahdavi V, Karathanasis SK (1991) A retinoic acidresponsive element in the apolipoprotein AI gene distinguishes between two different retinoic acid response pathways. Mol Cell Biol 11:3814-3820

Rousselle A, Qadri F, Leukel L, Yilmaz R, Fontaine JF, Sihn G et al (2013) CXCL5 limits macrophage foam cell formation in atherosclerosis. J Clin Invest 123:1343-1347 
Rubin EM, Ishida BY, Clift SM, Krauss RM (1991) Expression of human apolipoprotein A-I in transgenic mice results in reduced plasma levels of murine apolipoprotein A-I and the appearance of two new high density lipoprotein size subclasses. Proc Natl Acad Sci USA 88: $434-438$

Sakai T, Kamanna VS, Kashyap ML (2001) Niacin, but not gemfibrozil, selectively increases LP-AI, a cardioprotective subfraction of HDL, in patients with low HDL cholesterol. Arterioscler Thromb Vasc Biol 21:1783-1789

Salero E, Perez-Sen R, Aruga J, Gimenez C, Zafra F (2001) Transcription factors Zic1 and Zic2 bind and transactivate the apolipoprotein E gene promoter. J Biol Chem 276:1881-1888

Salero E, Gimenez C, Zafra F (2003) Identification of a non-canonical E-box motif as a regulatory element in the proximal promoter region of the apolipoprotein E gene. Biochem J 370:979-986

Salmena L, Poliseno L, Tay Y, Kats L, Pandolfi PP (2011) A ceRNA hypothesis: the Rosetta Stone of a hidden RNA language? Cell 146:353-358

Sanoudou D, Duka A, Drosatos K, Hayes KC, Zannis VI (2009) Role of Esrrg in the fibratemediated regulation of lipid metabolism genes in human ApoA-I transgenic mice. Pharmacogenomics J 10:165-179

Santamarina-Fojo S, Peterson K, Knapper C, Qiu Y, Freeman L, Cheng JF et al (2000) Complete genomic sequence of the human ABCA1 gene: analysis of the human and mouse ATP-binding cassette A promoter. Proc Natl Acad Sci USA 97:7987-7992

Sanyal A, Lajoie BR, Jain G, Dekker J (2012) The long-range interaction landscape of gene promoters. Nature 489:109-113

Schaefer EJ, Lamon-Fava S, Cole T, Sprecher DL, Cilla DD Jr, Balagtas CC et al (1996) Effects of regular and extended-release gemfibrozil on plasma lipoproteins and apolipoproteins in hypercholesterolemic patients with decreased HDL cholesterol levels. Atherosclerosis 127: $113-122$

Schmitz G, Langmann T (2005) Transcriptional regulatory networks in lipid metabolism control ABCA1 expression. Biochim Biophys Acta 1735:1-19

Schnall-Levin M, Zhao Y, Perrimon N, Berger B (2010) Conserved microRNA targeting in Drosophila is as widespread in coding regions as in $3^{\prime}$ UTRs. Proc Natl Acad Sci USA 107: $15751-15756$

Schoonjans K, Annicotte JS, Huby T, Botrugno OA, Fayard E, Ueda Y et al (2002) Liver receptor homolog 1 controls the expression of the scavenger receptor class B type I. EMBO Rep 3: $1181-1187$

Schou J, Frikke-Schmidt R, Kardassis D, Thymiakou E, Nordestgaard BG, Jensen G et al (2012) Genetic variation in ABCG1 and risk of myocardial infarction and ischemic heart disease. Arterioscler Thromb Vasc Biol 32:506-515

Schreyer SA, Peschon JJ, LeBoeuf RC (1996) Accelerated atherosclerosis in mice lacking tumor necrosis factor receptor p55. J Biol Chem 271:26174-26178

Schreyer SA, Vick CM, LeBoeuf RC (2002) Loss of lymphotoxin-alpha but not tumor necrosis factor-alpha reduces atherosclerosis in mice. J Biol Chem 277:12364-12368

Schwartz K, Lawn RM, Wade DP (2000) ABC1 gene expression and ApoA-I-mediated cholesterol efflux are regulated by LXR. Biochem Biophys Res Commun 274:794-802

Shea-Eaton W, Lopez D, McLean MP (2001) Yin yang 1 protein negatively regulates high-density lipoprotein receptor gene transcription by disrupting binding of sterol regulatory element binding protein to the sterol regulatory element. Endocrinology 142:49-58

Shetty S, Eckhardt ER, Post SR, van der Westhuyzen DR (2006) Phosphatidylinositol-3-kinase regulates scavenger receptor class B type I subcellular localization and selective lipid uptake in hepatocytes. Arterioscler Thromb Vasc Biol 26:2125-2131

Shih SJ, Allan C, Grehan S, Tse E, Moran C, Taylor JM (2000) Duplicated downstream enhancers control expression of the human apolipoprotein $\mathrm{E}$ gene in macrophages and adipose tissue. J Biol Chem 275:31567-31572 
Shih DQ, Bussen M, Sehayek E, Ananthanarayanan M, Shneider BL, Suchy FJ et al (2001) Hepatocyte nuclear factor-1alpha is an essential regulator of bile acid and plasma cholesterol metabolism. Nat Genet 27:375-382

Shirasaki T, Honda M, Shimakami T, Horii R, Yamashita T, Sakai Y et al (2013) MicroRNA-27a regulates lipid metabolism and inhibits hepatitis $\mathrm{C}$ virus replication in human hepatoma cells. J Virol 87:5270-5286

Singaraja RR, Bocher V, James ER, Clee SM, Zhang LH, Leavitt BR et al (2001) Human ABCA1 BAC transgenic mice show increased high density lipoprotein cholesterol and ApoAIdependent efflux stimulated by an internal promoter containing liver $\mathrm{X}$ receptor response elements in intron 1. J Biol Chem 276:33969-33979

Singaraja RR, James ER, Crim J, Visscher H, Chatterjee A, Hayden MR (2005) Alternate transcripts expressed in response to diet reflect tissue-specific regulation of ABCA1. J Lipid Res 46:2061-2071

Singaraja RR, Visscher H, James ER, Chroni A, Coutinho JM, Brunham LR et al (2006) Specific mutations in ABCA1 have discrete effects on ABCA1 function and lipid phenotypes both in vivo and in vitro. Circ Res 99:389-397

Singaraja RR, Kang MH, Vaid K, Sanders SS, Vilas GL, Arstikaitis P et al (2009) Palmitoylation of ATP-binding cassette transporter A1 is essential for its trafficking and function. Circ Res 105:138-147

Singh NN, Ramji DP (2006) Transforming growth factor-beta-induced expression of the apolipoprotein E gene requires c-Jun N-terminal kinase, p38 kinase, and casein kinase 2. Arterioscler Thromb Vasc Biol 26:1323-1329

Sladek FM (1994) Orphan receptor HNF-4 and liver-specific gene expression. Receptor 4:64

Small EM, Olson EN (2011) Pervasive roles of microRNAs in cardiovascular biology. Nature 469: 336-342

Smit M, van der Kooij-Meijs E, Frants RR, Havekes L, Klasen EC (1988) Apolipoprotein gene cluster on chromosome 19. Definite localization of the APOC2 gene and the polymorphic Hpa I site associated with type III hyperlipoproteinemia. Hum Genet 78:90-93

Smith JD, Melian A, Leff T, Breslow JL (1988) Expression of the human apolipoprotein E gene is regulated by multiple positive and negative elements. J Biol Chem 263:8300-8308

Song H, Saito K, Fujigaki S, Noma A, Ishiguro H, Nagatsu T et al (1998) IL-1 beta and TNF-alpha suppress apolipoprotein (apo) E secretion and apo A-I expression in HepG2 cells. Cytokine 10: $275-280$

Sparrow CP, Baffic J, Lam MH, Lund EG, Adams AD, Fu X et al (2002) A potent synthetic LXR agonist is more effective than cholesterol loading at inducing ABCA1 mRNA and stimulating cholesterol efflux. J Biol Chem 277:10021-10027

Sporstol M, Mousavi SA, Eskild W, Roos N, Berg T (2007) ABCA1, ABCG1 and SR-BI: hormonal regulation in primary rat hepatocytes and human cell lines. BMC Mol Biol 8:5

Srivastava RA, Srivastava N, Averna M (2000) Dietary cholic acid lowers plasma levels of mouse and human apolipoprotein A-I primarily via a transcriptional mechanism. Eur J Biochem 267: $4272-4280$

Staels B, Auwerx J (1998) Regulation of apo A-I gene expression by fibrates. Atherosclerosis 137(Suppl):S19-S23

Sticozzi C, Belmonte G, Pecorelli A, Cervellati F, Leoncini S, Signorini C et al (2013) Scavenger receptor B1 post-translational modifications in Rett syndrome. FEBS Lett 587:2199-2204

Sumi K, Tanaka T, Uchida A, Magoori K, Urashima Y, Ohashi R et al (2007) Cooperative interaction between hepatocyte nuclear factor 4 alpha and GATA transcription factors regulates ATP-binding cassette sterol transporters ABCG5 and ABCG8. Mol Cell Biol 27: 4248-4260

Sun Y, Wang N, Tall AR (1999) Regulation of adrenal scavenger receptor-BI expression by ACTH and cellular cholesterol pools. J Lipid Res 40:1799-1805

Sun D, Zhang J, Xie J, Wei W, Chen M, Zhao X (2012) MiR-26 controls LXR-dependent cholesterol efflux by targeting ABCA1 and ARL7. FEBS Lett 586:1472-1479 
Suzuki S, Nishimaki-Mogami T, Tamehiro N, Inoue K, Arakawa R, Abe-Dohmae S et al (2004) Verapamil increases the apolipoprotein-mediated release of cellular cholesterol by induction of ABCA1 expression via Liver X receptor-independent mechanism. Arterioscler Thromb Vasc Biol 24:519-525

Tall AR, Yvan-Charvet L, Terasaka N, Pagler T, Wang N (2008) HDL, ABC transporters, and cholesterol efflux: implications for the treatment of atherosclerosis. Cell Metab 7:365-375

Tamehiro N, Zhou S, Okuhira K, Benita Y, Brown CE, Zhuang DZ et al (2008) SPTLC1 binds ABCA1 to negatively regulate trafficking and cholesterol efflux activity of the transporter. Biochemistry 47:6138-6147

Tan CL, Plotkin JL, Veno MT, von Schimmelmann M, Feinberg P, Mann S et al (2013) MicroRNA-128 governs neuronal excitability and motor behavior in mice. Science 342: $1254-1258$

Tang C, Vaughan AM, Oram JF (2004) Janus kinase 2 modulates the apolipoprotein interactions with ABCA1 required for removing cellular cholesterol. J Biol Chem 279:7622-7628

Tarling EJ, Edwards PA (2012) Dancing with the sterols: critical roles for ABCG1, ABCA1, miRNAs, and nuclear and cell surface receptors in controlling cellular sterol homeostasis. Biochim Biophys Acta 1821:386-395

Tay Y, Zhang J, Thomson AM, Lim B, Rigoutsos I (2008) MicroRNAs to Nanog, Oct4 and Sox2 coding regions modulate embryonic stem cell differentiation. Nature 455:1124-1128

Taylor AH, Wishart P, Lawless DE, Raymond J, Wong NC (1996) Identification of functional positive and negative thyroid hormone-responsive elements in the rat apolipoprotein AI promoter. Biochemistry 35:8281-8288

Thymiakou E, Zannis VI, Kardassis D (2007) Physical and functional interactions between liver X receptor/retinoid $\mathrm{X}$ receptor and $\mathrm{Sp} 1$ modulate the transcriptional induction of the human ATP binding cassette transporter A1 gene by oxysterols and retinoids. Biochemistry 46: 11473-11483

Towns R, Azhar S, Peegel H, Menon KM (2005) LH/hCG-stimulated androgen production and selective HDL-cholesterol transport are inhibited by a dominant-negative CREB construct in primary cultures of rat theca-interstitial cells. Endocrine 27:269-277

Trajkovski M, Hausser J, Soutschek J, Bhat B, Akin A, Zavolan M et al (2011) MicroRNAs 103 and 107 regulate insulin sensitivity. Nature 474:649-653

Truong TQ, Aubin D, Falstrault L, Brodeur MR, Brissette L (2010) SR-BI, CD36, and caveolin-1 contribute positively to cholesterol efflux in hepatic cells. Cell Biochem Funct 28:480-489

Trusca VG, Fuior EV, Florea IC, Kardassis D, Simionescu M, Gafencu AV (2011) Macrophagespecific up-regulation of apolipoprotein E gene expression by STAT1 is achieved via long range genomic interactions. J Biol Chem 286:13891-13904

Trusca VG, Florea IC, Kardassis D, Gafencu AV (2012) STAT1 interacts with RXRalpha to upregulate ApoCII gene expression in macrophages. PLoS ONE 7:e40463

Tu AY, Albers JJ (1999) DNA sequences responsible for reduced promoter activity of human phospholipid transfer protein by fibrate. Biochem Biophys Res Commun 264:802-807

Tu AY, Albers JJ (2001) Glucose regulates the transcription of human genes relevant to HDL metabolism: responsive elements for peroxisome proliferator-activated receptor are involved in the regulation of phospholipid transfer protein. Diabetes 50:1851-1856

Tzameli I, Zannis VI (1996) Binding specificity and modulation of the ApoA-I promoter activity by homo- and heterodimers of nuclear receptors. J Biol Chem 271:8402-8415

Uehara Y, Engel T, Li Z, Goepfert C, Rust S, Zhou X et al (2002) Polyunsaturated fatty acids and acetoacetate downregulate the expression of the ATP-binding cassette transporter A1. Diabetes 51:2922-2928

Uehara Y, Miura S, von Eckardstein A, Abe S, Fujii A, Matsuo Y et al (2007) Unsaturated fatty acids suppress the expression of the ATP-binding cassette transporter G1 (ABCG1) and ABCA1 genes via an LXR/RXR responsive element. Atherosclerosis 191:11-21 
Urizar NL, Dowhan DH, Moore DD (2000) The farnesoid X-activated receptor mediates bile acid activation of phospholipid transfer protein gene expression. J Biol Chem 275:39313-39317

Valadi H, Ekstrom K, Bossios A, Sjostrand M, Lee JJ, Lotvall JO (2007) Exosome-mediated transfer of mRNAs and microRNAs is a novel mechanism of genetic exchange between cells. Nat Cell Biol 9:654-659

Valenta DT, Bulgrien JJ, Banka CL, Curtiss LK (2006) Overexpression of human ApoAI transgene provides long-term atheroprotection in LDL receptor-deficient mice. Atherosclerosis 189: 255-263

Van Eck M, Herijgers N, Yates J, Pearce NJ, Hoogerbrugge PM, Groot PH et al (1997) Bone marrow transplantation in apolipoprotein E-deficient mice. Effect of ApoE gene dosage on serum lipid concentrations, (beta)VLDL catabolism, and atherosclerosis. Arterioscler Thromb Vasc Biol 17:3117-3126

Vasudevan S, Tong Y, Steitz JA (2007) Switching from repression to activation: microRNAs can up-regulate translation. Science 318:1931-1934

Vaziri ND, Sato T, Liang K (2003) Molecular mechanisms of altered cholesterol metabolism in rats with spontaneous focal glomerulosclerosis. Kidney Int 63:1756-1763

Vaziri ND, Gollapudi P, Han S, Farahmand G, Yuan J, Rahimi A et al (2011) Nephrotic syndrome causes upregulation of HDL endocytic receptor and PDZK-1-dependent downregulation of HDL docking receptor. Nephrol Dial Transplant 26:3118-3123

Venteclef N, Haroniti A, Tousaint JJ, Talianidis I, Delerive P (2008) Regulation of antiatherogenic apolipoprotein $\mathrm{M}$ gene expression by the orphan nuclear receptor LRH-1. J Biol Chem 283:3694-3701

Vickers KC, Rader DJ (2013) Nuclear receptors and microRNA-144 coordinately regulate cholesterol efflux. Circ Res 112:1529-1531

Vickers KC, Palmisano BT, Shoucri BM, Shamburek RD, Remaley AT (2011) MicroRNAs are transported in plasma and delivered to recipient cells by high-density lipoproteins. Nat Cell Biol 13:423-433

von Eckardstein A (1996) Cholesterol efflux from macrophages and other cells. Curr Opin Lipidol 7:308-319

von Eckardstein A, Hersberger M, Rohrer L (2005) Current understanding of the metabolism and biological actions of HDL. Curr Opin Clin Nutr Metab Care 8:147-152

Vu-Dac N, Schoonjans K, Laine B, Fruchart JC, Auwerx J, Staels B (1994) Negative regulation of the human apolipoprotein A-I promoter by fibrates can be attenuated by the interaction of the peroxisome proliferator-activated receptor with its response element. J Biol Chem 269: 31012-31018

Wagner J, Riwanto M, Besler C, Knau A, Fichtlscherer S, Roxe T et al (2013) Characterization of levels and cellular transfer of circulating lipoprotein-bound microRNAs. Arterioscler Thromb Vasc Biol 33:1392-1400

Walsh A, Ito Y, Breslow JL (1989) High levels of human apolipoprotein A-I in transgenic mice result in increased plasma levels of small high density lipoprotein (HDL) particles comparable to human HDL3. J Biol Chem 264:6488-6494

Wan YJ, An D, Cai Y, Repa JJ, Hung-Po Chen T, Flores M et al (2000) Hepatocyte-specific mutation establishes retinoid $\mathrm{X}$ receptor alpha as a heterodimeric integrator of multiple physiological processes in the liver. Mol Cell Biol 20:4436-4444

Wang Y, Oram JF (2002) Unsaturated fatty acids inhibit cholesterol efflux from macrophages by increasing degradation of ATP-binding cassette transporter A1. J Biol Chem 277:5692-5697

Wang Y, Oram JF (2007) Unsaturated fatty acids phosphorylate and destabilize ABCA1 through a protein kinase C delta pathway. J Lipid Res 48:1062-1068

Wang XQ, Panousis CG, Alfaro ML, Evans GF, Zuckerman SH (2002) Interferon-gammamediated downregulation of cholesterol efflux and $\mathrm{ABC} 1$ expression is by the Stat 1 pathway. Arterioscler Thromb Vasc Biol 22:e5-e9 
Wang N, Chen W, Linsel-Nitschke P, Martinez LO, Agerholm-Larsen B, Silver DL et al (2003) A PEST sequence in ABCA1 regulates degradation by calpain protease and stabilization of ABCA1 by apoA-I. J Clin Invest 111:99-107

Wang JH, Keisala T, Solakivi T, Minasyan A, Kalueff AV, Tuohimaa P (2009) Serum cholesterol and expression of ApoAI, LXRbeta and SREBP2 in vitamin D receptor knock-out mice. J Steroid Biochem Mol Biol 113:222-226

Wang D, Xia M, Yan X, Li D, Wang L, Xu Y et al (2012a) Gut microbiota metabolism of anthocyanin promotes reverse cholesterol transport in mice via repressing miRNA-10b. Circ Res 111:967-981

Wang K, Li H, Yuan Y, Etheridge A, Zhou Y, Huang D et al (2012b) The complex exogenous RNA spectra in human plasma: an interface with human gut biota? PLoS ONE 7:e51009

Wang L, Jia XJ, Jiang HJ, Du Y, Yang F, Si SY et al (2013a) MicroRNAs 185, 96, and 223 repress selective high-density lipoprotein cholesterol uptake through posttranscriptional inhibition. Mol Cell Biol 33:1956-1964

Wang M, Wang D, Zhang Y, Wang X, Liu Y, Xia M (2013b) Adiponectin increases macrophages cholesterol efflux and suppresses foam cell formation in patients with type 2 diabetes mellitus. Atherosclerosis 229:62-70

Wang W, Song W, Wang Y, Chen L, Yan X (2013c) HMG-CoA reductase inhibitors, simvastatin and atorvastatin, downregulate ABCG1-mediated cholesterol efflux in human macrophages. J Cardiovasc Pharmacol 62:90-98

Wehmeier K, Beers A, Haas MJ, Wong NC, Steinmeyer A, Zugel U et al (2005) Inhibition of apolipoprotein AI gene expression by 1, 25-dihydroxyvitamin D3. Biochim Biophys Acta 1737:16-26

Wei Z, Huang D, Gao F, Chang WH, An W, Coetzee GA et al (2013) Biological implications and regulatory mechanisms of long-range chromosomal interactions. J Biol Chem 288: 22369-22377

Wellington CL, Walker EK, Suarez A, Kwok A, Bissada N, Singaraja R et al (2002) ABCA1 mRNA and protein distribution patterns predict multiple different roles and levels of regulation. Lab Invest 82:273-283

Werb Z, Chin JR (1983a) Apoprotein E is synthesized and secreted by resident and thioglycollateelicited macrophages but not by pyran copolymer- or bacillus Calmette-Guerin-activated macrophages. J Exp Med 158:1272-1293

Werb Z, Chin JR (1983b) Endotoxin suppresses expression of apoprotein E by mouse macrophages in vivo and in culture. A biochemical and genetic study. J Biol Chem 258: 10642-10648

Werb Z, Chin JR (1983c) Onset of apoprotein E secretion during differentiation of mouse bone marrow-derived mononuclear phagocytes. J Cell Biol 97:1113-1118

Westerterp M, Murphy AJ, Wang M, Pagler TA, Vengrenyuk Y, Kappus MS et al (2013) Deficiency of ATP-binding cassette transporters A1 and G1 in macrophages increases inflammation and accelerates atherosclerosis in mice. Circ Res 112:1456-1465

Wightman B, Ha I, Ruvkun G (1993) Posttranscriptional regulation of the heterochronic gene lin-14 by lin-4 mediates temporal pattern formation in C. elegans. Cell 75:855-862

Wolfrum C, Poy MN, Stoffel M (2005) Apolipoprotein M is required for prebeta-HDL formation and cholesterol efflux to HDL and protects against atherosclerosis. Nat Med 11:418-422

Wolfrum C, Howell JJ, Ndungo E, Stoffel M (2008) Foxa2 activity increases plasma high density lipoprotein levels by regulating apolipoprotein M. J Biol Chem 283:16940-16949

Wood P, Mulay V, Darabi M, Chan KC, Heeren J, Pol A et al (2011) Ras/mitogen-activated protein kinase (MAPK) signaling modulates protein stability and cell surface expression of scavenger receptor SR-BI. J Biol Chem 286:23077-23092

Xu N, Ahren B, Jiang J, Nilsson-Ehle P (2006) Down-regulation of apolipoprotein M expression is mediated by phosphatidylinositol 3-kinase in HepG2 cells. Biochim Biophys Acta 1761: 256-260 
Yang XP, Freeman LA, Knapper CL, Amar MJ, Remaley A, Brewer HB Jr et al (2002) The E-box motif in the proximal ABCA1 promoter mediates transcriptional repression of the ABCA1 gene. J Lipid Res 43:297-306

Yang C, McDonald JG, Patel A, Zhang Y, Umetani M, Xu F et al (2006) Sterol intermediates from cholesterol biosynthetic pathway as liver X receptor ligands. J Biol Chem 281:27816-27826

Yang Y, Zhang Z, Jiang W, Gao L, Zhao G, Zheng Z et al (2007) Identification of novel human high-density lipoprotein receptor Up-regulators using a cell-based high-throughput screening assay. J Biomol Screen 12:211-219

Yang Y, Jiang W, Wang L, Zhang ZB, Si SY, Hong B (2009) Characterization of the isoflavone pratensein as a novel transcriptional up-regulator of scavenger receptor class B type I in HepG2 cells. Biol Pharm Bull 32:1289-1294

Yang T, Chen C, Zhang B, Huang H, Wu G, Wen J et al (2010) Induction of Kruppel-like factor 4 by high-density lipoproteins promotes the expression of scavenger receptor class B type I. FEBS J 277:3780-3788

Yang JS, Phillips MD, Betel D, Mu P, Ventura A, Siepel AC et al (2011) Widespread regulatory activity of vertebrate microRNA* species. RNA 17:312-326

Yokoyama S, Arakawa R, Wu CA, Iwamoto N, Lu R, Tsujita M et al (2012) Calpain-mediated ABCA1 degradation: post-translational regulation of ABCA1 for HDL biogenesis. Biochim Biophys Acta 1821:547-551

Yoshikawa T, Shimano H, Amemiya-Kudo M, Yahagi N, Hasty AH, Matsuzaka T et al (2001) Identification of liver $\mathrm{X}$ receptor-retinoid $\mathrm{X}$ receptor as an activator of the sterol regulatory element-binding protein 1c gene promoter. Mol Cell Biol 21:2991-3000

Yu L, Hammer RE, Li-Hawkins J, Von Bergmann K, Lutjohann D, Cohen JC et al (2002a) Disruption of Abcg5 and Abcg8 in mice reveals their crucial role in biliary cholesterol secretion. Proc Natl Acad Sci USA 99:16237-16242

Yu L, Li-Hawkins J, Hammer RE, Berge KE, Horton JD, Cohen JC et al (2002b) Overexpression of ABCG5 and ABCG8 promotes biliary cholesterol secretion and reduces fractional absorption of dietary cholesterol. J Clin Invest 110:671-680

Yu XH, Jiang HL, Chen WJ, Yin K, Zhao GJ, Mo ZC et al (2012) Interleukin-18 and interleukin12 together downregulate ATP-binding cassette transporter A1 expression through the interleukin-18R/nuclear factor-kappaB signaling pathway in THP-1 macrophage-derived foam cells. Circ J 76:1780-1791

Yu XH, Qian K, Jiang N, Zheng XL, Cayabyab FS, Tang CK (2014) ABCG5/ABCG8 in cholesterol excretion and atherosclerosis. Clin Chim Acta 428:82-88

Zaiou M, Azrolan N, Hayek T, Wang H, Wu L, Haghpassand M et al (1998) The full induction of human apoprotein A-I gene expression by the experimental nephrotic syndrome in transgenic mice depends on cis-acting elements in the proximal 256 base-pair promoter region and the trans-acting factor early growth response factor 1. J Clin Invest 101:1699-1707

Zannis VI, Cole FS, Jackson CL, Kurnit DM, Karathanasis SK (1985) Distribution of apolipoprotein A-I, C-II, C-III, and E mRNA in fetal human tissues. Time-dependent induction of apolipoprotein E mRNA by cultures of human monocyte-macrophages. Biochemistry 24: 4450-4455

Zannis VI, Kan HY, Kritis A, Zanni E, Kardassis D (2001a) Transcriptional regulation of the human apolipoprotein genes. Front Biosci 6:D456-D504

Zannis VI, Kan HY, Kritis A, Zanni EE, Kardassis D (2001b) Transcriptional regulatory mechanisms of the human apolipoprotein genes in vitro and in vivo. Curr Opin Lipidol 12: $181-207$

Zhang X, Jiang B, Luo G, Nilsson-Ehle P, Xu N (2007) Hyperglycemia down-regulates apolipoprotein $\mathrm{M}$ expression in vivo and in vitro. Biochim Biophys Acta 1771:879-882

Zhang Y, Shen C, Ai D, Xie X, Zhu Y (2011) Upregulation of scavenger receptor B1 by hepatic nuclear factor 4alpha through a peroxisome proliferator-activated receptor gamma-dependent mechanism in liver. PPAR Res 2011:164925 
Zhang L, Hou D, Chen X, Li D, Zhu L, Zhang Y et al (2012) Exogenous plant MIR168a specifically targets mammalian LDLRAP1: evidence of cross-kingdom regulation by microRNA. Cell Res 22:107-126

Zhao GJ, Tang SL, Lv YC, Ouyang XP, He PP, Yao F et al (2013) Antagonism of betulinic acid on LPS-mediated inhibition of ABCA1 and cholesterol efflux through inhibiting nuclear factorkappaB signaling pathway and miR-33 expression. PLoS ONE 8:e74782

Zuckerman SH, Evans GF, O’Neal L (1993) Exogenous glucocorticoids increase macrophage secretion of apo E by cholesterol-independent pathways. Atherosclerosis 103:43-54 